\title{
Part 4: Pediatric Basic and Advanced Life Support
}

\section{American Heart Association Guidelines for Cardiopulmonary Resuscitation and Emergency Cardiovascular Care}

\section{TOP 10 TAKE-HOME MESSAGES}

1. High-quality cardiopulmonary resuscitation (CPR) is the foundation of resuscitation. New data reaffirm the key components of high-quality CPR: providing adequate chest compression rate and depth, minimizing interruptions in CPR, allowing full chest recoil between compressions, and avoiding excessive ventilation.

2. A respiratory rate of 20 to 30 breaths per minute is new for infants and children who are (a) receiving CPR with an advanced airway in place or (b) receiving rescue breathing and have a pulse.

3. For patients with nonshockable rhythms, the earlier epinephrine is administered after CPR initiation, the more likely the patient is to survive.

4. Using a cuffed endotracheal tube decreases the need for endotracheal tube changes.

5. The routine use of cricoid pressure does not reduce the risk of regurgitation during bag-mask ventilation and may impede intubation success.

6. For out-of-hospital cardiac arrest, bag-mask ventilation results in the same resuscitation outcomes as advanced airway interventions such as endotracheal intubation.

7. Resuscitation does not end with return of spontaneous circulation (ROSC). Excellent post-cardiac arrest care is critically important to achieving the best patient outcomes. For children who do not regain consciousness after ROSC, this care includes targeted temperature management and continuous electroencephalography monitoring. The prevention and/or treatment of hypotension, hyperoxia or hypoxia, and hypercapnia or hypocapnia is important.

8. After discharge from the hospital, cardiac arrest survivors can have physical, cognitive, and emotional challenges and may need ongoing therapies and interventions.

9. Naloxone can reverse respiratory arrest due to opioid overdose, but there is no evidence that it benefits patients in cardiac arrest.

10. Fluid resuscitation in sepsis is based on patient response and requires frequent reassessment. Balanced crystalloid, unbalanced crystalloid, and colloid fluids are all acceptable for sepsis resuscitation. Epinephrine or norepinephrine infusions are used for fluid-refractory septic shock.

\section{PREAMBLE}

More than 20000 infants and children have a cardiac arrest per year in the United States. ${ }^{1-4}$ In 2015, emergency medical service-documented out-of-hospital cardiac arrest (OHCA) occurred in more than 7000 infants and children. ${ }^{4}$

\author{
Alexis A. Topjian, MD, \\ MSCE, Chair \\ Tia T. Raymond, MD, \\ Vice-Chair \\ Dianne Atkins, MD \\ Melissa Chan, MD \\ Jonathan P. Duff, MD, \\ MEd \\ Benny L. Joyner Jr, MD, \\ MPH
}

Javier J. Lasa, MD

Eric J. Lavonas, MD, MS

Arielle Levy, MD, MEd

Melissa Mahgoub, PhD

Garth D. Meckler, MD, MSHS

Kathryn E. Roberts, MSN, RN

Robert M. Sutton, MD, MSCE

Stephen M. Schexnayder, MD

On behalf of the Pediatric Basic and Advanced Life Support Collaborators

Key Words: AHA Scientific Statements - arrhythmia - cardiopulmonary

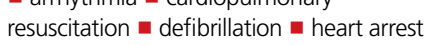
- pediatrics post-cardiac arrest care 
Approximately $11.4 \%$ of pediatric OHCA patients survived to hospital discharge, but outcomes varied by age, with survival rates of $17.1 \%$ in adolescents, $13.2 \%$ in children, and $4.9 \%$ in infants. In the same year, pediatric in-hospital cardiac arrest (IHCA) incidence was 12.66 events per 1000 infant and child hospital admissions, with an overall survival to hospital discharge rate of $41.1 \% .{ }^{4}$ Neurological outcomes remain difficult to assess across the pediatric age spectrum, with variability in reporting metrics and time to follow-up across studies of both OHCA and IHCA. Favorable neurological outcome has been reported in up to $47 \%$ of survivors to discharge. ${ }^{5}$ Despite increases in survival from IHCA, there is more to be done to improve both survival and neurological outcomes. $^{6}$

The International Liaison Committee on Resuscitation (ILCOR) Formula for Survival emphasizes 3 essential components for good resuscitation outcomes: guidelines based on sound resuscitation science, effective education of the lay public and resuscitation providers, and implementation of a well-functioning Chain of Survival. ${ }^{7}$

These guidelines contain recommendations for pediatric basic and advanced life support, excluding the newborn period, and are based on the best available resuscitation science. The Chain of Survival (Section 2), which is now expanded to include recovery from cardiac arrest, requires coordinated efforts from medical professionals in a variety of disciplines and, in the case of OHCA, from bystanders, emergency dispatchers, and first responders. In addition, specific recommendations about the training of resuscitation providers are provided in Part 6: Resuscitation Education Science, and recommendations about systems of care are provided in Part 7.

\section{INTRODUCTION}

\section{Scope of Guidelines}

These guidelines are intended to be a resource for lay rescuers and healthcare providers to identify and treat infants and children in the prearrest, intra-arrest, and postarrest states. These apply to infants and children in multiple settings; the community, prehospital, and the hospital environment. Prearrest, intra-arrest, and postarrest topics are reviewed, including cardiac arrest in special circumstances, such as in patients with congenital heart disease.

For the purposes of the pediatric advanced life support guidelines, pediatric patients are infants, children, and adolescents up to 18 years of age, excluding newborns. For pediatric basic life support (BLS), guidelines apply as follows:
- Infant guidelines apply to infants younger than approximately 1 year of age.

- Child guidelines apply to children approximately 1 year of age until puberty. For teaching purposes, puberty is defined as breast development in females and the presence of axillary hair in males.

- For those with signs of puberty and beyond, adult basic life support guidelines should be followed.

Resuscitation of the neonate is addressed in "Part 5: Neonatal Resuscitation" and applies to the newborn typically only during the first hospitalization following birth. Pediatric basic and advanced life support guidelines apply to neonates (less than 30 days old) after hospital discharge.

\section{Coronavirus Disease 2019 Guidance}

Together with other professional societies, the American Heart Association (AHA) has provided interim guidance for basic and advanced life support in adults, children, and neonates with suspected or confirmed coronavirus disease 2019 (COVID-19). Because evidence and guidance are evolving with the COVID-19 situation, this interim guidance is maintained separately from the emergency cardiovascular care (ECC) guidelines. Readers are directed to the AHA website for the most recent guidance. $^{8}$

\section{Organization of the Pediatric Writing Committee}

The Pediatric Writing Group consisted of pediatric clinicians including intensivists, cardiac intensivists, cardiologists, emergency medicine physicians, medical toxicologists, and nurses. Volunteers with recognized expertise in resuscitation are nominated by the writing group chair and selected by the AHA ECC Committee. The AHA has rigorous conflict of interest policies and procedures to minimize the risk of bias or improper influence during development of the guidelines. ${ }^{9}$ Prior to appointment, writing group members and peer reviewers disclosed all commercial relationships and other potential (including intellectual) conflicts. Writing group members whose research led to changes in guidelines were required to declare those conflicts during discussions and abstain from voting on those specific recommendations. This process is described more fully in "Part 2: Evidence Evaluation and Guidelines Development." Disclosure information for writing group members is listed in Appendix 1.

\section{Methodology and Evidence Review}

These pediatric guidelines are based on the extensive evidence evaluation performed in conjunction with the ILCOR and affiliated ILCOR member councils. Three different types of evidence reviews (systematic reviews, scoping reviews, and evidence updates) were used in 
Table 1. Applying Class of Recommendation and Level of Evidence to Clinical Strategies, Interventions, Treatments, or Diagnostic Testing in Patient Care (Updated May 2019)*

\begin{tabular}{l} 
CLASS (STRENGTH) OF RECOMMENDATION \\
\hline CLASS 1 (STRONG) Benefit $\gg>$ Risk \\
\hline Suggested phrases for writing recommendations: \\
- Is recommended \\
- Is indicated/useful/effective/beneficial \\
- Should be performed/administered/other \\
- Treatment/strategy A is recommended/indicated in preference to \\
treatment B \\
- Treatment A should be chosen over treatment B \\
\hline
\end{tabular}

CLASS 2a (MODERATE) Benefit $>>$ Risk
Suggested phrases for writing recommendations:
- Is reasonable
- Can be useful/effective/beneficial
- Treatment/strategy A is probably recommended/indicated in
preference to treatment B
- It is reasonable to choose treatment A over treatment B

CLASS 2b (WEAK) Benefit $\geq$ Risk
Suggested phrases for writing recommendations:
- May/might be reasonable
- May/might be considered
- Usefulness/effectiveness is unknown/unclear/uncertain or not well-
established

CLASS 3: No Benefit (MODERATE) Benefit $=$ Risk
(Generally, LOE A or B use only)

Suggested phrases for writing recommendations:
- Is not recommended
- Is not indicated/useful/effective/beneficial
- Should not be performed/administered/other

\begin{tabular}{l}
\hline Class 3: Harm (STRONG) \\
\hline Suggested phrases for writing recommendations: \\
- Potentially harmful \\
- Causes harm \\
- Associated with excess morbidity/mortality
\end{tabular}

the 2020 process. ${ }^{10,11}$ After review by the ILCOR Science Advisory Committee Chair, the evidence update worksheets were included in Appendix C of the 2020 ILCOR Consensus on CPR and ECC Science With Treatment Recommendations. ${ }^{11 a}$ Each of these resulted in a description of the literature that facilitated guideline development. This process is described more fully in "Part 2: Evidence Evaluation and Guidelines Development."12

\section{Class of Recommendation and Level of Evidence}

The writing group reviewed all relevant and current AHA Guidelines for Cardiopulmonary Resuscitation (CPR) and ECC and all relevant 2020 ILCOR Consensus on CPR and

LEVEL (QUALITY) OF EVIDENCEF
LEVEL A
- High-quality evidenceł from more than 1 RCT
- Meta-analyses of high-quality RCTs
- One or more RCTs corroborated by high-quality registry studies

\begin{tabular}{l|l|}
\hline LEVEL B-R & (Randomized) \\
\hline - Moderate-quality evidence $\neq$ from 1 or more RCTs & \\
- Meta-analyses of moderate-quality RCTs &
\end{tabular}

LEVEL B-NR
- Moderate-quality evidence $\neq$ from 1 or more well-designed, well-
executed nonrandomized studies, observational studies, or registry
studies
- Meta-analyses of such studies

LEVEL C-LD
- Randomized or nonrandomized observational or registry studies with
- Metaimitations of design or execution
- Physiological or mechanistic studies in human subjects

LEVEL C-EO (Expert Opinion)

- Consensus of expert opinion based on clinical experience

COR and LOE are determined independently (any COR may be paired with any LOE). A recommendation with $\mathrm{LOE} C$ does not imply that the recommendation is weak. Many important clinical questions addressed in guidelines do not lend themselves to clinical trials. Although RCTs are unavailable, there may be a very clear clinical consensus that a particular test or therapy is useful or effective.

* The outcome or result of the intervention should be specified (an improved clinical outcome or increased diagnostic accuracy or incremental prognostic information).

$\dagger$ For comparative-effectiveness recommendations (COR 1 and 2a; LOE A and B only), studies that support the use of comparator verbs should involve direct comparisons of the treatments or strategies being evaluated.

‡ The method of assessing quality is evolving, including the application of standardized, widely-used, and preferably validated evidence grading tools; and for systematic reviews, the incorporation of an Evidence Review Committee.

COR indicates Class of Recommendation; EO, expert opinion; LD, limited data; LOE, Level of Evidence; NR, nonrandomized; R, randomized; and RCT, randomized controlled trial.

ECC Science With Treatment Recommendations evidence and recommendations to determine if current guidelines should be reaffirmed, revised, or retired or if new recommendations were needed. The writing group then drafted, reviewed, and approved recommendations, assigning to each a Class of Recommendation (COR; ie, strength) and Level of Evidence (LOE; ie, quality, certainty). Criteria for each COR and LOE are described in Table 1.

\section{Guideline Structure}

The 2020 Guidelines are organized in discrete modules of information on specific topics or management issues. ${ }^{13}$ Each modular "knowledge chunk" includes a table of recommendations using standard AHA nomenclature of 
COR and LOE. Recommendations are presented in order of COR: most potential benefit (Class 1), followed by lesser certainty of benefit (Class 2 ), and finally potential for harm or no benefit (Class 3). Following the COR, recommendations are ordered by the certainty of supporting LOE: Level A (high-quality randomized controlled trials) to Level C-EO (expert opinion). This order does not reflect the order in which care should be provided.

A brief introduction or short synopsis is provided to contextualize the recommendations with important background information and overarching management or treatment concepts. Recommendation-specific supportive text clarifies the rationale and key study data supporting the recommendations. When appropriate, flow diagrams or additional tables are included. Hyperlinked references are provided to facilitate quick access and review.

\section{Document Review and Approval}

The guideline was submitted for blinded peer review to 5 subject matter experts nominated by the AHA. Peer reviewer feedback was provided for guidelines in draft format and again in final format. The guideline was also reviewed and approved for publication by the AHA Science Advisory and Coordinating Committee and AHA Executive Committee. Disclosure information for peer reviewers is listed in Appendix 2.

\section{Abbreviations}

\begin{tabular}{|c|c|}
\hline Abbreviation & Meaning/Phrase \\
\hline ACLS & advanced cardiovascular life support \\
\hline AED & automated external defibrillator \\
\hline ALS & advanced life support \\
\hline $\mathrm{AHA}$ & American Heart Association \\
\hline BLS & basic life support \\
\hline $\mathrm{COI}$ & conflict of interest \\
\hline COR & Class of Recommendation \\
\hline CPR & cardiopulmonary resuscitation \\
\hline ECC & emergency cardiovascular care \\
\hline ECLS & extracorporeal life support \\
\hline ECMO & extracorporeal membrane oxygenation \\
\hline ECPR & extracorporeal cardiopulmonary resuscitation \\
\hline EO & Expert Opinion \\
\hline ETI & endotracheal intubation \\
\hline FBAO & foreign body airway obstruction \\
\hline IHCA & in-hospital cardiac arrest \\
\hline ILCOR & International Liaison Committee on Resuscitation \\
\hline LD & limited data \\
\hline LOE & Level of Evidence \\
\hline MCS & mechanical circulatory support \\
\hline NR & nonrandomized \\
\hline OHCA & out-of-hospital cardiac arrest \\
\hline
\end{tabular}

\begin{tabular}{|l|l|}
\hline PALS & pediatric advanced life support \\
\hline PICO & population, intervention, comparator, outcome \\
\hline PVT & pulseless ventricular tachycardia \\
\hline RCT & randomized clinical trial \\
\hline ROSC & return of spontaneous circulation \\
\hline SGA & supraglottic airway \\
\hline TTM & targeted temperature management \\
\hline VF & ventricular fibrillation \\
\hline
\end{tabular}

\section{REFERENCES}

1. Holmberg MJ, Ross CE, Fitzmaurice GM, Chan PS, Duval-Arnould J, Grossestreuer AV, Yankama T, Donnino MW, Andersen LW; American Heart Association's Get With The Guidelines-Resuscitation Investigators. Annual Incidence of Adult and Pediatric In-Hospital Cardiac Arrest in the United States. Circ Cardiovasc Qual Outcomes. 2019;12:e005580

2. Atkins DL, Everson-Stewart S, Sears GK, Daya M, Osmond MH, Warden CR, Berg RA; Resuscitation Outcomes Consortium Investigators. Epidemiology and outcomes from out-of-hospital cardiac arrest in children: the Resuscitation Outcomes Consortium Epistry-Cardiac Arrest. Circulation. 2009;119:1484-1491. doi: 10.1161/CIRCULATIONAHA.108.802678

3. Knudson JD, Neish SR, Cabrera AG, Lowry AW, Shamszad P, Morales DL, Graves DE, Williams EA, Rossano JW. Prevalence and outcomes of pediatric in-hospital cardiopulmonary resuscitation in the United States: an analysis of the Kids' Inpatient Database*. Crit Care Med. 2012;40:2940-2944. doi: 10.1097/CCM.0b013e31825feb3f

4. Virani SS, Alonso A, Benjamin EJ, Bittencourt MS, Callaway CW, Carson AP, Chamberlain AM, Chang AR, Cheng S, Delling FN, et al: on behalf of the American Heart Association Council on Epidemiology and Prevention Statistics Committee and Stroke Statistics Subcommittee. Heart disease and stroke statistics-2020 update: a report from the American Heart Association. Circulation. 2020;141:e139-e596. doi: 10.1161/CIR.0000000000000757

5. Matos RI, Watson RS, Nadkarni VM, Huang HH, Berg RA, Meaney PA, Carroll CL, Berens RJ, Praestgaard A, Weissfeld L, Spinella PC; American Heart Association's Get With The Guidelines-Resuscitation (Formerly the National Registry of Cardiopulmonary Resuscitation) Investigators. Duration of cardiopulmonary resuscitation and illness category impact survival and neurologic outcomes for in-hospital pediatric cardiac arrests. Circulation. 2013:127:442-451. doi: 10.1161/CIRCULATIONAHA.112.125625

6. Girotra S, Spertus JA, Li Y, Berg RA, Nadkarni VM, Chan PS; American Heart Association Get With the Guidelines-Resuscitation Investigators. Survival trends in pediatric in-hospital cardiac arrests: an analysis from Get With the Guidelines-Resuscitation. Circ Cardiovasc Qual Outcomes. 2013;6:42-49. doi: 10.1161/CIRCOUTCOMES.112.967968

7. Søreide E, Morrison L, Hillman K, Monsieurs K, Sunde K, Zideman D, Eisenberg M, Sterz F, Nadkarni VM, Soar J, Nolan JP; Utstein Formula for Survival Collaborators. The formula for survival in resuscitation. Resuscitation. 2013;84:1487-1493. doi: 10.1016/j.resuscitation.2013.07.020

8. American Heart Association. CPR \& ECC. https://cpr.heart.org/. Accessed June 19, 2020

9. American Heart Association. Conflict of interest policy. https://www. heart.org/en/about-us/statements-and-policies/conflict-of-interest-policy. Accessed December 31, 2019.

10. International Liaison Committee on Resuscitation (ILCOR). Continuous evidence evaluation guidance and templates: 2020 evidence update process final. https://www.ilcor.org/documents/continuous-evidence-evaluation-guidance-and-templates. Accessed December 31, 2019.

11. Institute of Medicine (US) Committee of Standards for Systematic Reviews of Comparative Effectiveness Research. Finding What Works in Health Care: Standards for Systematic Reviews. Eden J, Levit L, Berg A, Morton S, eds. Washington, DC: The National Academies Press; 2011.

11a. Maconochie IK, Aickin R, Hazinski MF, Atkins DL, Bingham R, Couto TB, Guerguerian A-M, Nadkarni VM, Ng K-C, Nuthall GA, et al; on behalf of the Pediatric Life Support Collaborators. Pediatric life support: 2020 International Consensus on Cardiopulmonary Resuscitation and Emergency Cardiovascular Care Science With Treatment Recommendations. Circulation. 2020;142(suppl 1):S140-S184. doi: 10.1161/CIR.0000000000000894 
12. Magid DJ, Aziz K, Cheng A, Hazinski MF, Hoover AV, Mahgoub M, Panchal AR, Sasson C, Topjian AA, Rodriguez AJ, et al. Part 2: evidence evaluation and guidelines development: 2020 American Heart Association Guidelines for Cardiopulmonary Resuscitation and Emergency Cardiovascular Care. Circulation. 2020;142(suppl 2):S358-S365. doi: 10.1161/CIR.0000000000000898

13. Levine GN, O'GaraPT, Beckman JA, Al-KhatibSM, Birtcher KK, Cigarroa JE, de Las Fuentes L, Deswal A, Fleisher LA, Gentile F, Goldberger ZD, Hlatky MA, Joglar JA, Piano MR, Wijeysundera DN. Recent Innovations, Modifications, and Evolution of ACC/AHA Clinical Practice Guidelines: An Update for Our Constituencies: A Report of the American College of Cardiology/American Heart Association Task Force on Clinical Practice Guidelines. Circulation. 2019;139:e879-e886. doi 10.1161/CIR.0000000000000651

\section{MAJOR CONCEPTS}

The epidemiology, pathophysiology, and common etiologies of pediatric cardiac arrest are distinct from adult and neonatal cardiac arrest. Cardiac arrest in infants and children does not usually result from a primary cardiac cause; rather, it is the end result of progressive respiratory failure or shock. In these patients, cardiac arrest is preceded by a variable period of deterioration, which eventually results in cardiopulmonary failure, bradycardia, and cardiac arrest. In children with congenital heart disease, cardiac arrest is often due to a primary cardiac cause, although the etiology is distinct from adults.

Outcomes for pediatric IHCA have improved over the past 20 years, in part because of early recognition, high-quality CPR, postarrest care, and extracorporeal cardiopulmonary resuscitation (ECPR). ${ }^{1,2}$ In a recent analysis of the Get With The Guidelines Resuscitation Registry, a large multicenter, hospital-based cardiac arrest registry, pediatric cardiac arrest survival to hospital discharge was $19 \%$ in 2000 and $38 \%$ in 2018. ${ }^{2}$ Survival has increased on average by $0.67 \%$ per year, though that increase has plateaued since 2010. ${ }^{2}$ New directions of research and therapy may be required to improve cardiac arrest survival. More cardiac arrest events now occur in an intensive care unit (ICU) setting, suggesting that patients at risk for cardiac arrest are being identified sooner and transferred to a higher level of care. ${ }^{3}$

Survival rates from OHCA remain less encouraging. In a recent analysis of the Resuscitation Outcomes Consortium Epidemiological Registry, a multicenter OHCA registry, annual survival to hospital discharge of pediatric OHCA between 2007 and 2012 ranged from $6.7 \%$ to $10.2 \%$ depending on region and patient age. ${ }^{4}$ There was no significant change in these rates over time, consistent with other national registries from Japan and from Australia and New Zealand. 5,6 In the Resuscitation Outcomes Consortium Epidemiological Registry, survival of OHCA was higher in regions with more arrests that were witnessed by emergency medical services and with higher bystander CPR rates, stressing the importance of early recognition and treatment of these patients. ${ }^{4}$

As survival rates from pediatric cardiac arrest increase, there has been a shift with more focus on neurodevelopmental, physical, and emotional outcomes of survivors. Recent studies demonstrate that a quarter of patients with favorable outcomes have global cognitive impairment and that $85 \%$ of older children who were reported to have favorable outcomes have selective neuropsychological deficits. ${ }^{7}$
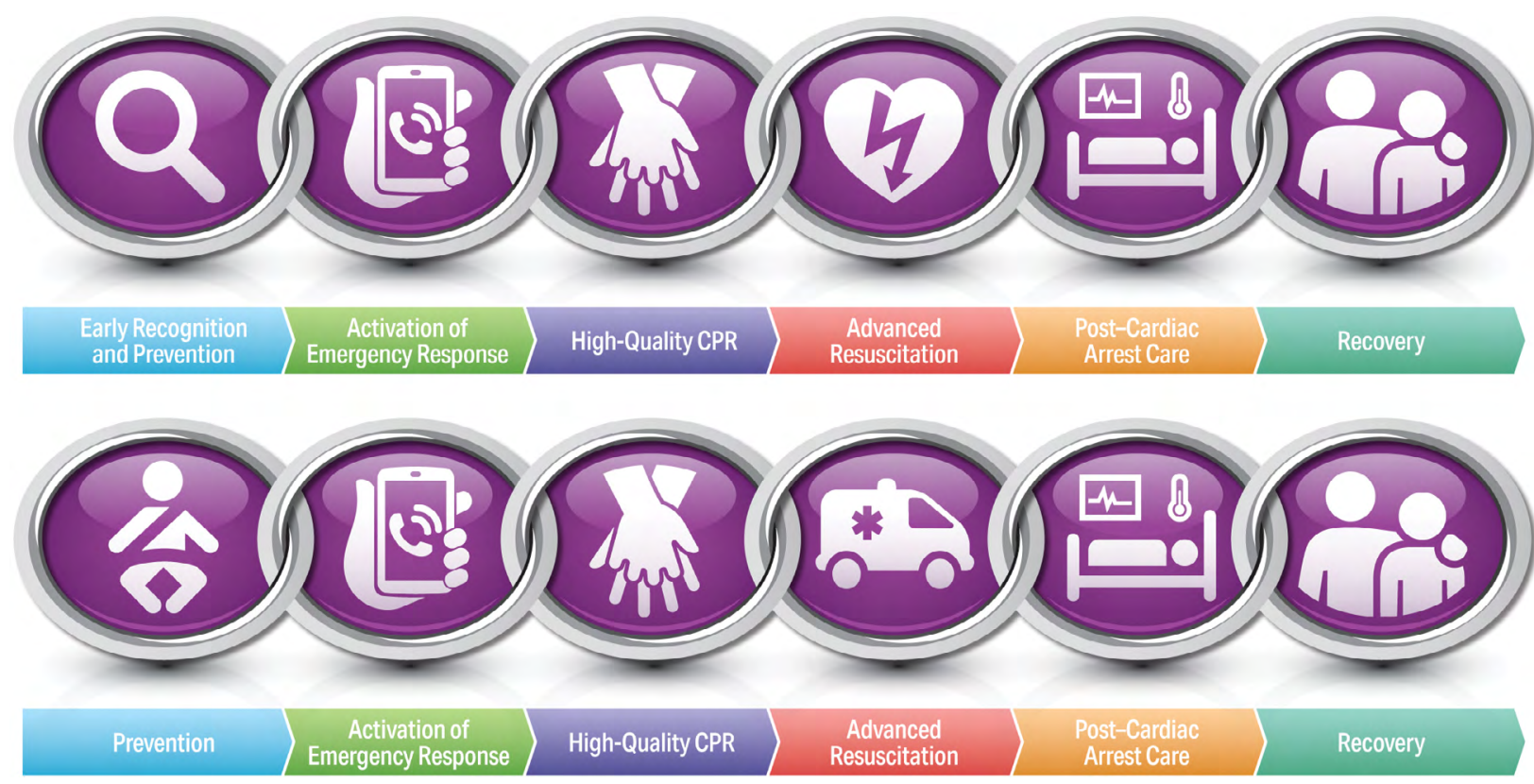

Figure 1. Pediatric Chains of Survival for in-hospital (top) and out-of-hospital (bottom) cardiac arrest.

CPR indicates cardiopulmonary resuscitation. 


\section{The Pediatric Chain of Survival}

Historically, cardiac arrest care has largely focused on the management of the cardiac arrest itself, highlighting high-quality CPR, early defibrillation, and effective teamwork. However, there are aspects of prearrest and postarrest care that are critical to improve outcomes. As pediatric cardiac arrest survival rates have plateaued, the prevention of cardiac arrest becomes even more important. In the out-of-hospital environment, this includes safety initiatives (eg, bike helmet laws), sudden infant death syndrome prevention, lay rescuer CPR training, and early access to emergency care. When OHCA occurs, early bystander CPR is critical in improving outcomes. In the in-hospital environment, cardiac arrest prevention includes early recognition and treatment of patients at risk for cardiac arrest such as neonates undergoing cardiac surgical procedures, patients presenting with acute fulminant myocarditis, acute decompensated heart failure, or pulmonary hypertension.

Following resuscitation from cardiac arrest, management of the post-cardiac arrest syndrome (which may include brain dysfunction, myocardial dysfunction with low cardiac output, and ischemia or reperfusion injury) is important to avoid known contributors to secondary injury, such as hypotension..$^{8,9}$ Accurate neuroprognostication is important to guide caregiver discussions and decision-making. Finally, given the high risk of neurodevelopmental impairment in cardiac arrest survivors, early referral for rehabilitation assessment and intervention is key.

To highlight these different aspects of cardiac arrest management, the Pediatric Chain of Survival has been updated (Figure 1). A separate OHCA Chain of Survival has been created to distinguish the differences between OHCA and IHCA. In both the OHCA and IHCA chains, a sixth link has been added to stress the importance of recovery, which focuses on short- and long-term treatment evaluation, and support for survivors and their families. For both chains of survival, activating the emergency response is followed immediately by the initiation of high-quality CPR. If help is nearby or a cell phone is available, activating the emergency response and starting CPR can be nearly simultaneous. However, in the out-of-hospital setting, a single rescuer who does not have access to a cell phone should begin CPR (compressions-airway-breathing) for infants and children before calling for help because respiratory arrest is the most common cause of cardiac arrest and help may not be nearby. In the event of sudden witnessed collapse, rescuers should use an available automatic external defibrillator (AED), because early defibrillation can be lifesaving.
1. Girotra S, Spertus JA, Li Y, Berg RA, Nadkarni VM, Chan PS; American Heart Association Get With the Guidelines-Resuscitation Investigators. Survival trends in pediatric in-hospital cardiac arrests: an analysis from Get With the Guidelines-Resuscitation. Circ Cardiovasc Qual Outcomes. 2013;6:42-49. doi: 10.1161/CIRCOUTCOMES.112.967968

2. Holmberg MJ, Wiberg S, Ross CE, Kleinman M, Hoeyer-Nielsen AK, Donnino MW, Andersen LW. Trends in Survival After Pediatric In-Hospital Cardiac Arrest in the United States. Circulation. 2019;140:1398-1408. doi: 10.1161/CIRCULATIONAHA.119.041667

3. Berg RA, Sutton RM, Holubkov R, Nicholson CE, Dean JM, Harrison R, Heidemann S, Meert K, Newth C, Moler F, Pollack M, Dalton H, Doctor A, Wessel D, Berger J, Shanley T, Carcillo J, Nadkarni VM; Eunice Kennedy Shriver National Institute of Child Health and Human Development Collaborative Pediatric Critical Care Research Network and for the American Heart Association's Get With the Guidelines-Resuscitation (formerly the National Registry of Cardiopulmonary Resuscitation) Investigators. Ratio of PICU versus ward cardiopulmonary resuscitation events is increasing. Crit Care Med. 2013;41:2292-2297. doi: 10.1097/CCM.0b013e31828cf0c0

4. Fink EL, Prince DK, Kaltman JR, Atkins DL, Austin M, Warden C, Hutchison J, Daya M, Goldberg S, Herren H, Tijssen JA, Christenson J, Vaillancourt C, Miller R, Schmicker RH, Callaway CW; Resuscitation Outcomes Consortium. Unchanged pediatric out-of-hospital cardiac arrest incidence and survival rates with regional variation in North America. Resuscitation. 2016;107:121-128. doi: 10.1016/j.resuscitation.2016.07.244

5. Kitamura T, Iwami T, Kawamura T, Nitta M, Nagao K, Nonogi $H$, Yonemoto N, Kimura T; Japanese Circulation Society Resuscitation Science Study Group. Nationwide improvements in survival from out-ofhospital cardiac arrest in Japan. Circulation. 2012;126:2834-2843. doi: 10.1161/CIRCULATIONAHA.112.109496

6. Straney LD, Schlapbach L, Yong G, Bray JE, Millar J, Slater A, Alexander J, Finn J; Australian and New Zealand Intensive Care Society Paediatric Study Group. Trends in PICU Admission and Survival Rates in Children in Australia and New Zealand Following Cardiac Arrest. Pediatr Crit Care Med. 2015;16:613-620. doi: 10.1097/PCC.0000000000000425

7. Slomine BS, Silverstein FS, Christensen JR, Page K, Holubkov R, Dean JM, Moler FW. Neuropsychological Outcomes of Children 1 Year After Pediatric Cardiac Arrest: Secondary Analysis of 2 Randomized Clinical Trials. JAMA Neurol. 2018;75:1502-1510. doi: 10.1001/jamaneurol.2018.2628

8. Topjian AA, de Caen A, Wainwright MS, Abella BS, Abend NS, Atkins DL, Bembea MM, Fink EL, Guerguerian AM, Haskell SE, Kilgannon JH, Lasa JJ, Hazinski MF. Pediatric Post-Cardiac Arrest Care: A Scientific Statement From the American Heart Association. Circulation. 2019;140:e194-e233. doi: 10.1161/CIR.0000000000000697

9. Laverriere EK, Polansky M, French B, Nadkarni VM, Berg RA, Topjian AA. Association of Duration of Hypotension With Survival After Pediatric Cardiac Arrest. Pediatr Crit Care Med. 2020;21:143-149. doi: 10.1097/PCC.0000000000002119

\section{SEQUENCE OF RESUSCITATION}

Rapid recognition of cardiac arrest, immediate initiation of high-quality chest compressions, and delivery of effective ventilations are critical to improve outcomes from cardiac arrest. Lay rescuers should not delay starting CPR in a child with no "signs of life." Healthcare providers may consider assessing the presence of a pulse as long as the initiation of CPR is not delayed more than 10 seconds. Palpation for the presence or absence of a pulse is not reliable as the sole determinant of cardiac arrest and the need for chest compressions. In infants and children, asphyxial cardiac arrest is more common than cardiac arrest from a primary cardiac event; therefore, effective ventilation is important during resuscitation of children. When CPR is initiated, the sequence is compressions-airway-breathing. 
High-quality CPR generates blood flow to vital organs and increases the likelihood of return of spontaneous circulation (ROSC). The 5 main components of high-quality CPR are (1) adequate chest compression depth, (2) optimal chest compression rate, (3) minimizing interruptions in CPR (ie, maximizing chest compression fraction or the proportion of time that chest compressions are provided for cardiac arrest), (4) allowing full chest recoil between compressions, and (5) avoiding excessive ventilation. Compressions of inadequate depth and rate, ${ }^{1,2}$ incomplete chest recoil, $^{3}$ and high ventilation rates ${ }^{4,5}$ are common during pediatric resuscitation.

\section{Initiation of CPR}

\begin{tabular}{|c|c|c|}
\hline \multicolumn{2}{|c|}{ Recommendations for Initiation of CPR } \\
\hline COR & LOE & Recommendations \\
\hline 1 & C-LD & $\begin{array}{l}\text { 1. Lay rescuers should begin CPR for any victim } \\
\text { who is unresponsive, not breathing normally, } \\
\text { and does not have signs of life; do not check } \\
\text { for a pulse. }{ }^{6-20}\end{array}$ \\
\hline $2 a$ & C-LD & $\begin{array}{l}\text { 2. In infants and children with no signs of life, } \\
\text { it is reasonable for healthcare providers to } \\
\text { check for a pulse for up to 10 s and begin } \\
\text { compressions unless a definite pulse is felt. }\end{array}$ \\
\hline 2 b-23 & C-EO & $\begin{array}{l}\text { 3. It may be reasonable to initiate CPR with } \\
\text { compressions-airway-breathing over airway- } \\
\text { breathing-compressions. }{ }^{24}\end{array}$ \\
\hline
\end{tabular}

\section{Recommendation-Specific Supportive Text}

1. Lay rescuers are unable to reliably determine the presence or absence of a pulse. ${ }^{6-20}$

2. No clinical trials have compared manual pulse checks with observations of "signs of life." However, adult and pediatric studies have identified a high error rate and harmful CPR pauses during manual pulse checks by trained rescuers. ${ }^{21-23}$ In 1 study, healthcare provider pulse palpation accuracy was $78 \%{ }^{21}$ compared with lay rescuer pulse palpation accuracy of $47 \%$ at 5 seconds and $73 \%$ at 10 seconds. ${ }^{6}$

3. One pediatric study demonstrated only a small delay (5.74 seconds) in commencement of rescue breathing with compressions-airway-breathing compared with airway-breathing-compressions. ${ }^{24}$ Although the evidence is of low certainty, continuing to recommend compressions-airwaybreathing likely results in minimal delays in rescue breathing and allows for a consistent approach to cardiac arrest treatment in adults and children.

\section{Components of High-Quality CPR}

\begin{tabular}{|c|c|c|}
\hline COR & LOE & Recommendations \\
\hline 1 & B-NR & $\begin{array}{l}\text { 1. CPR using chest compressions with rescue } \\
\text { breaths should be provided to infants and } \\
\text { children in cardiac arrest. }{ }^{25-29}\end{array}$ \\
\hline 1 & B-NR & $\begin{array}{l}\text { 2. For infants and children, if bystanders are } \\
\text { unwilling or unable to deliver rescue breaths, } \\
\text { it is recommended that rescuers should } \\
\text { provide chest compressions only. } .^{27,28}\end{array}$ \\
\hline 1 & C-EO & $\begin{array}{l}\text { 3. After each compression, rescuers should allow } \\
\text { the chest to recoil completely. } 2,3,30\end{array}$ \\
\hline $2 a$ & $C-L D$ & $\begin{array}{l}\text { 4. It is reasonable to use a chest compression rate } \\
\text { of } \approx 100-120 / \mathrm{min} \text { for infants and children. }{ }^{31,32}\end{array}$ \\
\hline $2 a$ & C-LD & $\begin{array}{l}\text { 5. For infants and children, it is reasonable } \\
\text { for rescuers to provide chest compressions } \\
\text { that depress the chest at least one third the } \\
\text { anterior-posterior diameter of the chest, which } \\
\text { equates to approximately } 1.5 \text { inches }(4 \mathrm{~cm}) \\
\text { in infants to } 2 \text { inches }(5 \mathrm{~cm}) \text { in children. Once } \\
\text { children have reached puberty, it is reasonable } \\
\text { to use the adult compression depth of at least } \\
5 \mathrm{~cm} \text { but no more than } 6 \mathrm{~cm} .^{33-36}\end{array}$ \\
\hline $2 a$ & C-EO & $\begin{array}{l}\text { 6. For healthcare providers, it is reasonable to } \\
\text { perform a rhythm check, lasting no more than } \\
10 \mathrm{~s} \text {, approximately every } 2 \text { min. }\end{array}$ \\
\hline $2 a$ & C-EO & $\begin{array}{l}\text { 7. It is reasonable to ventilate with } 100 \% \text { oxygen } \\
\text { during CPR. }\end{array}$ \\
\hline $2 a$ & C-EO & $\begin{array}{l}\text { 8. When performing CPR without an advanced } \\
\text { airway, it is reasonable for single rescuers } \\
\text { to provide a compression-to-ventilation } \\
\text { ratio of } 30: 2 \text { and for } 2 \text { rescuers to provide a } \\
\text { compression-to-ventilation ratio of } 15: 2 .{ }^{25}\end{array}$ \\
\hline $2 b$ & $C-L D$ & $\begin{array}{l}\text { 9. When performing CPR in infants and } \\
\text { children with an advanced airway, it may be } \\
\text { reasonable to target a respiratory rate range } \\
\text { of } 1 \text { breath every } 2-3 \mathrm{~s} \text { ( } 20-30 \text { breaths/min), } \\
\text { accounting for age and clinical condition. } \\
\text { Rates exceeding these recommendations may } \\
\text { compromise hemodynamics. }{ }^{5}\end{array}$ \\
\hline
\end{tabular}

\section{Recommendation-Specific Supportive Text}

1. Large observational studies of children with OHCA show the best outcomes with compression-ventilation CPR, though outcomes for infants with OHCA are often poor regardless of resuscitation strategy. ${ }^{25-29}$

2. Large observational studies of children with OHCA show that compression-only CPR is superior to no bystander CPR, though outcomes for infants with OHCA are often poor. ${ }^{27,28}$

3. Allowing complete chest re-expansion improves the flow of blood returning to the heart and thereby blood flow to the body during CPR. There are no pediatric studies evaluating the effect of residual leaning during CPR, although 
leaning during pediatric CPR is common. ${ }^{2,3}$ In 1 observational study of invasively monitored and anesthetized children, leaning was associated with elevated cardiac filling pressures, leading to decreased coronary perfusion pressures during sinus rhythm. ${ }^{30}$

4. A small observational study found that a compression rate of at least 100/min was associated with improved systolic and diastolic blood pressures during CPR for pediatric IHCA. ${ }^{31}$ One multicenter, observational study of pediatric IHCA demonstrated increased systolic blood pressures with chest compression rates between 100 and 120 /min when compared with rates exceeding 120/min..$^{32}$ Rates less than 100/min were associated with improved survival compared to rates of 100 to $120 / \mathrm{min}$; however, the median rate in this slower category was approximately $95 / \mathrm{min}$ (ie, very close to $100 / \mathrm{min}$ ). ${ }^{32}$

5. Three anthropometric studies have shown that the pediatric chest can be compressed to one third of the anterior-posterior chest diameter without damaging intrathoracic organs. ${ }^{33-35}$ An observational study found an improvement in rates of ROSC and 24-hour survival, when at least 60\% of 30-second epochs of CPR achieve an average chest compression depth greater than $5 \mathrm{~cm}$ for pediatric IHCA. ${ }^{36}$
6. Current recommendations include a brief rhythm check every 2 minutes when a monitor or AED is available.

7. There are no human studies addressing the effect of varying inhaled oxygen concentrations during CPR on outcomes in infants and children.

8. The optimum compression-to-ventilation ratio is uncertain. Large observational studies of children with OHCA demonstrated better outcomes with compression-ventilation CPR with ratios of either $15: 2$ or $30: 2$ compared with compression-only CPR. ${ }^{25}$

9. One small, multicenter observational study of intubated pediatric patients found that ventilation rates (at least 30 breaths/min in children less than 1 year of age, at least 25 breaths/min in older children) were associated with improved rates of ROSC and survival. ${ }^{5}$ However, increasing ventilation rates are associated with decreased systolic blood pressure in children. The optimum ventilation rate during continuous chest compressions in children with an advanced airway is based on limited data and requires further study.

Recommendations 1 and 2 were reviewed in the "2017 American Heart Association Focused Update on Pediatric Basic Life Support and Cardiopulmonary Resuscitation Quality: An Update to the American Heart Association Guidelines for Cardiopulmonary Resuscitation and Emergency Cardiovascular Care." 37

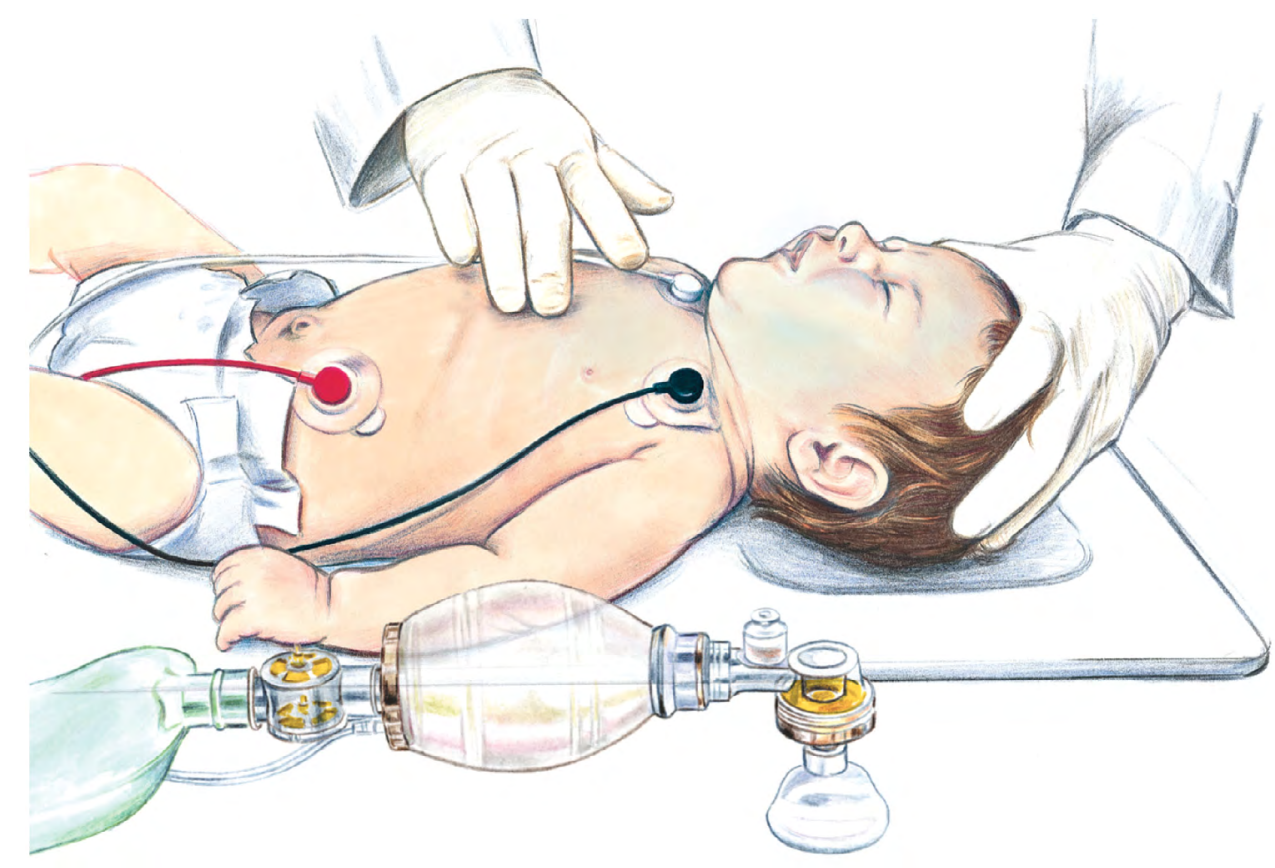




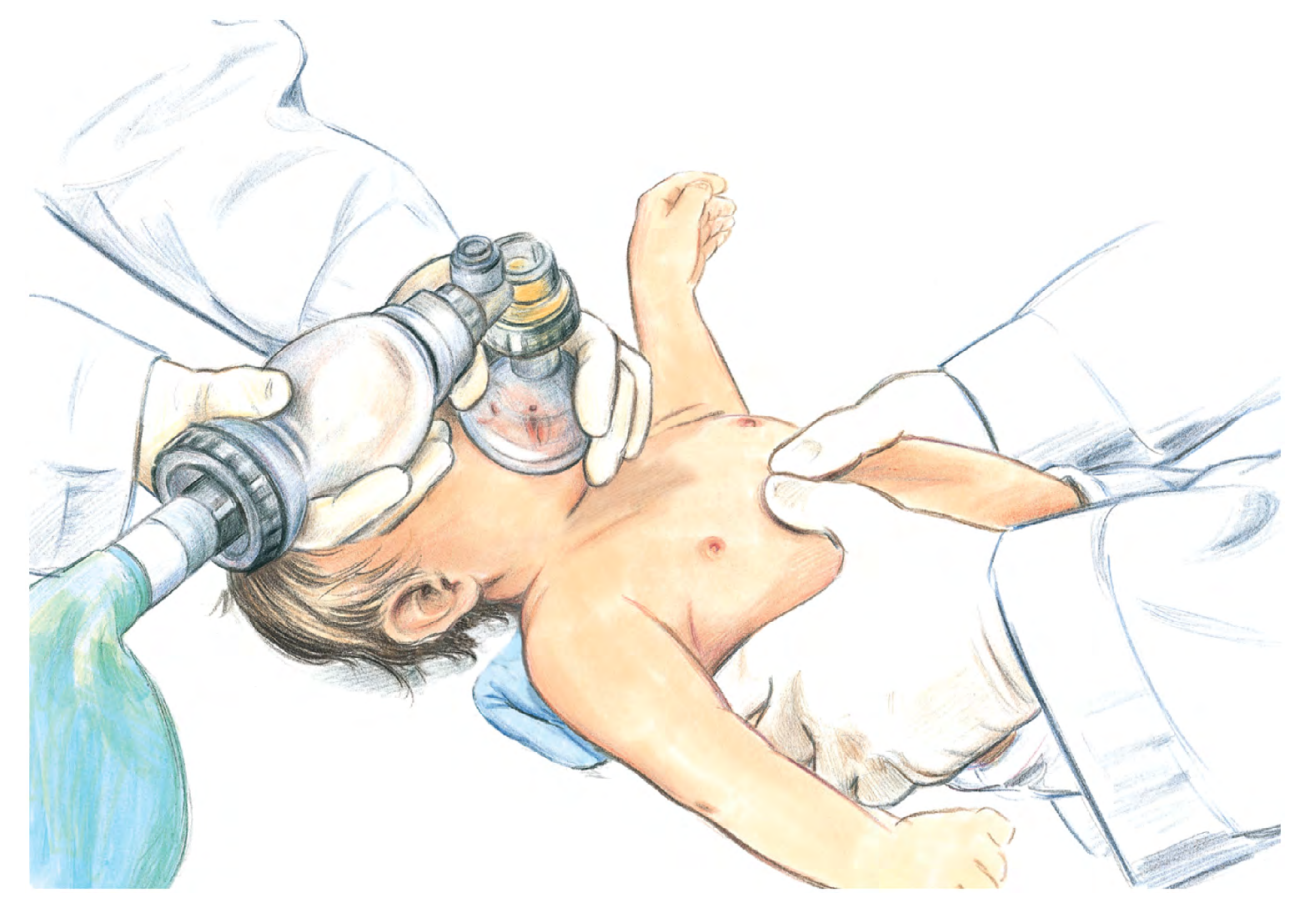

Figure 3. 2-Thumb-encircling hands compressions.

\section{CPR Technique}

\begin{tabular}{|c|c|c|}
\hline COR & LOE & Recommendations \\
\hline 1 & C-LD & $\begin{array}{l}\text { 1. For infants, single rescuers (whether lay } \\
\text { rescuers or healthcare providers) should } \\
\text { compress the sternum with } 2 \text { fingers } \\
\text { (Figure } 2 \text { ) or } 2 \text { thumbs placed just below the } \\
\text { intermammary line. }{ }^{38-41}\end{array}$ \\
\hline 1 & C-LD & $\begin{array}{l}\text { 2. For infants, the } 2 \text {-thumb-encircling hands } \\
\text { technique (Figure } 3 \text { ) is recommended when } \\
\text { CPR is provided by } 2 \text { rescuers. If the rescuer } \\
\text { cannot physically encircle the victim's chest, } \\
\text { compress the chest with } 2 \text { fingers. }{ }^{42-46}\end{array}$ \\
\hline $2 b$ & C-LD & $\begin{array}{l}\text { 3. For children, it may be reasonable to use } \\
\text { either a 1- or 2-hand technique to perform } \\
\text { chest compressions. }{ }^{47-49}\end{array}$ \\
\hline $2 b$ & C-EO & $\begin{array}{l}\text { 4. For infants, if the rescuer is unable to } \\
\text { achieve guideline recommended depths } \\
\text { (at least one third the anterior-posterior } \\
\text { diameter of the chest), it may be reasonable } \\
\text { to use the heel of } 1 \text { hand. }\end{array}$ \\
\hline
\end{tabular}

\section{Recommendation-Specific Supportive Text}

1. One anthropometric ${ }^{38}$ and 3 radiological studies ${ }^{39-41}$ found that optimal cardiac compressions occur when fingers are placed just below the intermammary line. One observational pediatric study found that blood pressure was higher when compressions were performed over the lower third of the sternum compared to the midsternum. ${ }^{41}$ See Figure 2 for the 2 -finger technique.

2. Systematic reviews suggest that the 2-thumbencircling hands technique may improve CPR quality when compared with 2-finger compressions, particularly for depth. ${ }^{42,43}$ However, recent manikin studies suggest that the 2-thumb-encircling hands technique may be associated with lower chest compression fractions (percent of cardiac arrest time that chest compression are provided) ${ }^{44}$ and incomplete chest recoil, ${ }^{45,46}$ especially when performed by single rescuers. See Figure 3 for the 2-thumb-encircling hands technique.

3. There are no pediatric-specific clinical data to determine if the 1-hand or 2-hand technique produces better outcomes for children receiving CPR. In manikin studies, the 2-hand technique has been associated with improved compression depth, ${ }^{47}$ compression force, ${ }^{48}$ and less rescuer fatigue. ${ }^{49}$

4. There were no human studies comparing the 1-hand compression versus the 2-thumb-encircling hands technique in infants.

\section{Support Surfaces for CPR}

\begin{tabular}{|c|c|c|}
\hline \multicolumn{2}{|c|}{ Recommendations for Support Surfaces for CPR } \\
\hline COR & LOE & Recommendations \\
\hline 1 & C-LD & $\begin{array}{l}\text { 1. During IHCA, when available, activate the } \\
\text { bed's "CPR mode" to increase mattress } \\
\text { stiffness. }\end{array}$ \\
\hline $2 a-53$
\end{tabular}




\section{STEP 1}

Make sure the scene is safe.

Check to see if the person is awake and breathing normally.

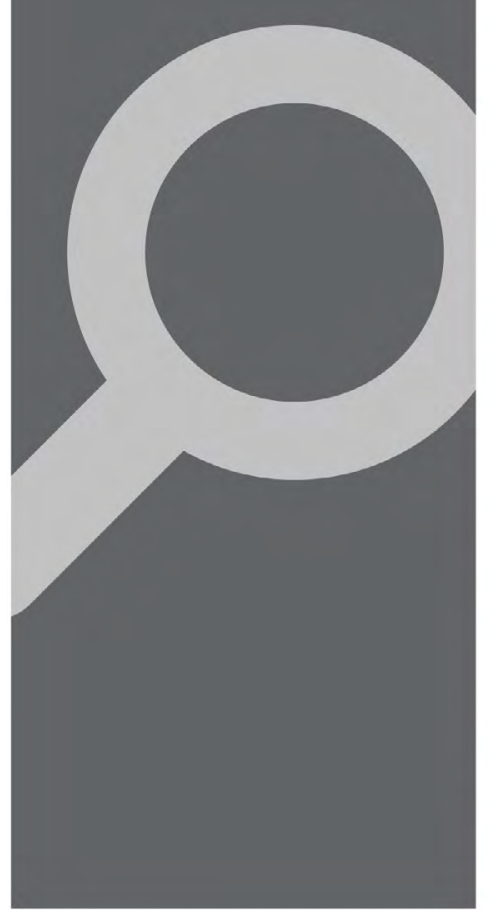

\section{STEP 2}

Shout for help.

If you're alone

- With a cell phone, phone 9-1-1, perform CPR ( 30 compressions and then 2 breaths) for 5 cycles, and then get an AED

- Without a cell phone, perform CPR

(30 compressions and then 2 breaths) for 5 cycles, and then phone 9-1-1 and get an AED

If help is available, phone 9-1-1. Start CPR while you send someone to get an AED.

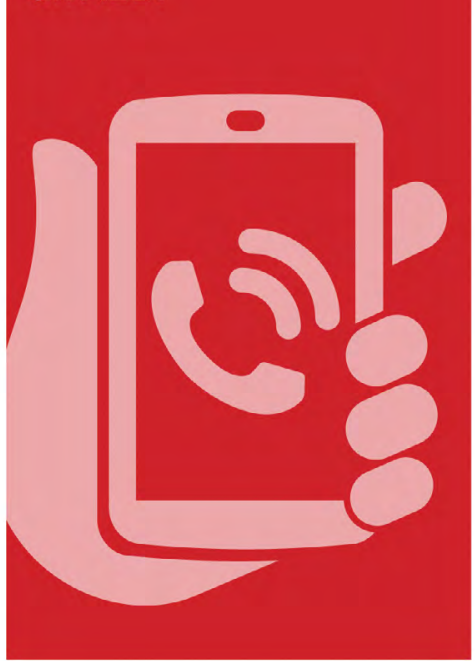

\section{STEP 3}

\section{Repeat cycles of} 30 compressions and then 2 breaths.

\section{a Child CPR}

Push in the middle of the chest at least one third the chest depth or approximately 2 inches with 1 or 2 hands.

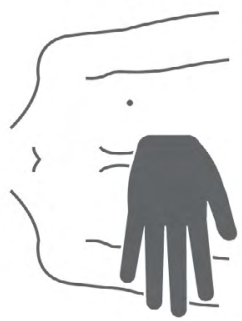

\section{- Infant CPR}

Push in the middle of the chest at least one third the chest depth or approximately $1 \frac{1}{2}$ inches with 2 fingers.

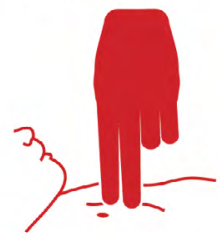

Use the AED as soon as it arrives.

\section{Continue CPR until} EMS arrives.

Figure 4. Pediatric BLS for lay rescuers.

AED indicates automated external defibrillator; BLS, basic life support; CPR, cardiopulmonary resuscitation; and EMS, emergency medical services. 


\section{Pediatric Basic Life Support Algorithm for Healthcare Providers-Single Rescuer}

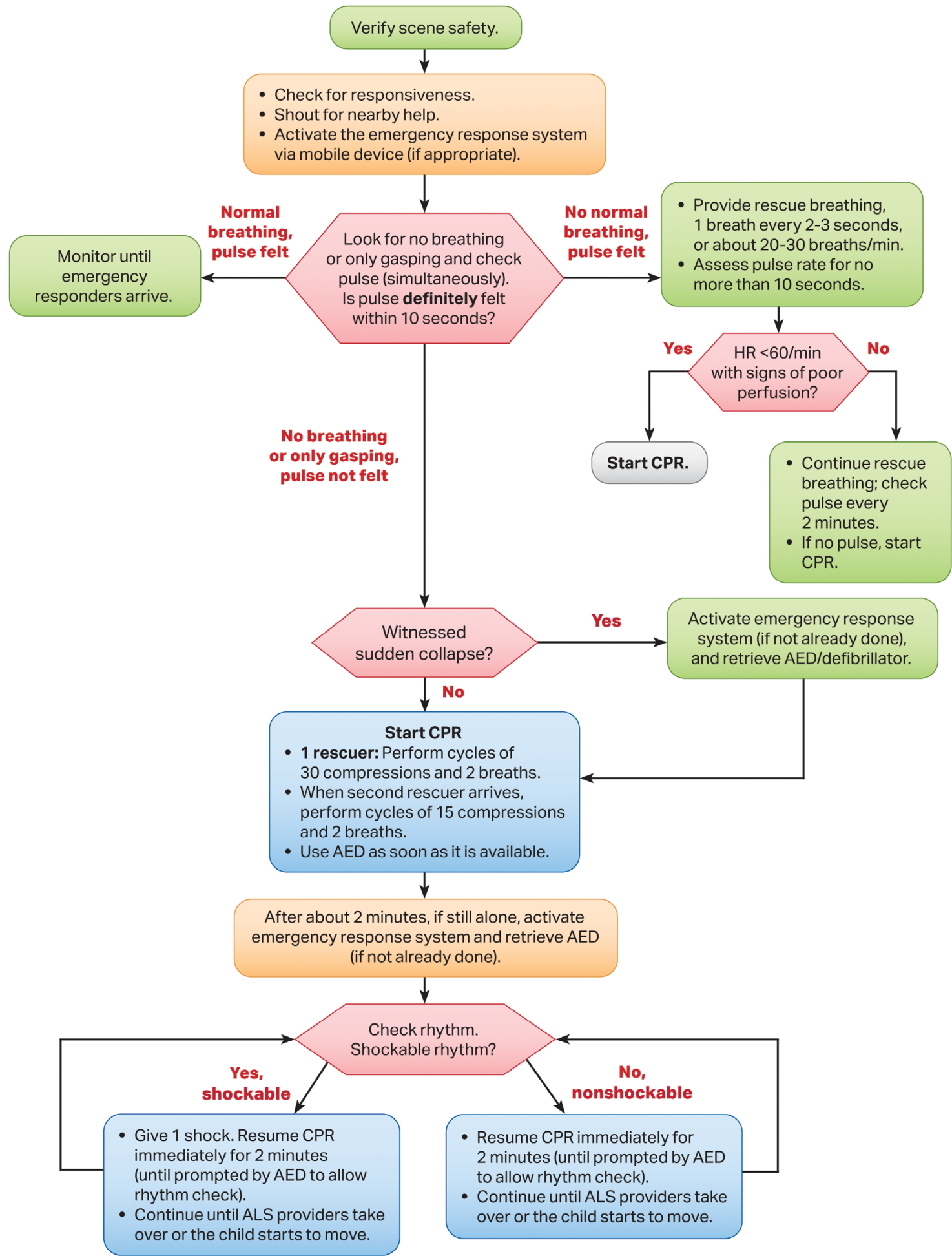

(c) 2020 American Heart Association

Figure 5. Pediatric Basic Life Support Algorithm for Healthcare Providers-Single Rescuer.

AED indicates automated external defibrillator; ALS, advanced life support; CPR, cardiopulmonary resuscitation; and HR, heart rate. 


\section{Pediatric Basic Life Support Algorithm for Healthcare Providers-2 or More Rescuers}

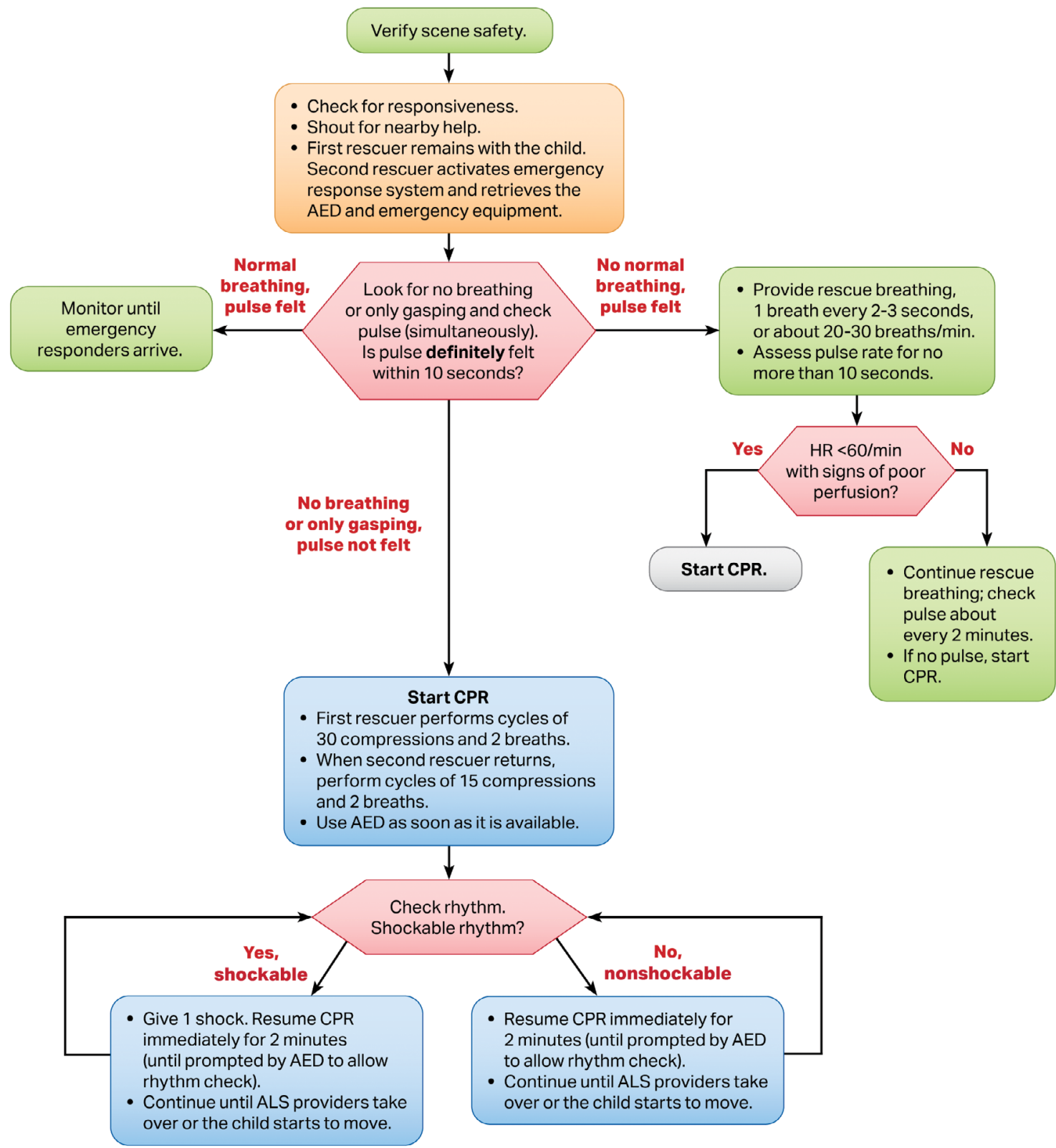

() 2020 American Heart Association

Figure 6. Pediatric Basic Life Support Algorithm for Healthcare Providers-2 or More Rescuers.

AED indicates automated external defibrillator; ALS, advanced life support; CPR, cardiopulmonary resuscitation; and HR, heart rate. 


\section{Pediatric Cardiac Arrest Algorithm}

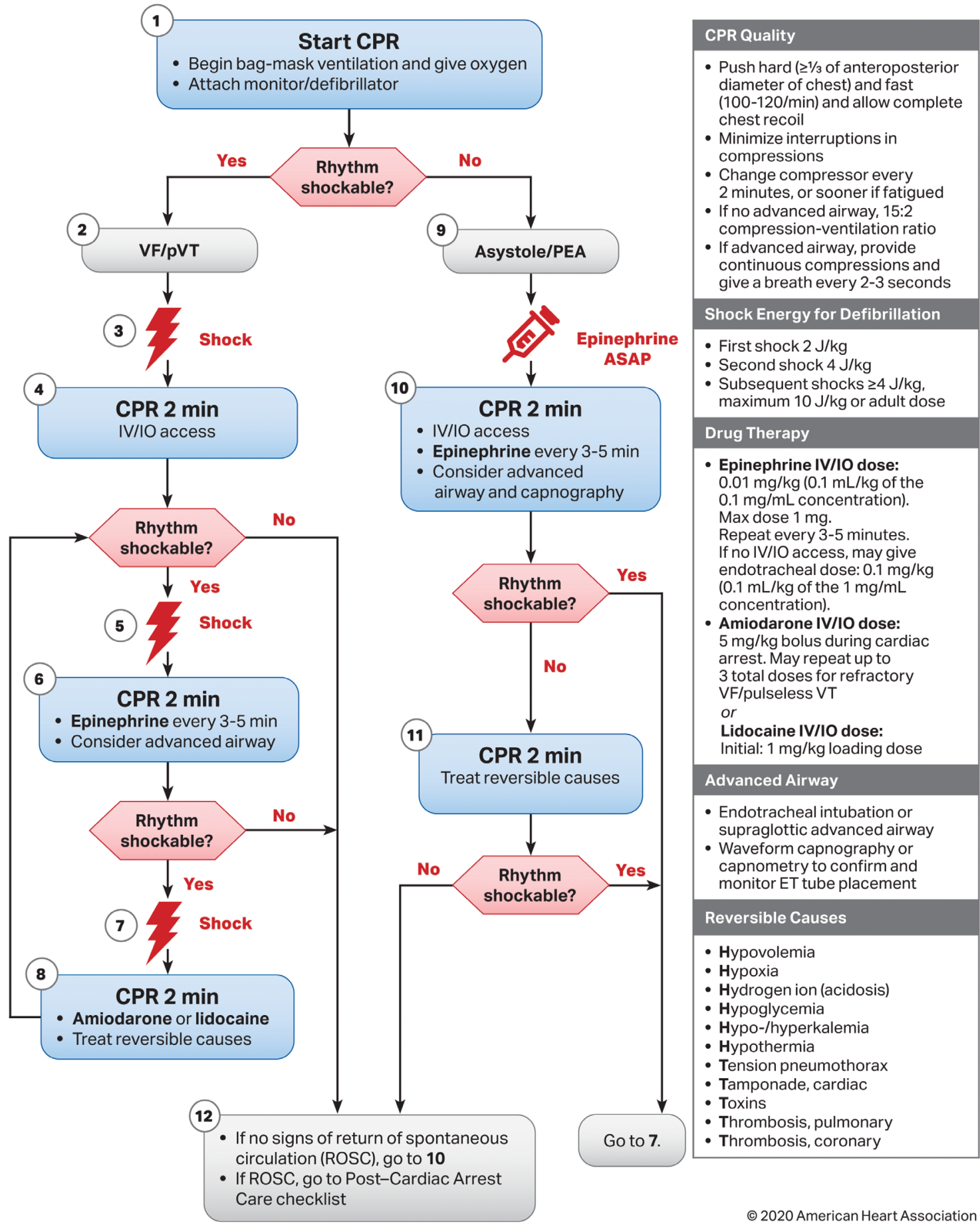

Figure 7. Pediatric Cardiac Arrest Algorithm.

ASAP indicates as soon as possible; CPR, cardiopulmonary resuscitation; ET, endotracheal; HR, heart rate; IO, intraosseous; IV, intravenous; PEA, pulseless electrical activity; and VF/pVT, ventricular fibrillation/pulseless ventricular tachycardia. 


\section{Recommendation-Specific Supportive Text}

1. "CPR mode" is available on some hospital beds to stiffen the mattress during CPR. Manikin models indicate that mattress compression ranges between $12 \%$ and $57 \%$ of total compression depth, with softer mattresses being compressed the most. ${ }^{50-53}$ This can lead to reduced sternal displacement and a reduction in effective chest compression depth.

2. Manikin studies and 1 pediatric case series show that effective compression depth can be achieved even on a soft surface, providing the CPR provider increases overall compression depth to compensate for mattress compression. ${ }^{53-59}$

3. Meta-analysis of 6 studies ${ }^{53,56,60-63}$ showed a 3-mm (95\% Cl 1-4 mm) improvement in chest compression depth associated with backboard use when CPR was performed on a manikin placed on a mattress or bed.

\section{Opening the Airway}

\begin{tabular}{|c|c|c|}
\hline \multicolumn{2}{|c|}{ Recommendations for Opening the Airway } \\
\hline COR & LOE & Recommendations \\
\hline 1 & C-LD & $\begin{array}{r}\text { 1. Unless a cervical spine injury is suspected, use a } \\
\text { head tilt-chin lift maneuver to open the airway. }{ }^{64}\end{array}$ \\
\hline 1 & C-EO & $\begin{array}{r}\text { 2. For the trauma patient with suspected cervical } \\
\text { spinal injury, use a jaw thrust without head tilt } \\
\text { to open the airway. }\end{array}$ \\
\hline 1 & C-EO & $\begin{array}{l}\text { 3. For the trauma patient with suspected cervical } \\
\text { spinal injury, if the jaw thrust does not open } \\
\text { the airway, use a head tilt-chin lift maneuver. }\end{array}$ \\
\hline
\end{tabular}

\section{Recommendation-Specific Supportive Text}

1. No data directly address the ideal method to open or maintain airway patency. One retrospective cohort study evaluated various head-tilt angles in neonates and young infants undergoing diagnostic MRI and found that the highest proportion of patent airways was at a head-tilt angle of 144 to 150 degrees based on a regression analysis. ${ }^{64}$

2. While no pediatric studies evaluate jaw thrust versus head tilt-chin lift to open the airway, the jaw thrust is widely accepted as an effective way to open the airway, and this maneuver theoretically limits cervical motion compared with the head tilt-chin lift.

3. There are no pediatric studies evaluating the impact of a head tilt-chin lift maneuver to open the airway in a trauma patient with suspected cervical spine injury. However, if providers are unable to open the airway and deliver effective ventilations using a jaw thrust, given the importance of a patent airway, using a head tilt-chin lift maneuver is recommended.
Figures 4, 5, 6, and 7 show, respectively, an infographic for pediatric BLS for lay rescuers, the current pediatric BLS algorithms for healthcare provider, single-rescuer CPR and 2-rescuer CPR, and the current algorithm for pediatric cardiac arrest.

\section{REFERENCES}

1. Niles DE, Duval-Arnould J, Skellett S, Knight L, Su F, Raymond TT, Sweberg T, Sen Al, Atkins DL, Friess SH, de Caen AR, Kurosawa H, Sutton RM, Wolfe H, Berg RA, Silver A, Hunt EA, Nadkarni VM; pediatric Resuscitation Quality (pediRES-Q) Collaborative Investigators. Characterization of Pediatric InHospital Cardiopulmonary Resuscitation Quality Metrics Across an International Resuscitation Collaborative. Pediatr Crit Care Med. 2018;19:421432. doi: 10.1097/PCC.0000000000001520

2. Sutton RM, Niles D, Nysaether J, Abella BS, Arbogast KB, Nishisaki A, Maltese MR, Donoghue A, Bishnoi R, Helfaer MA, Myklebust H, Nadkarni V. Quantitative analysis of CPR quality during in-hospital resuscitation of older children and adolescents. Pediatrics. 2009;124:494-499. doi: 10.1542/ peds.2008-1930

3. NilesD, Nysaether J, Sutton R, Nishisaki A, Abella BS, ArbogastK, Maltese MR, Berg RA, Helfaer M, Nadkarni V. Leaning is common during in-hospital pediatric CPR, and decreased with automated corrective feedback. Resuscitation. 2009;80:553-557. doi: 10.1016/j.resuscitation.2009.02.012

4. Mclnnes $A D$, Sutton RM, Orioles $A$, Nishisaki $A$, Niles $D$, Abella BS, Maltese MR, Berg RA, Nadkarni V. The first quantitative report of ventilation rate during in-hospital resuscitation of older children and adolescents. Resuscitation. 2011;82:1025-1029. doi: 10.1016/j. resuscitation.2011.03.020

5. Sutton RM, ReederRW, LandisWP, MeertKL, YatesAR, Morgan RW, Berger JT, Newth CJ, Carcillo JA, McQuillen PS, Harrison RE, Moler FW, Pollack MM, Carpenter TC, Notterman DA, Holubkov R, Dean JM, Nadkarni VM, Berg RA; Eunice Kennedy Shriver National Institute of Child Health and Human Development Collaborative Pediatric Critical Care Research Network (CPCCRN). Ventilation Rates and Pediatric In-Hospital Cardiac Arrest Survival Outcomes. Crit Care Med. 2019;47:1627-1636. doi: 10.1097/CCM.0000000000003898

6. Bahr J, Klingler H, Panzer W, Rode H, Kettler D. Skills of lay people in checking the carotid pulse. Resuscitation. 1997;35:23-26. doi: 10.1016/s0300-9572(96)01092-1

7. Brearley S, Shearman CP, Simms MH. Peripheral pulse palpation: an unreliable physical sign. Ann R Coll Surg Engl. 1992;74:169-171.

8. Cavallaro DL, Melker RJ. Comparison of two techniques for detecting cardiac activity in infants. Crit Care Med. 1983;11:189-190. doi: 10.1097/00003246-198303000-00009

9. Inagawa G, Morimura N, Miwa T, Okuda K, Hirata M, Hiroki K. A comparison of five techniques for detecting cardiac activity in infants. Paediatr Anaesth. 2003;13:141-146. doi: 10.1046/j.1460-9592.2003.00970.x

10. Kamlin CO, O'Donnell CP, Everest NJ, Davis PG, Morley CJ. Accuracy of clinical assessment of infant heart rate in the delivery room. Resuscitation. 2006;71:319-321. doi: 10.1016/j.resuscitation.2006.04.015

11. Lee CJ, Bullock LJ. Determining the pulse for infant CPR: time for a change? Mil Med. 1991;156:190-193.

12. Mather C, O'Kelly S. The palpation of pulses. Anaesthesia. 1996;51:189191. doi: 10.1111/j.1365-2044.1996.tb07713.x

13. Ochoa FJ, Ramalle-Gómara E, Carpintero JM, García A, Saralegui I. Competence of health professionals to check the carotid pulse. Resuscitation. 1998;37:173-175. doi: 10.1016/s0300-9572(98)00055-0

14. Owen CJ, Wyllie JP. Determination of heart rate in the baby at birth. Resuscitation. 2004;60:213-217. doi: 10.1016/j.resuscitation.2003.10.002

15. Sarti A, Savron F, Casotto V, Cuttini M. Heartbeat assessment in infants: a comparison of four clinical methods. Pediatr Crit Care Med. 2005;6:212215. doi: 10.1097/01.PCC.0000154952.59176.E0

16. Sarti A, Savron F, Ronfani L, Pelizzo G, Barbi E. Comparison of three sites to check the pulse and count heart rate in hypotensive infants. Paediatr Anaesth. 2006;16:394-398. doi: 10.1111/j.1460-9592.2005.01803.x

17. Tanner M, Nagy S, Peat JK. Detection of infant's heart beat/pulse by caregivers: a comparison of 4 methods. J Pediatr. 2000;137:429-430. doi: 10.1067/mpd.2000.107188

18. Whitelaw CC, Goldsmith LJ. Comparison of two techniques for determining the presence of a pulse in an infant. Acad Emerg Med. 1997;4:153154. doi: 10.1111/j.1553-2712.1997.tb03725.x 
19. Dick WF, Eberle B, Wisser G, Schneider T. The carotid pulse check revisited what if there is no pulse? Crit Care Med. 2000;28(suppl):N183-N185. doi: 10.1097/00003246-200011001-00002

20. Eberle B, Dick WF, Schneider T, Wisser G, Doetsch S, Tzanova I. Checking the carotid pulse check: diagnostic accuracy of first responders in patients with and without a pulse. Resuscitation. 1996;33:107-116. doi: 10.1016/s0300-9572(96)01016-7

21. Tibballs J, Russell P. Reliability of pulse palpation by healthcare personnel to diagnose paediatric cardiac arrest. Resuscitation. 2009;80:61-64. doi: 10.1016/j.resuscitation.2008.10.002

22. Tibballs J, Weeranatna $C$. The influence of time on the accuracy of healthcare personnel to diagnose paediatric cardiac arrest by pulse palpation. $R e-$ suscitation. 2010;81:671-675. doi: 10.1016/j.resuscitation.2010.01.030

23. O'Connell KJ, Keane RR, Cochrane NH, Sandler AB, Donoghue AJ, Kerrey BT, Myers SR, Vazifedan T, Mullan PC. Pauses in compressions during pediatric CPR: Opportunities for improving CPR quality. Resuscitation. 2019;145:158-165. doi: 10.1016/j.resuscitation.2019.08.015

24. Lubrano R, Cecchetti C, Bellelli E, Gentile I, Loayza Levano H, Orsini F, Bertazzoni G, Messi G, Rugolotto S, Pirozzi N, Elli M. Comparison of times of intervention during pediatric CPR maneuvers using $A B C$ and $C A B$ sequences: a randomized trial. Resuscitation. 2012;83:1473-1477. doi 10.1016/j.resuscitation.2012.04.011

25. Kitamura T, Iwami T, Kawamura T, Nagao K, Tanaka H, Nadkarni VM, Berg RA, Hiraide A; implementation working group for All-Japan Utstein Registry of the Fire and Disaster Management Agency. Conventional and chest-compressiononly cardiopulmonary resuscitation by bystanders for children who have outof-hospital cardiac arrests: a prospective, nationwide, population-based cohort study. Lancet. 2010;375:1347-1354. doi: 10.1016/S0140-6736(10)60064-5

26. Goto Y, Maeda T, Goto Y. Impact of dispatcher-assisted bystander cardiopulmonary resuscitation on neurological outcomes in children with out-ofhospital cardiac arrests: a prospective, nationwide, population-based cohort study. J Am Heart Assoc. 2014;3:e000499. doi: 10.1161/JAHA.113.000499

27. Naim MY, Burke RV, McNally BF, Song L, Griffis HM, Berg RA, Vellano $K$, Markenson D, Bradley RN, Rossano JW. Association of Bystander Cardiopulmonary Resuscitation With Overall and Neurologically Favorable Survival After Pediatric Out-of-Hospital Cardiac Arrest in the United States: A Report From the Cardiac Arrest Registry to Enhance Survival Surveillance Registry. JAMA Pediatr. 2017;171:133-141. doi: 10.1001/jamapediatrics.2016.3643

28. Fukuda T, Ohashi-Fukuda N, Kobayashi H, Gunshin M, Sera T, Kondo $\mathrm{Y}$, Yahagi N. Conventional Versus Compression-Only Versus No-Bystander Cardiopulmonary Resuscitation for Pediatric Outof-Hospital Cardiac Arrest. Circulation. 2016;134:2060-2070. doi 10.1161/CIRCULATIONAHA.116.023831

29. Ashoor HM, Lillie E, Zarin W, Pham B, Khan PA, Nincic V, Yazdi F, Ghassemi M, Ivory J, Cardoso R, Perkins GD, de Caen AR, Tricco AC; ILCOR Basic Life Support Task Force. Effectiveness of different compression-to-ventilation methods for cardiopulmonary resuscitation: A systematic review. Resuscitation. 2017;118:112-125. doi: 10.1016/j.resuscitation.2017.05.032

30. Glatz AC, Nishisaki A, Niles DE, Hanna BD, Eilevstjonn J, Diaz LK, Gillespie MJ, Rome JJ, Sutton RM, Berg RA, Nadkarni VM. Sternal wall pressure comparable to leaning during CPR impacts intrathoracic pressure and haemodynamics in anaesthetized children during cardiac catheterization. Resuscitation. 2013;84:1674-1679. doi: 10.1016/j.resuscitation.2013.07.010

31. Sutton RM, French $B$, Nishisaki A, Niles DE, Maltese MR, Boyle $L$, Stavland M, Eilevstjønn J, Arbogast KB, Berg RA, et al. American Heart Association cardiopulmonary resuscitation quality targets are associated with improved arterial blood pressure during pediatric cardiac arrest. Resuscitation. 2013;84:168-172. doi: 10.1016/j.resuscitation.2012.08.335

32. Sutton RM, Reeder RW, Landis W, Meert KL, Yates AR, Berger JT, Newth CJ, Carcillo JA, McQuillen PS, Harrison RE, Moler FW, Pollack MM, Carpenter TC, Notterman DA, Holubkov R, Dean JM, Nadkarni VM, Berg RA; Eunice Kennedy Shriver National Institute of Child Health and Human Development Collaborative Pediatric Critical Care Research Network (CPCCRN) Investigators. Chest compression rates and pediatric in-hospital cardiac arrest survival outcomes. Resuscitation. 2018;130:159-166. doi: 10.1016/j.resuscitation.2018.07.015

33. Kao PC, Chiang WC, Yang CW, Chen SJ, Liu YP, Lee CC, Hsidh MJ, Ko PC, Chen SC, Ma MH. What is the correct depth of chest compression for infants and children? A radiological study. Pediatrics. 2009;124:49-55. doi: 10.1542/peds.2008-2536

34. Sutton RM, Niles D, Nysaether J, Arbogast KB, Nishisaki A, Maltese MR, Bishnoi R, Helfaer MA, Nadkarni V, Donoghue A. Pediatric CPR quality monitoring: analysis of thoracic anthropometric data. Resuscitation. 2009;80:1137-1141. doi: 10.1016/j.resuscitation. 2009.06.031
35. Braga MS, Dominguez TE, Pollock AN, Niles D, Meyer A, Myklebust $H$, Nysaether J, Nadkarni V. Estimation of optimal CPR chest compression depth in children by using computer tomography. Pediatrics. 2009;124:e69e74. doi: 10.1542/peds.2009-0153

36. Sutton RM, French $B$, Niles DE, Donoghue A, Topjian AA, Nishisaki A, Leffelman J, Wolfe H, Berg RA, Nadkarni VM, et al. 2010 American Heart Association recommended compression depths during pediatric in-hospital resuscitations are associated with survival. Resuscitation. 2014;85:11791184. doi: 10.1016/j.resuscitation.2014.05.007

37. Atkins $D L$, de Caen AR, Berger $S$, Samson RA, Schexnayder SM, Joyner BL Jr, Bigham BL, Niles DE, Duff JP, Hunt EA, Meaney PA. 2017 American Heart Association Focused Update on Pediatric Basic Life Support and Cardiopulmonary Resuscitation Quality: An Update to the American Heart Association Guidelines for Cardiopulmonary Resuscitation and Emergency Cardiovascular Care. Circulation. 2018;137:e1-e6. doi: 10.1161/CIR.0000000000000540

38. Clements F, McGowan J. Finger position for chest compressions in cardiac arrest in infants. Resuscitation. 2000;44:43-46. doi: 10.1016/s0300-9572(99)00165-3

39. Finholt DA, Kettrick RG, Wagner HR, Swedlow DB. The heart is under the lower third of the sternum. Implications for external cardiac massage. Am J Dis Child. 1986;140:646-649. doi: 10.1001/archpedi.1986.02140210044022

40. Phillips GW, Zideman DA. Relation of infant heart to sternum: its significance in cardiopulmonary resuscitation. Lancet. 1986;1:1024-1025. doi: 10.1016/s0140-6736(86)91284-5

41. Orlowski JP. Optimum position for external cardiac compression in infants and young children. Ann Emerg Med. 1986;15:667-673. doi: 10.1016/s0196-0644(86)80423-1

42. Douvanas A, Koulouglioti C, Kalafati M. A comparison between the two methods of chest compression in infant and neonatal resuscitation: a review according to 2010 CPR guidelines. J Matern Fetal Neonatal Med. 2018;31:805-816. doi: 10.1080/14767058.2017.1295953

43. Lee JE, Lee J, Oh J, Park CH, Kang H, Lim TH, Yoo KH. Comparison of twothumb encircling and two-finger technique during infant cardiopulmonary resuscitation with single rescuer in simulation studies: a systematic review and meta-analysis. Medicine (Baltimore). 2019;98:e17853. doi: 10.1097/MD.0000000000017853

44. Lee SY, Hong JY, Oh JH, Son SH. The superiority of the two-thumb over the two-finger technique for single-rescuer infant cardiopulmonary resuscitation. Eur J Emerg Med. 2018;25:372-376. doi: 10.1097/MEJ.0000000000000461

45. Tsou JY, Kao CL, Chang CJ, Tu YF, Su FC, Chi CH. Biomechanics of twothumb versus two-finger chest compression for cardiopulmonary resuscitation in an infant manikin model. Eur J Emerg Med. 2020;27:132-136. doi: 10.1097/MEJ.0000000000000631

46. Pellegrino JL, Bogumil D, Epstein JL, Burke RV. Two-thumbencircling advantageous for lay responder infant CPR: a randomised manikin study. Arch Dis Child. 2019;104:530-534. doi: 10.1136/archdischild-2018-314893

47. Kim MJ, Lee HS, Kim S, Park YS. Optimal chest compression technique for paediatric cardiac arrest victims. Scand J Trauma Resusc Emerg Med. 2015;23:36. doi: 10.1186/s13049-015-0118-y

48. Stevenson AG, McGowan J, Evans AL, Graham CA. CPR for children: one hand or two? Resuscitation. 2005;64:205-208. doi: 10.1016/j.resuscitation.2004.07.012

49. Peska E, Kelly AM, Kerr D, Green D. One-handed versus two-handed chest compressions in paediatric cardio-pulmonary resuscitation. Resuscitation. 2006;71:65-69. doi: 10.1016/j.resuscitation.2006.02.007

50. Lin Y, Wan B, Belanger C, Hecker K, Gilfoyle E, Davidson J, Cheng A. Reducing the impact of intensive care unit mattress compressibility during CPR: a simulation-based study. Adv Simul (Lond). 2017;2:22. doi: 10.1186/s41077-017-0057-y

51. Noordergraaf GJ, Paulussen IW, Venema A, van Berkom PF, Woerlee PH, Scheffer GJ, Noordergraaf A. The impact of compliant surfaces on in-hospital chest compressions: effects of common mattresses and a backboard. Resuscitation. 2009;80:546-552. doi: 10.1016/j. resuscitation.2009.03.023

52. Oh J, Chee $Y$, Song $Y$, Lim T, Kang H, Cho Y. A novel method to decrease mattress compression during CPR using a mattress compression cover and a vacuum pump. Resuscitation. 2013;84:987-991. doi: 10.1016/j.resuscitation.2012.12.027 
53. Song $Y$, Oh J, Lim T, Chee $Y$. A new method to increase the quality of cardiopulmonary resuscitation in hospital. Conf Proc IEEE Eng Med Biol Soc. 2013;2013:469-472. doi: 10.1109/EMBC.2013.6609538

54. Beesems SG, Koster RW. Accurate feedback of chest compression depth on a manikin on a soft surface with correction for total body displacement. Resuscitation. 2014;85:1439-1443. doi: 10.1016/j. resuscitation.2014.08.005

55. Nishisaki A, Maltese MR, Niles DE, Sutton RM, Urbano J, Berg RA, Nadkarni VM. Backboards are important when chest compressions are provided on a soft mattress. Resuscitation. 2012;83:1013-1020. doi: 10.1016/j.resuscitation.2012.01.016

56. Sato $H$, Komasawa $N$, Ueki $R$, Yamamoto $N$, Fujii A, Nishi $S$ Kaminoh Y. Backboard insertion in the operating table increases chest compression depth: a manikin study. J Anesth. 2011;25:770-772. doi: 10.1007/s00540-011-1196-2

57. Lee S, Oh J, Kang H, Lim T, Kim W, Chee Y, Song Y, Ahn C, Cho JH. Proper target depth of an accelerometer-based feedback device during CPR performed on a hospital bed: a randomized simulation study. Am J Emerg Med. 2015;33:1425-1429. doi: 10.1016/j.ajem.2015.07.010

58. Oh J, Song $Y$, Kang B, Kang H, Lim T, Suh Y, Chee $Y$. The use of dual accelerometers improves measurement of chest compression depth. Resuscitation. 2012;83:500-504. doi: 10.1016/j.resuscitation.2011.09.028

59. Ruiz de Gauna S, González-Otero DM, Ruiz J, Gutiérrez JJ, Russell JK. A feasibility study for measuring accurate chest compression depth and rate on soft surfaces using two accelerometers and spectral analysis. Biomed Res Int. 2016;2016:6596040. doi: 10.1155/2016/6596040

60. Andersen L $\varnothing$, Isbye DL, Rasmussen LS. Increasing compression depth during manikin CPR using a simple backboard. Acta Anaesthesiol Scand. 2007;51:747-750. doi: 10.1111/j.1399-6576.2007.01304.x

61. Fischer EJ, Mayrand K, Ten Eyck RP. Effect of a backboard on compression depth during cardiac arrest in the ED: a simulation study. Am J Emerg Med. 2016;34:274-277. doi: 10.1016/j.ajem.2015.10.035

62. Perkins GD, Smith CM, Augre C, Allan M, Rogers H, Stephenson B, Thickett DR. Effects of a backboard, bed height, and operator position on compression depth during simulated resuscitation. Intensive Care Med. 2006;32:1632-1635. doi: 10.1007/s00134-006-0273-8

63. Sanri E, Karacabey S. The Impact of Backboard Placement on Chest Compression Quality: A Mannequin Study. Prehosp Disaster Med. 2019;34:182-187. doi: 10.1017/S1049023X19000153

64. Bhalala US, Hemani M, Shah M, Kim B, Gu B, Cruz A, Arunachalam P, Tian E, Yu C, Punnoose J, Chen S, Petrillo C, Brown A, Munoz K, Kitchen G, Lam T, Bosemani T, Huisman TA, Allen RH, Acharya S. Defining Optimal Head-Tilt Position of Resuscitation in Neonates and Young Infants Using Magnetic Resonance Imaging Data. PLoS One. 2016;11:e0151789. doi: 10.1371/journal.pone.0151789

\section{ADVANCED AIRWAY INTERVENTIONS DURING CPR}

Most pediatric cardiac arrests are triggered by respiratory deterioration. Airway management and effective ventilation are fundamental to pediatric resuscitation. Although the majority of patients can be successfully ventilated with bag-mask ventilation, this method requires interruptions in chest compressions and is associated with risk of aspiration and barotrauma.

Advanced airway interventions, such as supraglottic airway (SGA) placement or endotracheal intubation (ETI), may improve ventilation, reduce the risk of aspiration, and enable uninterrupted compression delivery. However, airway placement may interrupt the delivery of compressions or result in a malpositioned device. Advanced airway placement requires specialized equipment and skilled providers, and it may be difficult for professionals who do not routinely intubate children.
Recommendation for Advanced Airway Interventions During CPR

\begin{tabular}{|c|c|c|}
\hline COR & LOE & Recommendation \\
\hline $2 a$ & C-LD & $\begin{array}{l}\text { 1. Bag-mask ventilation is reasonable compared } \\
\text { with advanced airway interventions (SGA and } \\
\text { ETI) in the management of children during } \\
\text { cardiac arrest in the out-of-hospital setting. }\end{array}$ \\
\hline
\end{tabular}

\section{Recommendation-Specific Supportive Text}

1. A clinical trial and 2 propensity-matched retrospective studies show that ETI and bag-mask ventilation achieve similar rates of survival with good neurological function and survival to hospital discharge in pediatric patients with OHCA. ${ }^{1-3}$ Propensity-matched retrospective studies also show similar rates of survival with good neurological function and survival to discharge when comparing SGA with bag-mask ventilation in pediatric OHCA. ${ }^{2,3}$ No difference was observed in outcomes between SGA and ETI.,3 There are limited data to compare outcomes between bagmask ventilation versus ETI in the management of IHCA ${ }^{4}$ and there are no hospital-based studies of SGA. The data are not sufficient to support a recommendation for advanced airway use in IHCA. There may be specific circumstances or populations in which early advanced airway interventions are beneficial.

This recommendation was reviewed in the "2019 American Heart Association Focused Update on Pediatric Advanced Life Support: An Update to the American Heart Association Guidelines for Cardiopulmonary Resuscitation and Emergency Cardiovascular Care." ${ }^{5}$

\section{REFERENCES}

1. Gausche M, Lewis RJ, Stratton SJ, Haynes BE, Gunter CS, Goodrich SM, Poore PD, McCollough MD, Henderson DP, Pratt FD, et al. Effect of outof-hospital pediatric endotracheal intubation on survival and neurological outcome: a controlled clinical trial. JAMA. 2000;283:783-790.

2. Hansen $M L$, Lin A, Eriksson C, Daya M, McNally B, Fu R, Yanez D, Zive D, Newgard C; CARES surveillance group. A comparison of pediatric airway management techniques during out-of-hospital cardiac arrest using the CARES database. Resuscitation. 2017;120:51-56. doi: 10.1016/j.resuscitation.2017.08.015

3. Ohashi-Fukuda N, Fukuda T, Doi K, Morimura N. Effect of prehospital advanced airway management for pediatric out-of-hospital cardiac arrest. Resuscitation. 2017;114:66-72. doi: 10.1016/j.resuscitation.2017.03.002

4. Andersen LW, Raymond TT, Berg RA, Nadkarni VM, Grossestreuer AV, Kurth T, Donnino MW; American Heart Association's Get With The Guidelines-Resuscitation Investigators. Association Between Tracheal Intubation During Pediatric In-Hospital Cardiac Arrest and Survival. JAMA 2016;316:1786-1797. doi: 10.1001/jama.2016.14486

5. Duff JP, Topjian AA, Berg MD, Chan M, Haskell SE, Joyner BL Jr, Lasa JJ, Ley SJ, Raymond TT, Sutton RM, Hazinski MF, Atkins DL. 2019 American Heart Association Focused Update on Pediatric Advanced Life Support: An Update to the American Heart Association Guidelines for Cardiopulmonary Resuscitation and Emergency Cardiovascular Care. Circulation. 2019;140:e904-e914. doi: 10.1161/CIR.0000000000000731 


\section{DRUG ADMINISTRATION DURING CPR}

Vasoactive agents, such as epinephrine, are used during cardiac arrest to restore spontaneous circulation by optimizing coronary perfusion and maintaining cerebral perfusion, but the benefit and optimal timing of administration remain unclear. ${ }^{1,2}$ Antiarrhythmics reduce the risk of recurrent ventricular fibrillation (VF) and pulseless ventricular tachycardia ( $p V T)$ following defibrillation and may improve defibrillation success. Routine use of sodium bicarbonate and calcium is not supported by current data. ${ }^{3-7}$ However, there are specific circumstances when their a dministration is indicated, such as electrolyte imbalances and certain drug toxicities.

Medication dosing for children is based on weight, which is often difficult to obtain in an emergency setting. There are numerous approaches to estimating weight when an actual weight cannot be obtained. ${ }^{8}$

\section{Drug Administration During Cardiac Arrest}

\begin{tabular}{|c|c|c|}
\hline \multicolumn{3}{|c|}{ Recommendations for Drug Administration During Cardiac Arrest } \\
\hline COR & LOE & Recommendations \\
\hline $2 a$ & C-LD & $\begin{array}{l}\text { 1. For pediatric patients in any setting, it is } \\
\text { reasonable to administer epinephrine. IV/ } \\
\text { IO is preferable to endotracheal tube (ETT) } \\
\text { administration. } .^{2,9-11}\end{array}$ \\
\hline $2 a$ & C-LD & $\begin{array}{l}\text { 2. For pediatric patients in any setting, it is } \\
\text { reasonable to administer the initial dose of } \\
\text { epinephrine within } 5 \text { min from the start of } \\
\text { chest compressions. }{ }^{12-16}\end{array}$ \\
\hline $2 a$ & C-LD & $\begin{array}{l}\text { 3. For pediatric patients in any setting, it is } \\
\text { reasonable to administer epinephrine every } \\
3-5 \text { min until ROSC is achieved. } .^{17,18}\end{array}$ \\
\hline $2 b$ & C-LD & $\begin{array}{l}\text { 4. For shock-refractory VF/pVT, either } \\
\text { amiodarone or lidocaine may be used. }{ }^{19,20}\end{array}$ \\
\hline 3: Harm & B-NR & $\begin{array}{l}\text { 5. Routine administration of sodium bicarbonate } \\
\text { is not recommended in pediatric cardiac arrest } \\
\text { in the absence of hyperkalemia or sodium } \\
\text { channel blocker (eg, tricyclic antidepressant) } \\
\text { toxicity. }{ }^{5-7,21-25}\end{array}$ \\
\hline 3: Harm & B-NR & $\begin{array}{l}\text { 6. Routine calcium administration is not } \\
\text { recommended for pediatric cardiac arrest in } \\
\text { the absence of documented hypocalcemia, } \\
\text { calcium channel blocker overdose, } \\
\text { hypermagnesemia, or hyperkalemia. }{ }^{3,4,23}\end{array}$ \\
\hline
\end{tabular}

\section{Recommendation-Specific Supportive Text}

1. There are limited data in pediatrics comparing epinephrine administration to no epinephrine administration in any setting. In an OHCA study of 65 children, 12 patients did not receive epinephrine due to lack of a route of administration, and only 1 child had ROSC. ${ }^{2}$ An OHCA study of 9 children who had cardiac arrest during sport or exertion noted a survival rate of $67 \%$, of whom $83 \%$ did not receive epinephrine. All survivors received early chest compressions (within 5 minutes) and early defibrillation (within 10 minutes), and the initial cardiac arrest rhythm was a shockable rhythm. ${ }^{9}$ Intravenous/intraosseous (IV/ IO) administration of epinephrine is preferred over ETT administration when possible. ${ }^{10,11}$

2. One retrospective observational study of children with IHCA who received epinephrine for an initial nonshockable rhythm demonstrated that, for every minute delay in administration of epinephrine, there was a significant decrease in ROSC, survival at 24 hours, survival to discharge, and survival with favorable neurological outcome. ${ }^{12}$ Patients who received epinephrine within 5 minutes of CPR compared to those who received epinephrine more than 5 minutes after CPR initiation were more likely to survive to discharge. ${ }^{12}$ Four observational studies of pediatric OHCA demonstrated that earlier epinephrine administration increased rates of ROSC, ${ }^{13,14}$ survival to ICU admission, ${ }^{14}$ survival to discharge, ${ }^{14,16}$ and 30 -day survival. ${ }^{15}$

3. One observational study demonstrated an increased survival rate at 1 year in the group that was administered epinephrine at an interval of less than 5 minutes. ${ }^{17}$ One observational study of pediatric IHCA demonstrated that an average epinephrine administration interval of 5 to 8 minutes and of 8 to 10 minutes was associated with increased odds of survival compared with an epinephrine interval of 1 to 5 minutes. ${ }^{18}$ Both studies $^{17,18}$ calculated the average interval of epinephrine doses by averaging all doses over total arrest time, which does not account for potential differences in dosing intervals throughout resuscitations of varying duration. No studies of pediatric OHCA on frequency of epinephrine dosing were identified.

4. Two studies examined drug therapy of VF/pVT in infants and children. ${ }^{19,20}$ In Valdes et al, administration of lidocaine, but not amiodarone, was associated with higher rates of ROSC and survival to hospital admission. ${ }^{19}$ Neither lidocaine nor amiodarone significantly affected the odds of survival to hospital discharge; neurological outcome was not assessed. A propensity-matched study of an IHCA registry demonstrated no difference in outcomes for patients receiving lidocaine compared with amiodarone. ${ }^{20}$

5. A recent evidence review identified 8 observational studies of sodium bicarbonate administration during cardiac arrest. ${ }^{5-7,21-25}$ Bicarbonate administration was associated with worse survival outcomes for both IHCA and OHCA. There are special circumstances in which bicarbonate is used, such as the treatment of hyperkalemia and 
sodium channel blocker toxicity, including from tricyclic antidepressants.

6. Two observational studies examining the administration of calcium during cardiac arrest demonstrated worse survival and ROSC with calcium administration. ${ }^{4,23}$ There are special circumstances in which calcium administration is used, such as hypocalcemia, calcium channel blocker overdose, hypermagnesemia, and hyperkalemia. $^{3}$

Recommendation 4 was reviewed in "2018 American Heart Association Focused Update on Pediatric Advanced Life Support: An Update to the American Heart Association Guidelines for Cardiopulmonary Resuscitation and Emergency Cardiovascular Care." 26

\section{Weight-Based Dosing of Resuscitation Medications}

\begin{tabular}{|c|c|c|}
\hline \multicolumn{3}{|c|}{$\begin{array}{l}\text { Recommendations for Weight-Based Dosing of Resuscitation } \\
\text { Medications }\end{array}$} \\
\hline COR & LOE & Recommendations \\
\hline 1 & $C-E O$ & $\begin{array}{l}\text { 1. For resuscitation medication dosing, it is } \\
\text { recommended to use the child's body weight } \\
\text { to calculate resuscitation drug doses while } \\
\text { not exceeding the recommended dose for } \\
\text { adults. }{ }^{27-31}\end{array}$ \\
\hline $2 b$ & B-NR & $\begin{array}{l}\text { 2. When possible, inclusion of body habitus } \\
\text { or anthropomorphic measurements may } \\
\text { improve the accuracy of length-based } \\
\text { estimated weight. }^{8}\end{array}$ \\
\hline $2 b$ & C-LD & $\begin{array}{l}\text { 3. If the child's weight is unknown, a body } \\
\text { length tape for estimating weight and other } \\
\text { cognitive aids to calculate resuscitation } \\
\text { drug dosing and administration may be } \\
\text { considered. }{ }^{29,32,33}\end{array}$ \\
\hline
\end{tabular}

\section{Recommendation-Specific Supportive Text}

1. There are many theoretical concerns about the use of actual body weight (especially in overweight or obese patients). ${ }^{27-29}$ However, there are no data about the safety and efficacy of adjusting medication dosing in obese patients. Such adjustments could result in inaccurate dosing of medications. ${ }^{30,31}$

2. Several studies suggest that inclusion of body habitus or anthropometric measurements further refines and improves weight estimations using length-based measures. ${ }^{8}$ However, there is considerable variation in these methods, and the training required to use these measures may not be practical in every context.

3. Cognitive aids can assist in the accurate approximation of body weight (described as being within $10 \%$ to $20 \%$ of measured total body weight). Several recent studies demonstrated high variability of weight estimates, with a tendency toward underestimation of total body weight yet closely approximating ideal body weight. ${ }^{29,32,33}$

\section{REFERENCES}

1. Campbell ME, Byrne PJ. Cardiopulmonary resuscitation and epinephrine infusion in extremely low birth weight infants in the neonatal intensive care unit. J Perinatol. 2004;24:691-695. doi: 10.1038/sj.jp.7211174

2. Dieckmann RA, Vardis R. High-dose epinephrine in pediatric out-of-hospital cardiopulmonary arrest. Pediatrics. 1995;95:901-913.

3. Kette F, Ghuman J, Parr M. Calcium administration during cardiac arrest: a systematic review. Eur J Emerg Med. 2013;20:72-78. doi: 10.1097/MEJ.0b013e328358e336

4. Lasa JJ, Alali A, Minard CG, Parekh D, Kutty S, Gaies M, Raymond TT, Guerguerian AM, Atkins D, Foglia $E$, et al; on behalf of the American Heart Association's Get With the Guidelines-Resuscitation Investigators. Cardiopulmonary resuscitation in the pediatric cardiac catheterization laboratory: A report from the American Heart Association's Get With the Guidelines-Resuscitation Registry. Pediatr Crit Care Med. 2019;20:10401047. doi: 10.1097/PCC.0000000000002038

5. Matamoros M, Rodriguez R, Callejas A, Carranza D, Zeron H, Sánchez C, Del Castillo J, López-Herce J; Iberoamerican Pediatric Cardiac Arrest Study Network (RIBEPCI). In-hospital pediatric cardiac arrest in Honduras. Pediatr Emerg Care. 2015;31:31-35. doi: 10.1097/PEC.0000000000000323

6. Nehme Z, Namachivayam S, Forrest A, Butt W, Bernard S, Smith K. Trends in the incidence and outcome of paediatric out-of-hospital cardiac arrest: A 17-year observational study. Resuscitation. 2018;128:43-50. doi: 10.1016/j.resuscitation.2018.04.030

7. Raymond TT, Stromberg D, Stigall W, Burton G, Zaritsky A; American Heart Association's Get With The Guidelines-Resuscitation Investigators. Sodium bicarbonate use during in-hospital pediatric pulseless cardiac arrest - a report from the American Heart Association Get With The Guidelines@-Resuscitation. Resuscitation. 2015;89:106-113. doi: 10.1016/j.resuscitation.2015.01.007

8. Young KD, Korotzer NC. Weight Estimation Methods in Children: A Systematic Review. Ann Emerg Med. 2016;68:441-451.e10. doi: 10.1016/j.annemergmed.2016.02.043

9. Enright K, Turner C, Roberts P, Cheng N, Browne G. Primary cardiac arrest following sport or exertion in children presenting to an emergency department: chest compressions and early defibrillation can save lives, but is intravenous epinephrine always appropriate? Pediatr Emerg Care. 2012;28:336-339. doi: 10.1097/PEC.0b013e31824d8c78

10. Niemann JT, Stratton SJ, Cruz B, Lewis RJ. Endotracheal drug administration during out-of-hospital resuscitation: where are the survivors? Resuscitation. 2002;53:153-157. doi: 10.1016/s0300-9572(02)00004-7

11. Niemann JT, Stratton SJ. Endotracheal versus intravenous epinephrine and atropine in out-of-hospital "primary" and postcountershock asystole. Crit Care Med. 2000;28:1815-1819. doi: 10.1097/00003246-200006000-00022

12. Andersen LW, Berg KM, Saindon BZ, Massaro JM, Raymond TT, Berg RA, Nadkarni VM, Donnino MW; American Heart Association Get With the Guidelines-Resuscitation Investigators. Time to Epinephrine and Survival After Pediatric In-Hospital Cardiac Arrest. JAMA. 2015;314:802-810. doi: 10.1001/jama.2015.9678

13. Lin YR, Wu MH, Chen TY, Syue YJ, Yang MC, Lee TH, Lin CM, Chou CC, Chang CF, Li CJ. Time to epinephrine treatment is associated with the risk of mortality in children who achieve sustained ROSC after traumatic out-of-hospital cardiac arrest. Crit Care. 2019;23:101. doi: 10.1186/s13054-019-2391-z

14. Lin YR, Li CJ, Huang CC, Lee TH, Chen TY, Yang MC, Chou CC, Chang CF, Huang HW, Hsu HY, Chen WL. Early Epinephrine Improves the Stabilization of Initial Post-resuscitation Hemodynamics in Children With Nonshockable Out-of-Hospital Cardiac Arrest. Front Pediatr. 2019;7:220. doi: 10.3389/fped.2019.00220

15. Fukuda T, Kondo Y, Hayashida K, Sekiguchi H, Kukita I. Time to epinephrine and survival after paediatric out-of-hospital cardiac arrest. Eur Heart J Cardiovasc Pharmacother. 2018;4:144-151. doi: 10.1093/ehjcvp/pvx023

16. Hansen $M$, Schmicker $R H$, Newgard $C D$, Grunau B, Scheuermeyer $F$, Cheskes S, Vithalani V, Alnaji F, Rea T, Idris AH, Herren H, Hutchison J, Austin M, Egan D, Daya M; Resuscitation Outcomes Consortium Investigators. Time to Epinephrine Administration and Survival From Nonshockable Out-of-Hospital Cardiac Arrest Among Children and Adults. Circulation. 2018;137:2032-2040. doi: 10.1161/CIRCULATIONAHA.117.033067 
17. Meert K, Telford R, Holubkov R, Slomine BS, Christensen JR, Berger J, Ofori-Amanfo G, Newth CJL, Dean JM, Moler FW. Paediatric in-hospital cardiac arrest: factors associated with survival and neurobehavioural outcome one year later. Resuscitation. 2018;124:96-105. doi: 10.1016/j.resuscitation.2018.01.013

18. Hoyme DB, Patel SS, Samson RA, Raymond TT, Nadkarni VM, Gaies MG, Atkins DL; American Heart Association Get With The Guidelines-Resuscitation Investigators. Epinephrine dosing interval and survival outcomes during pediatric in-hospital cardiac arrest. Resuscitation. 2017;117:18-23. doi: 10.1016/j.resuscitation.2017.05.023

19. Valdes SO, Donoghue AJ, Hoyme DB, Hammond R, Berg MD, Berg RA, Samson RA; American Heart Association Get With The Guidelines-Resuscitation Investigators. Outcomes associated with amiodarone and lidocaine in the treatment of in-hospital pediatric cardiac arrest with pulseless ventricular tachycardia or ventricular fibrillation. Resuscitation. 2014;85:381-386. doi: 10.1016/j.resuscitation.2013.12.008

20. Holmberg MJ, Ross CE, Atkins DL, Valdes SO, Donnino MW, Andersen LW on behalf of the American Heart Association's Get With The GuidelinesResuscitation Pediatric Research Task Force. Lidocaine versus amiodarone for pediatric in-hospital cardiac arrest: an observational study. Resuscitation. 2020:Epub ahead of print. doi: 10.1016/j.resuscitation.2019.12.033

21. López-Herce J, del Castillo J, Cañadas S, Rodríguez-Núñez A, Carrillo A Spanish Study Group of Cardiopulmonary Arrest in Children. In-hospital pediatric cardiac arrest in Spain. Rev Esp Cardiol (Engl Ed). 2014;67:189195. doi: 10.1016/j.rec.2013.07.017

22. Wolfe HA, Sutton RM, Reeder RW, Meert KL, Pollack MM, Yates AR, Berger JT, Newth CJ, Carcillo JA, McQuillen PS, Harrison RE, Moler FW, Carpenter TC, Notterman DA, Holubkov R, Dean JM, Nadkarni VM, Berg RA; Eunice Kennedy Shriver National Institute of Child Health; Human Development Collaborative Pediatric Critical Care Research Network; Pediatric Intensive Care Quality of Cardiopulmonary Resuscitation Investigators. Functional outcomes among survivors of pediatric in-hospital cardiac arrest are associated with baseline neurologic and functional status, but not with diastolic blood pressure during CPR. Resuscitation. 2019;143:57-65. doi: 10.1016/j.resuscitation.2019.08.006

23. Mok YH, Loke AP, Loh TF, Lee JH. Characteristics and Risk Factors for Mortality in Paediatric In-Hospital Cardiac Events in Singapore: Retrospective Single Centre Experience. Ann Acad Med Singapore. 2016;45:534-541.

24. Del Castillo J, López-Herce J, Cañadas S, Matamoros M, RodríguezNúnez A, Rodríguez-Calvo A, Carrillo A; Iberoamerican Pediatric Cardiac Arrest Study Network RIBEPCI. Cardiac arrest and resuscitation in the pediatric intensive care unit: a prospective multicenter multinational study. Resuscitation. 2014;85:1380-1386. doi: 10.1016/j. resuscitation.2014.06.024

25. Wu ET, Li MJ, Huang SC, Wang CC, Liu YP, Lu FL, Ko WJ, Wang MJ, Wang JK, Wu MH. Survey of outcome of CPR in pediatric in-hospital cardiac arrest in a medical center in Taiwan. Resuscitation. 2009;80:443-448. doi: 10.1016/j.resuscitation.2009.01.006

26. Duff JP, Topjian A, Berg MD, Chan M, Haskell SE, Joyner BL Jr, Lasa J נر Ley SJ, Raymond TT, Sutton RM, Hazinski MF, Atkins DL. 2018 American Heart Association Focused Update on Pediatric Advanced Life Support: An Update to the American Heart Association Guidelines for Cardiopulmonary Resuscitation and Emergency Cardiovascular Care. Circulation. 2018;138:e731-e739. doi: 10.1161/CIR.0000000000000612

27. Wells M, Goldstein LN, Bentley A. It is time to abandon age-based emergency weight estimation in children! A failed validation of 20 different age-based formulas. Resuscitation. 2017;116:73-83. doi: 10.1016/j.resuscitation.2017.05.018

28. Tanner D, Negaard A, Huang R, Evans N, Hennes H. A Prospective Evaluation of the Accuracy of Weight Estimation Using the Broselow Tape in Overweight and Obese Pediatric Patients in the Emergency Department. Pediatr Emerg Care. 2017;33:675-678. doi: 10.1097/PEC.0000000000000894

29. Waseem M, Chen J, Leber M, Giambrone $A E$, Gerber LM. A reexamination of the accuracy of the Broselow tape as an instrument for weight estimation. Pediatr Emerg Care. 2019;35:112-116. doi: 10.1097/PEC.0000000000000982

30. van Rongen $A$, Brill MJE, Vaughns JD, Välitalo PAJ, van Dongen EPA van Ramshorst B, Barrett JS, van den Anker JN, Knibbe CAJ. Higher midazolam clearance in obese adolescents compared with morbidly obese adults. Clin Pharmacokinet. 2018;57:601-611. doi: 10.1007/s40262-017-0579-4

31. Vaughns JD, Ziesenitz VC, Williams EF, Mushtaq A, Bachmann R, Skopp G, Weiss J, Mikus G, van den Anker JN. Use of fentanyl in adolescents with clinically severe obesity undergoing bariatric surgery: a pilot study. Paediatr Drugs. 2017;19:251-257. doi: 10.1007/s40272-017-0216-6

32. Shrestha K, Subedi P, Pandey O, Shakya L, Chhetri K, House DR. Estimating the weight of children in Nepal by Broselow, PAWPER XL and Mercy method. World J Emerg Med. 2018;9:276-281. doi: 10.5847/wjem.j. 1920-8642.2018.04.007

33. Wells M, Goldstein LN, Bentley A. The accuracy of paediatric weight estimation during simulated emergencies: the effects of patient position, patient cooperation, and human errors. Afr J Emerg Med. 2018;8:43-50. doi: 10.1016/j.afjem.2017.12.003

\section{MANAGEMENT OF VF/pVT}

The risk of VF/pVT steadily increases throughout childhood and adolescence but remains less frequent than in adults. Cardiac arrest due to an initial rhythm of VF/pVT has better rates of survival to hospital discharge with favorable neurological function than cardiac arrests due to an initial nonshockable rhythm. Shockable rhythms may be the initial rhythm of the cardiac arrest (primary VF/ $\mathrm{pVT}$ ) or may develop during the resuscitation (secondary $\mathrm{VF} / \mathrm{pVT}$ ). Defibrillation is the definitive treatment for VF/ $\mathrm{pVT}$. The shorter the duration of VF/pVT, the more likely that the shock will result in a perfusing rhythm. Both manual defibrillators and AEDs can be used to treat VF/pVT in children. Manual defibrillators are preferred when a shockable rhythm is identified by a healthcare provider because the energy dose can be titrated to the patient's weight. AEDs have high specificity in recognizing pediatric shockable rhythms. Biphasic, instead of monophasic, defibrillators are recommended because less energy is required to achieve termination of $\mathrm{VF} / \mathrm{pVT}$, with fewer side effects. Many AEDs are equipped to attenuate (reduce) the energy dose to make them suitable for infants and children younger than 8 years of age.

\section{Energy Dose}

\begin{tabular}{|c|c|l|}
\hline \multicolumn{2}{|c|}{ Recommendations for Energy Dose } \\
\hline COR & LOE & Recommendations \\
\hline $2 a$ & C-LD & $\begin{array}{r}\text { 1. It is reasonable to use an initial dose of } 2-4 \\
\mathrm{~J} / \mathrm{kg} \text { of monophasic or biphasic energy for } \\
\text { defibrillation, but, for ease of teaching, an } \\
\text { initial dose of } 2 \mathrm{~J} / \mathrm{kg} \text { may be considered. }{ }^{1-7}\end{array}$ \\
\hline $2 \mathrm{~b}$ & C-LD & $\begin{array}{l}\text { 2. For refractory VF, it may be reasonable to } \\
\text { increase the defibrillation dose to } 4 \mathrm{~J} / \mathrm{kg}^{1-7}\end{array}$ \\
\hline $2 \mathrm{~b}$ & C-LD & $\begin{array}{l}\text { 3. For subsequent energy levels, a dose of } 4 \mathrm{~J} / \mathrm{kg} \\
\text { may be reasonable, and higher energy levels } \\
\text { may be considered, though not to exceed } 10 \\
\mathrm{~J} / \mathrm{kg} \text { or the adult maximum dose. }{ }^{1-7}\end{array}$ \\
\hline
\end{tabular}

\section{Recommendation-Specific Supportive Text}

1. 1, 2, and 3. A systematic review ${ }^{1}$ demonstrated no relationship between energy dose and any outcome. No randomized controlled trials were available, and most studies only evaluated the first shock. An IHCA case series of 71 shocks in 27 patients concluded that $2 \mathrm{~J} / \mathrm{kg}$ terminated VF, but neither the subsequent rhythm nor the outcome of 
the resuscitation was reported. ${ }^{2} \mathrm{~A}$ small case series of prolonged OHCA observed that 2 to $4 \mathrm{~J} / \mathrm{kg}$ shock terminated VF 14 times in 11 patients, resulting in asystole or pulseless electric activity, with no survivors to hospital discharge. ${ }^{3}$ In 1 observational study of IHCA, ${ }^{4}$ a higher initial energy dose of more than 3 to $5 \mathrm{~J} / \mathrm{kg}$ was less effective than 1 to $3 \mathrm{~J} / \mathrm{kg}$ in achieving ROSC. Three small, observational studies of pediatric IHCA $\mathrm{HC}^{3,5}$ and $\mathrm{OHCA}^{6}$ found no specific initial energy dose that was associated with successful defibrillation. One study suggested that $2 \mathrm{~J} / \mathrm{kg}$ was an ineffective dose, especially for secondary VF.?

\section{Coordination of Shock and CPR}

\begin{tabular}{|c|c|c|}
\hline \multicolumn{2}{|c|}{ Recommendations for Coordination of Shock and CPR } \\
\hline COR & LOE & Recommendations \\
\hline 1 & C-EO & $\begin{array}{r}\text { 1. Perform CPR until the device is ready to } \\
\text { deliver a shock. }{ }^{8-12}\end{array}$ \\
\hline 1 & C-EO & $\begin{array}{l}\text { 2. A single shock followed by immediate chest } \\
\text { compressions is recommended for children } \\
\text { with VF/pVT. }{ }^{13,14}\end{array}$ \\
\hline 1 & C-EO & $\begin{array}{r}\text { 3. Minimize interruptions of chest } \\
\text { compressions. }{ }^{13,15}\end{array}$ \\
\hline
\end{tabular}

\section{Recommendation-Specific Supportive Text}

1. There are currently no pediatric data available regarding the optimal timing of CPR prior to defibrillation. Adult studies demonstrate no benefit of a prolonged period of CPR prior to initial defibrillation. ${ }^{8-12}$

2. There are currently no pediatric data concerning the best sequence for coordination of shocks and CPR. Adult studies comparing a 1-shock protocol versus a 3-shock protocol for treatment of VF suggest significant survival benefit with the single-shock protocol. ${ }^{13,14}$

3. Prolonged pauses in chest compressions decrease blood flow and oxygen delivery to vital organs, such as the brain and heart, and are associated with lower survival. ${ }^{13,15}$

\section{Defibrillator Paddle Size, Type, and Position}

\begin{tabular}{|c|c|c|}
\hline \multicolumn{2}{|c|}{ Recommendations for Defibrillator Paddle Size, Type, and Position } \\
\hline COR & LOE & Recommendations \\
\hline 1 & C-EO & $\begin{array}{r}\text { 1. Use the largest paddles or self-adhering } \\
\text { electrodes that will fit on the child's chest } \\
\text { while still maintaining good separation } \\
\text { between the pads/paddles. }{ }^{16-18}\end{array}$ \\
\hline $2 b$ & C-LD & $\begin{array}{l}\text { 2. When affixing self-adhering pads, either } \\
\text { anterior-lateral placement or anterior-posterior } \\
\text { placement may be reasonable. }{ }^{7,19}\end{array}$ \\
\hline $2 b$ & C-LD & $\begin{array}{l}\text { 3. Paddles and self-adhering pads may be } \\
\text { considered equally effective in delivering } \\
\text { electricity. }{ }^{20}\end{array}$ \\
\hline
\end{tabular}

\section{Recommendation-Specific Supportive Text}

1. Larger pad or paddle size decreases transthoracic impedance, which is a major determinant of current delivery. ${ }^{16-18}$

2. One human and 1 porcine study demonstrated no significant difference in shock success or ROSC when comparing anterior-lateral with anteriorposterior position. ${ }^{7,19}$

3. One study demonstrated no significant difference in median time to shock with paddles compared with self-adhesive pads. ${ }^{20}$

\section{Type of Defibrillator}

\begin{tabular}{|c|c|c|}
\hline \multicolumn{2}{|c|}{ Recommendations for Type of Defibrillator } \\
\hline COR & LOE & Recommendations \\
\hline 1 & C-LD & $\begin{array}{l}\text { 1. When using an AED on infants and children } \\
<8 \text { y old, use of a pediatric attenuator is } \\
\text { recommended. }{ }^{21-32}\end{array}$ \\
\hline 1 & C-EO & $\begin{array}{l}\text { 2. For infants under the care of a trained } \\
\text { healthcare provider, a manual defibrillator is } \\
\text { recommended when a shockable rhythm is } \\
\text { identified. }{ }^{33,34}\end{array}$ \\
\hline 2b & C-EO & $\begin{array}{l}\text { 3. If neither a manual defibrillator nor an AED } \\
\text { equipped with a pediatric attenuator is } \\
\text { available, an AED without a dose attenuator } \\
\text { may be used. }{ }^{26-28,30,35}\end{array}$ \\
\hline
\end{tabular}

\section{Recommendation-Specific Supportive Text}

1. Shockable rhythms are infrequent in infants. 21,22 Studies of rhythm identification algorithms have demonstrated high specificity for shockable rhythms in infants and children. ${ }^{23-25}$ Although there are no direct comparisons between pediatric attenuator and nonattenuator AED-delivered shocks, multiple case reports and case series document shock success with survival when a pediatric attenuator was used. ${ }^{26-32}$

2. There are no specific studies comparing manual defibrillators with AEDs in infants or children. Manual defibrillators are preferred for in-hospital use because the energy dose can be titrated to the patient's weight. In adults, use of an AED in hospitals did not improve survival, ${ }^{33}$ and the perishock pauses needed for rhythm analysis were prolonged. ${ }^{34}$

3. AEDs without pediatric modifications deliver 120 to 360 Joules, exceeding the recommended dose for children weighing less than $25 \mathrm{~kg}$. However, there are reports of safe and effective AED use in infants and young children when the dose exceeded 2 to $4 \mathrm{~J} / \mathrm{kg}^{26-28,30,35}$ Because defibrillation is the only effective therapy for $V F$, an AED without a dose attenuator may be lifesaving. 


\section{REFERENCES}

1. Mercier E, Laroche E, Beck B, Le Sage N, Cameron PA, Émond M, Berthelot S, Mitra B, Ouellet-Pelletier J. Defibrillation energy dose during pediatric cardiac arrest: Systematic review of human and animal model studies. Resuscitation. 2019;139:241-252. doi: 10.1016/j.resuscitation.2019.04.028

2. Gutgesell HP, Tacker WA, Geddes LA, Davis S, Lie JT, McNamara DG. Energy dose for ventricular defibrillation of children. Pediatrics. 1976;58:898901.

3. Berg MD, Samson RA, Meyer RJ, Clark LL, Valenzuela TD, Berg RA. Pediatric defibrillation doses often fail to terminate prolonged out-of-hospital ventricular fibrillation in children. Resuscitation. 2005;67:63-67. doi: 10.1016/j.resuscitation.2005.04.018

4. Meaney PA, Nadkarni VM, Atkins DL, Berg MD, Samson RA, Hazinski MF Berg RA; American Heart Association National Registry of Cardiopulmonary Resuscitation Investigators. Effect of defibrillation energy dose during in-hospital pediatric cardiac arrest. Pediatrics. 2011;127:e16-e23. doi: 10.1542/peds.2010-1617

5. Rodríguez-Núñez A, López-Herce J, del Castillo J, Bellón JM; and the lberian-American Paediatric Cardiac Arrest Study Network RIBEPCI. Shockable rhythms and defibrillation during in-hospital pediatric cardiac arrest. $R e-$ suscitation. 2014;85:387-391. doi: 10.1016/j.resuscitation.2013.11.015

6. Rossano JW, Quan L, Kenney MA, Rea TD, Atkins DL. Energy doses for treatment of out-of-hospital pediatric ventricular fibrillation. Resuscitation. 2006;70:80-89. doi: 10.1016/j.resuscitation.2005.10.031

7. Tibballs J, Carter B, Kiraly NJ, Ragg P, Clifford M. External and internal biphasic direct current shock doses for pediatric ventricular fibrillation and pulseless ventricular tachycardia. Pediatr Crit Care Med. 2011:12:14-20. doi: 10.1097/PCC.0b013e3181dbb4fc

8. Baker PW, Conway J, Cotton C, Ashby DT, Smyth J, Woodman RJ, Grantham H; Clinical Investigators. Defibrillation or cardiopulmonary resuscitation first for patients with out-of-hospital cardiac arrests found by paramedics to be in ventricular fibrillation? A randomised control trial. $R e-$ suscitation. 2008:79:424-431. doi: 10.1016/j.resuscitation.2008.07.017

9. Jacobs IG, Finn JC, Oxer HF, Jelinek GA. CPR before defibrillation in outof-hospital cardiac arrest: a randomized trial. Emerg Med Australas. 2005;17:39-45. doi: 10.1111/j.1742-6723.2005.00694.x

10. Ma MH, Chiang WC, Ko PC, Yang CW, Wang HC, Chen SY, Chang WT, Huang $\mathrm{CH}$, Chou $\mathrm{HC}$, Lai MS, Chien $\mathrm{KL}$, Lee BC, Hwang $\mathrm{CH}$, Wang $\mathrm{YC}$, Hsiung GH, Hsiao YW, Chang AM, Chen WJ, Chen SC. A randomized trial of compression first or analyze first strategies in patients with outof-hospital cardiac arrest: results from an Asian community. Resuscitation 2012;83:806-812. doi: 10.1016/j.resuscitation.2012.01.009

11. Stiell IG, Nichol G, Leroux BG, Rea TD, Ornato JP, Powell J, Christenson J, Callaway CW, Kudenchuk PJ, Aufderheide TP, Idris AH, Daya MR, Wang HE, Morrison L, Davis D, Andrusiek D, Stephens S, Cheskes S, Schmicker RH, Fowler R, Vaillancourt C, Hostler D, Zive D, Pirrallo RG, Vilke GM, Sopko G, Weisfeldt M; ROC Investigators. Early versus later rhythm analysis in patients with out-of-hospital cardiac arrest. N Engl J Med. 2011;365:787797. doi: 10.1056/NEJMoa1010076

12. Wik L, Hansen TB, Fylling F, Steen $T$, Vaagenes $P$, Auestad BH, Steen PA Delaying defibrillation to give basic cardiopulmonary resuscitation to patients with out-of-hospital ventricular fibrillation: a randomized trial. JAMA. 2003;289:1389-1395. doi: 10.1001/jama.289.11.1389

13. Bobrow BJ, Clark LL, Ewy GA, Chikani V, Sanders AB, Berg RA, Richman PB Kern KB. Minimally interrupted cardiac resuscitation by emergency medical services for out-of-hospital cardiac arrest. JAMA. 2008;299:11581165. doi: 10.1001/jama.299.10.1158

14. Rea TD, Helbock M, Perry S, Garcia M, Cloyd D, Becker L, Eisenberg M. Increasing use of cardiopulmonary resuscitation during out-of-hospital ventricular fibrillation arrest: survival implications of guideline changes. Circulation. 2006:114:2760-2765. doi: 10.1161/CIRCULATIONAHA. 106.654715

15. Sutton RM, Case E, Brown SP, Atkins DL, Nadkarni VM, Kaltman J, Callaway C, Idris A, Nichol G, Hutchison J, Drennan IR, Austin M, Daya M, Cheskes S, Nuttall J, Herren H, Christenson J, Andrusiek D, Vaillancourt C, Menegazzi JJ, Rea TD, Berg RA; ROC Investigators. A quantitative analysis of out-of-hospital pediatric and adolescent resuscitation quality-A report from the ROC epistry-cardiac arrest. Resuscitation. 2015;93:150-157. doi: 10.1016/j.resuscitation.2015.04.010

16. Atkins DL, Kerber RE. Pediatric defibrillation: current flow is improved by using "adult" electrode paddles. Pediatrics. 1994;94:90-93.

17. Samson RA, Atkins DL, Kerber RE. Optimal size of self-adhesive preapplied electrode pads in pediatric defibrillation. Am J Cardiol. 1995;75:544-545 doi: 10.1016/s0002-9149(99)80606-7
18. Atkins DL, Sirna S, Kieso R, Charbonnier F, Kerber RE. Pediatric defibrillation: importance of paddle size in determining transthoracic impedance. Pediatrics. 1988;82:914-918.

19. Ristagno G, Yu T, Quan W, Freeman G, Li Y. Comparison of defibrillation efficacy between two pads placements in a pediatric porcine model of cardiac arrest. Resuscitation. 2012;83:755-759. doi: 10.1016/j.resuscitation.2011.12.010

20. Bhalala US, Balakumar N, Zamora M, Appachi E. Hands-On Defibrillation Skills of Pediatric Acute Care Providers During a Simulated Ventricular Fibrillation Cardiac Arrest Scenario. Front Pediatr. 2018;6:107. doi: 10.3389/fped.2018.00107

21. Atkins DL, Everson-Stewart S, Sears GK, Daya M, Osmond MH, Warden CR, Berg RA; Resuscitation Outcomes Consortium Investigators. Epidemiology and outcomes from out-of-hospital cardiac arrest in children: the Resuscitation Outcomes Consortium Epistry-Cardiac Arrest. Circulation. 2009;119:1484-1491. doi: 10.1161/CIRCULATIONAHA.108.802678

22. Samson RA, Nadkarni VM, Meaney PA, Carey SM, Berg MD, Berg RA; American Heart Association National Registry of CPR Investigators. Outcomes of in-hospital ventricular fibrillation in children. $N$ Engl J Med. 2006:354:2328-2339. doi: 10.1056/NEJMoa052917

23. Cecchin F, Jorgenson DB, Berul Cl, Perry JC, Zimmerman AA, Duncan BW, Lupinetti FM, Snyder D, Lyster TD, Rosenthal GL, Cross B, Atkins DL. Is arrhythmia detection by automatic external defibrillator accurate for children?: sensitivity and specificity of an automatic external defibrillator algorithm in 696 pediatric arrhythmias. Circulation. 2001;103:2483-2488. doi: 10.1161/01.cir.103.20.2483

24. Atkinson E, Mikysa B, Conway JA, Parker M, Christian K, Deshpande J, Knilans TK, Smith J, Walker C, Stickney RE, Hampton DR, Hazinski MF. Specificity and sensitivity of automated external defibrillator rhythm analysis in infants and children. Ann Emerg Med. 2003;42:185-196. doi: 10.1067/mem.2003.287

25. Atkins DL, Scott WA, Blaufox AD, Law IH, Dick M II, Geheb F, Sobh J, Brewer JE. Sensitivity and specificity of an automated external defibrillator algorithm designed for pediatric patients. Resuscitation. 2008;76:168174. doi: 10.1016/j.resuscitation.2007.06.032

26. Atkins $\mathrm{DL}$, Jorgenson DB. Attenuated pediatric electrode pads for automated external defibrillator use in children. Resuscitation. 2005;66:3137. doi: 10.1016/j. resuscitation.2004.12.025

27. Bar-Cohen Y, Walsh EP, Love BA, Cecchin F. First appropriate use of automated external defibrillator in an infant. Resuscitation. 2005;67:135-137. doi: 10.1016/j.resuscitation.2005.05.003

28. Divekar A, Soni R. Successful parental use of an automated external defibrillator for an infant with long-QT syndrome. Pediatrics. 2006;118:e526e529. doi: 10.1542/peds.2006-0129

29. Hoyt WJ Jr, Fish FA, Kannankeril PJ. Automated external defibrillator use in a previously healthy 31-day-old infant with out-of-hospital cardiac arrest due to ventricular fibrillation. J Cardiovasc Electrophysiol. 2019;30:25992602. doi: 10.1111/jce. 14125

30. Gurnett CA, Atkins DL. Successful use of a biphasic waveform automated external defibrillator in a high-risk child. Am J Cardiol. 2000;86:10511053. doi: 10.1016/s0002-9149(00)01151-6

31. Mitani Y, Ohta K, Yodoya N, Otsuki S, Ohashi H, Sawada H, Nagashima M, Sumitomo N, Komada Y. Public access defibrillation improved the outcome after out-of-hospital cardiac arrest in school-age children: a nationwide, population-based, Utstein registry study in Japan. Europace. 2013;15:1259-1266. doi: 10.1093/europace/eut053

32. Pundi KN, Bos JM, Cannon BC, Ackerman MJ. Automated external defibrillator rescues among children with diagnosed and treated long QT syndrome. Heart Rhythm. 2015;12:776-781. doi: 10.1016/j.hrthm.2015.01.002

33. Chan PS, Krumholz HM, Spertus JA, Jones PG, Cram P, Berg RA, Peberdy MA, Nadkarni V, Mancini ME, Nallamothu BK. Automated external defibrillators and survival after in-hospital cardiac arrest. JAMA 2010;304:2129-2136. doi: 10.1001/jama.2010.1576

34. Cheskes S, Schmicker RH, Christenson J, Salcido DD, Rea T, Powell J, Edelson DP, Sell R, May S, Menegazzi JJ, Van Ottingham L, Olsufka M, Pennington S, Simonini J, Berg RA, Stiell I, Idris A, Bigham B, Morrison L; Resuscitation Outcomes Consortium (ROC) Investigators. Perishock pause: an independent predictor of survival from out-ofhospital shockable cardiac arrest. Circulation. 2011;124:58-66. doi: 10.1161/CIRCULATIONAHA. 110.010736

35. König B, Benger J, Goldsworthy L. Automatic external defibrillation in a 6 year old. Arch Dis Child. 2005;90:310-311. doi: 10.1136/adc.2004.054981 


\section{ASSESSMENT OF RESUSCITATION QUALITY}

Initiating and maintaining high-quality CPR is associated with improved rates of ROSC, survival, and favorable neurological outcome, yet measured CPR quality is often suboptimal. ${ }^{1-3}$ Noninvasive and invasive monitoring techniques may be used to assess and guide the quality of CPR. Invasive arterial blood pressure monitoring during CPR provides insight to blood pressures generated with compressions and medications. ${ }^{4}$ End-tidal $\mathrm{CO}_{2}\left(\mathrm{ETCO}_{2}\right)$ reflects both the cardiac output produced and ventilation efficacy and may provide feedback on the quality of CPR. ${ }^{5}$ A sudden rise in $\mathrm{ETCO}_{2}$ may be an early sign of ROSC. ${ }^{6}$ CPR feedback devices (ie, coaching, audio, and audiovisual devices) may improve compression rate, depth, and recoil within a system of training and quality assurance for high-quality CPR. Point of care ultrasound, specifically echocardiography, during CPR has been considered for identification of reversible causes of arrest. Technologies that are under evaluation to assess resuscitation quality include noninvasive measures of cerebral oxygenation, such as using near infrared spectroscopy during CPR.

\begin{tabular}{|c|c|c|}
\hline COR & LOE & Recommendations \\
\hline $2 a$ & C-LD & $\begin{array}{l}\text { 1. For patients with continuous invasive arterial } \\
\text { blood pressure monitoring in place at the } \\
\text { time of cardiac arrest, it is reasonable for } \\
\text { providers to use diastolic blood pressure to } \\
\text { assess CPR quality. }{ }^{4}\end{array}$ \\
\hline $2 b$ & C-LD & $\begin{array}{l}\text { 2. } \mathrm{ETCO}_{2} \text { monitoring may be considered to } \\
\text { assess the quality of chest compressions, but } \\
\text { specific values to guide therapy have not been } \\
\text { established in children. }{ }^{7,8}\end{array}$ \\
\hline $2 b$ & C-EO & $\begin{array}{l}\text { 3. It may be reasonable for the rescuer to use } \\
\text { CPR feedback devices to optimize adequate } \\
\text { chest compression rate and depth as } \\
\text { part of a continuous resuscitation quality } \\
\text { improvement system. } .^{9,10}\end{array}$ \\
\hline $2 b$ & C-EO & $\begin{array}{l}\text { 4. When appropriately trained personnel } \\
\text { are available, echocardiography may be } \\
\text { considered to identify potentially treatable } \\
\text { causes of the arrest, such as pericardial } \\
\text { tamponade and inadequate ventricular filling, } \\
\text { but the potential benefits should be weighed } \\
\text { against the known deleterious consequences } \\
\text { of interrupting chest compressions. }{ }^{11-13}\end{array}$ \\
\hline
\end{tabular}

\section{Recommendation-Specific Supportive Text}

1. A prospective observational study of pediatric patients with invasive arterial blood pressure monitoring during the first 10 minutes of CPR demonstrated higher rates of favorable neurological outcome if the diastolic blood pressure was at least $25 \mathrm{~mm} \mathrm{Hg}$ in infants and at least $30 \mathrm{~mm} \mathrm{Hg}$ in children. ${ }^{4}$ Of note, the cut points for diastolic blood pressure tracings were analyzed using post hoc waveform analysis; therefore, prospective evaluation is needed.
2. A single-center, retrospective study of in-hospital CPR in infants found that $\mathrm{ETCO}_{2}$ values between 17 and $18 \mathrm{~mm} \mathrm{Hg}$ had a positive predictive value for ROSC of 0.885. ${ }^{7}$ A prospective, multicenter observational study of IHCA did not find an association between mean $\mathrm{ETCO}_{2}$ and outcomes. ${ }^{8}$

3. A simulation trial of pediatric healthcare providers demonstrated a significant improvement in chest compression depth and rate compliance when they received visual feedback (compared to no feedback), although overall compression quality remained poor. ${ }^{9}$ One small observational study of 8 children with IHCA did not find an association between CPR with or without audiovisual feedback and survival to discharge, although feedback decreased excessive compression rates. ${ }^{10}$

4. Several case series evaluated the use of bedside echocardiography to identify reversible causes of cardiac arrest, including pulmonary embolism. ${ }^{11,12}$ One prospective observational study of children (without cardiac arrest) admitted to an ICU reported good agreement of estimates of shortening fraction and inferior vena cava volume between emergency physicians using bedside limited echocardiography and cardiologists performing formal echocardiography. ${ }^{13}$

\section{REFERENCES}

1. Niles DE, Duval-Arnould J, Skellett S, Knight L, Su F, Raymond TT, Sweberg T, Sen Al, Atkins DL, Friess SH, de Caen AR, Kurosawa H, Sutton RM, Wolfe H, Berg RA, Silver A, Hunt EA, Nadkarni VM; pediatric Resuscitation Quality (pediRES-Q) Collaborative Investigators. Characterization of Pediatric InHospital Cardiopulmonary Resuscitation Quality Metrics Across an International Resuscitation Collaborative. Pediatr Crit Care Med. 2018;19:421432. doi: 10.1097/PCC.0000000000001520

2. Sutton RM, Case $E$, Brown SP, Atkins DL, Nadkarni VM, Kaltman J, Callaway C, Idris A, Nichol G, Hutchison J, Drennan IR, Austin M, Daya M, Cheskes S, Nuttall J, Herren H, Christenson J, Andrusiek D, Vaillancourt C, Menegazzi JJ, Rea TD, Berg RA; ROC Investigators. A quantitative analysis of out-of-hospital pediatric and adolescent resuscitation quality-A report from the ROC epistry-cardiac arrest. Resuscitation. 2015;93:150-157. doi: 10.1016/j.resuscitation.2015.04.010

3. Wolfe H, Zebuhr C, Topjian AA, Nishisaki A, Niles DE, Meaney PA, Boyle L, Giordano RT, Davis D, Priestley M, Apkon M, Berg RA, Nadkarni VM, Sutton RM. Interdisciplinary ICU cardiac arrest debriefing improves survival outcomes*. Crit Care Med. 2014;42:1688-1695. doi: 10.1097/CCM. 0000000000000327

4. Berg RA, Sutton RM, Reeder RW, Berger JT, Newth CJ, Carcillo JA, McQuillen PS, Meert KL, Yates AR, Harrison RE, Moler FW, Pollack MM, Carpenter TC, Wessel DL, Jenkins TL, Notterman DA, Holubkov R, Tamburro RF, Dean JM, Nadkarni VM; Eunice Kennedy Shriver National Institute of Child Health and Human Development Collaborative Pediatric Critical Care Research Network (CPCCRN) PICqCPR (Pediatric Intensive Care Quality of Cardio-Pulmonary Resuscitation) Investigators. Association Between Diastolic Blood Pressure During Pediatric In-Hospital Cardiopulmonary Resuscitation and Survival. Circulation. 2018;137:1784-1795. doi: 10.1161/CIRCULATIONAHA.117.032270

5. Hamrick JL, Hamrick JT, Lee JK, Lee BH, Koehler RC, Shaffner DH. Efficacy of chest compressions directed by end-tidal CO2 feedback in a pediatric resuscitation model of basic life support. J Am Heart Assoc. 2014;3:e000450. doi: 10.1161/JAHA.113.000450

6. Hartmann SM, Farris RW, Di Gennaro JL, Roberts JS. Systematic Review and Meta-Analysis of End-Tidal Carbon Dioxide Values Associated With Return of Spontaneous Circulation During Cardiopulmonary Resuscitation. J Intensive Care Med. 2015;30:426-435. doi: 10.1177/0885066614530839 
7. Stine CN, Koch J, Brown LS, Chalak L, Kapadia V, Wyckoff MH. Quantitative end-tidal $\mathrm{CO} 2$ can predict increase in heart rate during infant cardiopulmonary resuscitation. Heliyon. 2019;5:e01871. doi: 10.1016/j. heliyon.2019.e01871

8. Berg RA, Reeder RW, Meert $K L$, Yates AR, Berger JT, Newth CJ, Carcillo JA, McQuillen PS, Harrison RE, Moler FW, Pollack MM, Carpenter TC, Notterman DA, Holubkov R, Dean JM, Nadkarni VM, Sutton RM; Eunice Kennedy Shriver National Institute of Child Health and Human Development Collaborative Pediatric Critical Care Research Network (CPCCRN) Pediatric Intensive Care Quality of Cardio-Pulmonary Resuscitation (PICq(PR) investigators. End-tidal carbon dioxide during pediatric in-hospital cardiopulmonary resuscitation. Resuscitation. 2018;133:173-179. doi: 10.1016/j.resuscitation.2018.08.013

9. Cheng A, Brown LL, Duff JP, Davidson J, Overly F, Tofil NM, Peterson DT, White ML, Bhanji F, Bank I, et al; on behalf of the International Network for Simulation-Based Pediatric Innovation, Research, \& Education (INSPIRE) CPR Investigators. Improving cardiopulmonary resuscitation with a CPR feedback device and refresher simulations (CPR CARES Study): a randomized clinical trial. JAMA Pediatr. 2015;169:137-144. doi: 10.1001/jamapediatrics.2014.2616

10. Sutton RM, Niles $D$, French $B$, Maltese MR, Leffelman J, Eilevstjonn J, Wolfe $\mathrm{H}$, Nishisaki A, Meaney PA, Berg RA, et al. First quantitative analysis of cardiopulmonary resuscitation quality during in-hospital cardiac arrests of young children. Resuscitation. 2014;85:70-74. doi: 10.1016/j. resuscitation.2013.08.014

11. Steffen K, Thompson WR, Pustavoitau A, Su E. Return of Viable Cardiac Function After Sonographic Cardiac Standstill in Pediatric Cardiac Arrest. Pediatr Emerg Care. 2017;33:58-59. doi: 10.1097/PEC.0000000000001002

12. Morgan RW, Stinson HR, Wolfe H, Lindell RB, Topjian AA, Nadkarni VM, Sutton RM, Berg RA, Kilbaugh TJ. Pediatric In-Hospital Cardiac Arrest Secondary to Acute Pulmonary Embolism. Crit Care Med. 2018;46:e229 e234. doi: 10.1097/CCM.0000000000002921

13. Pershad J, Myers S, Plouman C, Rosson C, Elam K, Wan J, Chin T. Bedside limited echocardiography by the emergency physician is accurate during evaluation of the critically ill patient. Pediatrics. 2004;114:e667-e671. doi: 10.1542/peds.2004-0881

\section{EXTRACORPOREAL CARDIOPULMONARY RESUSCITATION}

Extracorporeal cardiopulmonary resuscitation (ECPR) is defined as the rapid deployment of venoarterial extracorporeal membrane oxygenation (ECMO) for patients who do not achieve sustained ROSC. It is a resource-intense, complex, multidisciplinary therapy that traditionally has been limited to large pediatric medical centers with providers who have expertise in the management of children with cardiac disease. Judicious use of ECPR for specific patient populations and within dedicated and highly practiced environments has proved successful, especially for IHCA with reversible causes. ${ }^{1}$ ECPR use rates have increased, with single-center reports in both adults and children suggesting that application of this therapy across broader patient populations may improve survival after cardiac arrest. ${ }^{2-4}$

There are no studies of ECPR demonstrating improved outcomes following pediatric OHCA.

Recommendation for the Use of Extracorporeal Cardiopulmonary Resuscitation

\begin{tabular}{|c|c|c|}
\hline COR & LOE & Recommendation \\
\hline $2 b$ & C-LD & $\begin{array}{l}\text { 1. ECPR may be considered for pediatric patients } \\
\text { with cardiac diagnoses who have IHCA } \\
\text { in settings with existing ECMO protocols, } \\
\text { expertise, and equipment. }\end{array}$ \\
\hline
\end{tabular}

\section{Recommendation-Specific Supportive Text}

1. One observational registry study of ECPR for pediatric IHCA after cardiac surgery demonstrated that ECPR was associated with higher rates of survival to hospital discharge than conventional CPR. ${ }^{5} \mathrm{~A}$ propensity-matched analysis of ECPR compared with conventional CPR using the same registry found that ECPR was associated with favorable neurological outcome in patients with IHCA of any etiology. ${ }^{6}$ There is insufficient evidence to suggest for or against the use of ECPR for pediatric patients experiencing OHCA or pediatric patients with noncardiac disease experiencing IHCA refractory to conventional CPR.

This recommendation was reviewed in the "2019 American Heart Association Focused Update on Pediatric Advanced Life Support: An Update to the American Heart Association Guidelines for Cardiopulmonary Resuscitation and Emergency Cardiovascular Care." 7

\section{REFERENCES}

1. Brunetti MA, Gaynor JW, Retzloff LB, Lehrich JL, Banerjee M, Amula V, Bailly D, Klugman D, Koch J, Lasa J, Pasquali SK, Gaies M. Characteristics, Risk Factors, and Outcomes of Extracorporeal Membrane Oxygenation Use in Pediatric Cardiac ICUs: A Report From the Pediatric Cardiac Critical Care Consortium Registry. Pediatr Crit Care Med. 2018;19:544-552. doi: 10.1097/PCC.0000000000001571

2. Sakamoto T, Morimura N, Nagao K, Asai $Y$, Yokota H, Nara S, Hase M, Tahara Y, Atsumi T; SAVE-J Study Group. Extracorporeal cardiopulmonary resuscitation versus conventional cardiopulmonary resuscitation in adults with out-of-hospital cardiac arrest: a prospective observational study. Resuscitation. 2014;85:762-768. doi: 10.1016/j.resuscitation.2014.01.031

3. Stub D, Bernard S, Pellegrino V, Smith K, Walker T, Sheldrake J, Hockings L, Shaw J, Duffy SJ, Burrell A, Cameron P, Smit de V, Kaye DM. Refractory cardiac arrest treated with mechanical CPR, hypothermia, ECMO and early reperfusion (the CHEER trial). Resuscitation. 2015;86:88-94. doi: 10.1016/j.resuscitation.2014.09.010

4. Conrad SJ, Bridges BC, Kalra Y, Pietsch JB, Smith AH. Extracorporeal Cardiopulmonary Resuscitation Among Patients with Structurally Normal Hearts. ASAIO J. 2017;63:781-786. doi: 10.1097/MAT.0000000000000568

5. Ortmann L, Prodhan P, Gossett J, Schexnayder S, Berg R, Nadkarni V, Bhutta A; American Heart Association's Get With the Guidelines-Resuscitation Investigators. Outcomes after in-hospital cardiac arrest in children with cardiac disease: a report from Get With the Guidelines-Resuscitation. Circulation. 2011;124:2329-2337. doi: 10.1161/CIRCULATIONAHA. 110.013466

6. Lasa JJ, Rogers RS, Localio R, Shults J, Raymond T, Gaies M, Thiagarajan R, Laussen PC, Kilbaugh T, Berg RA, Nadkarni V, Topjian A. Extracorporeal Cardiopulmonary Resuscitation (E-CPR) During Pediatric In-Hospital Cardiopulmonary Arrest Is Associated With Improved Survival to Discharge: A Report from the American Heart Association's Get With The GuidelinesResuscitation (GWTG-R) Registry. Circulation. 2016;133:165-176. doi: 10.1161/CIRCULATIONAHA.115.016082

7. Duff JP, Topjian AA, Berg MD, Chan M, Haskell SE, Joyner BL Jr, Lasa JJ, Ley SJ, Raymond TT, Sutton RM, Hazinski MF, Atkins DL. 2019 American Heart Association Focused Update on Pediatric Advanced Life Support: An Update to the American Heart Association Guidelines for Cardiopulmonary Resuscitation and Emergency Cardiovascular Care. Circulation. 2019;140:e904-e914. doi: 10.1161/CIR.0000000000000731

\section{POST-CARDIAC ARREST CARE TREATMENT AND MONITORING}

Successful resuscitation from cardiac arrest results in a post-cardiac arrest syndrome that can evolve in the days 
after ROSC. The components of post-cardiac arrest syndrome are (1) brain injury, (2) myocardial dysfunction, (3) systemic ischemia and reperfusion response, and (4) persistent precipitating pathophysiology. ${ }^{1,2}$ Post-cardiac arrest brain injury remains a leading cause of morbidity and mortality in adults and children because the brain has limited tolerance of ischemia, hyperemia, or edema. Pediatric post-cardiac arrest care focuses on anticipating, identifying, and treating this complex physiology to improve survival and neurological outcomes.

Targeted temperature management (TTM) refers to continuous maintenance of patient temperature within a narrowly prescribed range while continuously monitoring temperature. All forms of TTM avoid fever, and hypothermic TTM attempts to treat reperfusion syndrome by decreasing metabolic demand, reducing free radical production, and decreasing apoptosis. ${ }^{2}$

Identification and treatment of derangementssuch as hypotension, fever, seizures, acute kidney injury, and abnormalities of oxygenation, ventilation, and electrolytes-are important because they may impact outcomes.

\section{Post-Cardiac Arrest Targeted Temperature Management}

Recommendations for Post-Cardiac Arrest Targeted Temperature Management

\begin{tabular}{|c|c|c|}
\hline COR & LOE & Recommendations \\
\hline 1 & A & $\begin{array}{l}\text { 1. Continuous measurement of core } \\
\text { temperature during TTM is recommended. } .^{3,4}\end{array}$ \\
\hline $2 a$ & B-R & $\begin{array}{l}\text { 2. For infants and children between } 24 \mathrm{~h} \text { and } 18 \\
\text { yr of age who remain comatose after } \mathrm{OHCA} \\
\text { or IHCA, it is reasonable to use either TTM of } \\
32^{\circ} \mathrm{C}-34^{\circ} \mathrm{C} \text { followed by } \mathrm{TTM} \text { of } 36^{\circ} \mathrm{C}-37.5^{\circ} \mathrm{C} \\
\text { or only TTM of } 36^{\circ} \mathrm{C}-37.5^{\circ} \mathrm{C} .3^{3,4}\end{array}$ \\
\hline
\end{tabular}

\section{Recommendation-Specific Supportive Text}

1 and 2. Two pediatric randomized clinical trials of $\operatorname{TTM}\left(32^{\circ} \mathrm{C}-34^{\circ} \mathrm{C}\right.$ for 48 hours followed by 3 days of TTM $36^{\circ} \mathrm{C}-37.5^{\circ} \mathrm{C}$ versus TTM $36^{\circ} \mathrm{C}-37.5^{\circ} \mathrm{C}$ for a total of 5 days) after IHCA or OHCA in children with coma following ROSC found no difference in 1-year survival with a favorable neurological outcome. ${ }^{3,4}$ Hyperthermia was actively prevented with TTM. Continuous core temperature monitoring was used for the 5 days of TTM in both trials.

Recommendations 1 and 2 were reviewed in the "2019 American Heart Association Focused Update on Pediatric Advanced Life Support: An Update to the American Heart Association Guidelines for Cardiopulmonary Resuscitation and Emergency Cardiovascular Care." 5

\section{Post-Cardiac Arrest Blood Pressure Management}

Recommendations for Post-Cardiac Arrest Blood Pressure Management

\begin{tabular}{|c|l|l|}
\hline COR & LOE & Recommendations \\
\hline 1 & C-LD & $\begin{array}{l}\text { 1. After ROSC, we recommend that parenteral } \\
\text { fluids and/or vasoactive drugs be used to } \\
\text { maintain a systolic blood pressure greater } \\
\text { than the fifth percentile for age. }{ }^{6-9}\end{array}$ \\
\hline 1 & C-EO & \begin{tabular}{l} 
2. $\begin{array}{l}\text { When appropriate resources are available, } \\
\text { continuous arterial pressure monitoring } \\
\text { is recommended to identify and treat } \\
\text { hypotension. }\end{array}$ \\
\hline
\end{tabular} \\
\hline
\end{tabular}

\section{Recommendation-Specific Supportive Text}

1 and 2. Two observational studies demonstrated that systolic hypotension (below 5 th percentile for age and sex) at approximately 6 to 12 hours following cardiac arrest is associated with decreased survival to discharge.6,7 Another observational study found that patients who had longer periods of hypotension within the first 72 hours of ICU post-cardiac arrest care had decreased survival to discharge. ${ }^{8}$ In an observational study of patients with arterial monitoring during and immediately after cardiac arrest, diastolic hypertension (above 90th percentile) in the first 20 minutes after ROSC was associated with an increased likelihood of survival to discharge. ${ }^{9}$ Because blood pressure is often labile in the post-cardiac arrest period, continuous arterial pressure monitoring is recommended.

\section{Post-Cardiac Arrest Oxygenation and Ventilation Management}

Recommendations for Post-Cardiac Arrest Oxygenation and Ventilation Management

\begin{tabular}{|c|l|l|}
\hline COR & LOE & Recommendations \\
\hline $2 b$ & C-LD & $\begin{array}{l}\text { 1. It may be reasonable for rescuers to target } \\
\text { normoxemia after ROSC that is appropriate } \\
\text { to the specific patient's underlying } \\
\text { condition. }{ }^{10-13}\end{array}$ \\
\hline $2 b$ & C-LD & $\begin{array}{l}\text { 2. It may be reasonable for rescuers to wean } \\
\text { oxygen to target an oxyhemoglobin } \\
\text { saturation between 94\% and 99\%. }{ }^{10-12,14}\end{array}$ \\
\hline $2 b$ & C-LD & $\begin{array}{l}\text { 3. It may be reasonable for practitioners to } \\
\text { target a partial pressure of carbon dioxide } \\
\text { (Paco }{ }_{2} \text { ) after ROSC that is appropriate to } \\
\text { the specific patient's underlying condition, } \\
\text { and limit exposure to severe hypercapnia or } \\
\text { hypocapnia. }{ }^{10,11,14}\end{array}$ \\
\hline
\end{tabular}

\section{Recommendation-Specific Supportive Text}

1 and 2. Because an arterial oxyhemoglobin saturation of $100 \%$ may correspond to a $\mathrm{PaO}_{2}$ between 80 and approximately $500 \mathrm{~mm} \mathrm{Hg}$, it is reasonable to target an oxyhemoglobin saturation between 94\% and 99\%. Three small observational studies 
of pediatric IHCA and OHCA did not show an association between hyperoxemia and outcome..$^{10,11,13}$ In a larger observational study of pediatric IHCA and OHCA patients, the presence of normoxemia compared with hyperoxemia after ROSC was associated with improved survival to pediatric ICU discharge. ${ }^{12}$

3. One observational study demonstrated that both hypercapnia and hypocapnia after ROSC were associated with increased mortality. ${ }^{11}$ One small observational study demonstrated no association between hypercapnia $\left(\mathrm{PaCO}_{2}\right.$ greater than $50 \mathrm{~mm} \mathrm{Hg}$ ) or hypocapnia $\left(\mathrm{PaCO}_{2}\right.$ less than $30 \mathrm{~mm} \mathrm{Hg}$ ) and outcome. ${ }^{10}$ Another observational study of pediatric IHCA, showed hypercapnia ( $\mathrm{PacO}_{2} 50 \mathrm{mmHg}$ or greater) was associated with decreased survival to hospital discharge. ${ }^{14}$ Because hypercapnia and hypocapnia impact cerebral blood flow, normocapnia should be the focus after ROSC while accounting for patients who have chronic hypercapnia.

\section{Post-Cardiac Arrest EEG Monitoring and Seizure Treatment}

\begin{tabular}{|c|c|c|}
\hline \multicolumn{3}{|c|}{$\begin{array}{l}\text { Recommendations for Post-Cardiac Arrest EEG Monitoring and } \\
\text { Seizure Treatment }\end{array}$} \\
\hline COR & LOE & Recommendations \\
\hline 1 & C-LD & $\begin{array}{l}\text { 1. When resources are available, continuous } \\
\text { electroencephalography (EEG) monitoring is } \\
\text { recommended for the detection of seizures } \\
\text { following cardiac arrest in patients with } \\
\text { persistent encephalopathy. }{ }^{15-18}\end{array}$ \\
\hline 1 & C-LD & $\begin{array}{l}\text { 2. It is recommended to treat clinical seizures } \\
\text { following cardiac arrest. }{ }^{19,20}\end{array}$ \\
\hline $2 a$ & C-EO & $\begin{array}{l}\text { 3. It is reasonable to treat nonconvulsive } \\
\text { status epilepticus following cardiac arrest in } \\
\text { consultation with experts. }{ }^{19,20}\end{array}$ \\
\hline
\end{tabular}

\section{Recommendation-Specific Supportive Text}

1. Nonconvulsive seizures and nonconvulsive status epilepticus are common after pediatric cardiac arrest. ${ }^{15-18}$ The American Clinical Neurophysiology Society recommends continuous EEG monitoring for encephalopathic patients after pediatric cardiac arrest. ${ }^{15}$ Nonconvulsive seizures and nonconvulsive status epilepticus cannot be detected without EEG monitoring. ${ }^{15}$

2 and 3 . There is insufficient evidence to determine whether treatment of convulsive or nonconvulsive seizures improves neurological and/or functional outcomes after pediatric cardiac arrest. Both convulsive and nonconvulsive status epilepticus are associated with worse outcomes. ${ }^{17}$ The Neurocritical Care Society recommends treating status epilepticus with the goal of stopping convulsive and electrographic seizure activity. ${ }^{19}$

Figure 8 shows the checklist for post-cardiac arrest care.

\section{REFERENCES}

1. Neumar RW, Nolan JP, Adrie C, Aibiki M, Berg RA, Böttiger BW, Callaway C, Clark RS, Geocadin RG, Jauch EC, Kern KB, Laurent I, Longstreth WT Jr, Merchant RM, Morley P, Morrison L, Nadkarni V, Peberdy MA, Rivers EP, Rodriguez-Nunez A, Sellke FW, Spaulding C, Sunde K, Vanden Hoek T. Post-cardiac arrest syndrome: epidemiology, pathophysiology, treatment, and prognostication. A consensus statement from the International Liaison Committee on Resuscitation (American Heart Association, Australian and New Zealand Council on Resuscitation, European Resuscitation Council, Heart and Stroke Foundation of Canada, InterAmerican Heart Foundation, Resuscitation Council of Asia, and the Resuscitation Council of Southern Africa); the American Heart Association Emergency Cardiovascular Care Committee; the Council on Cardiovascular Surgery and Anesthesia; the Council on Cardiopulmonary, Perioperative, and Critical Care; the Council on Clinical Cardiology; and the Stroke Council. Circulation. 2008;118:2452-2483. doi: 10.1161/CIRCULATIONAHA.108.190652

2. Topjian AA, de Caen A, Wainwright MS, Abella BS, Abend NS, Atkins DL, Bembea MM, Fink EL, Guerguerian AM, Haskell SE, Kilgannon JH, Lasa JJ, Hazinski MF. Pediatric post-cardiac arrest care: a scientific statement from the American Heart Association. Circulation. 2019;140:e194-e233. doi: 10.1161/CIR.0000000000000697

3. Moler FW, Silverstein FS, Holubkov R, Slomine BS, Christensen JR, Nadkarni VM, Meert KL, Browning B, Pemberton VL, Page K, et al; on behalf of the THAPCA Trial Investigators. Therapeutic hypothermia after in-hospital cardiac arrest in children. N Engl J Med. 2017;376:318-329. doi: 10.1056/NEJMoa1610493

4. Moler FW, Silverstein FS, Holubkov R, Slomine BS, Christensen JR, Nadkarni VM, Meert KL, Clark AE, Browning B, Pemberton VL, Page K, Shankaran S, Hutchison JS, Newth CJ, Bennett KS, Berger JT, Topjian A, Pineda JA, Koch JD, Schleien CL, Dalton HJ, Ofori-Amanfo G, Goodman DM, Fink EL, McQuillen P, Zimmerman JJ, Thomas NJ, van der Jagt EW, Porter MB, Meyer MT, Harrison R, Pham N, Schwarz AJ, Nowak JE, Alten J, Wheeler DS, Bhalala US, Lidsky K, Lloyd E, Mathur M, Shah S, Wu T, Theodorou AA, Sanders RC Jr, Dean JM; THAPCA Trial Investigators. Therapeutic hypothermia after out-of-hospital cardiac arrest in children. N Engl J Med. 2015;372:1898-1908. doi: 10.1056/NEJMoa1411480

5. Duff JP, Topjian AA, Berg MD, Chan M, Haskell SE, Joyner BL Jr, Lasa JJ, Ley SJ, Raymond TT, Sutton RM, Hazinski MF, Atkins DL. 2019 American Heart Association focused update on pediatric advanced life support: an update to the American Heart Association Guidelines for Cardiopulmonary Resuscitation and Emergency Cardiovascular Care. Circulation. 2019;140:e904-e914. doi: 10.1161/CIR.0000000000000731

6. Topjian AA, Telford R, Holubkov R, Nadkarni VM, Berg RA, Dean JM, Moler FW; on behalf of the Therapeutic Hypothermia after Pediatric Cardiac Arrest (THAPCA) Trial Investigators. The association of early postresuscitation hypotension with discharge survival following targeted temperature management for pediatric in-hospital cardiac arrest. Resuscitation. 2019;141:24-34. doi: 10.1016/j.resuscitation.2019.05.032

7. Topjian AA, Telford R, Holubkov R, Nadkarni VM, Berg RA, Dean JM, Moler FW; Therapeutic Hypothermia After Pediatric Cardiac Arrest (THAPCA) Trial Investigators. Association of Early Postresuscitation Hypotension With Survival to Discharge After Targeted Temperature Management for Pediatric Out-of-Hospital Cardiac Arrest: Secondary Analysis of a Randomized Clinical Trial. JAMA Pediatr. 2018;172:143-153. doi: 10.1001/jamapediatrics.2017.4043

8. Laverriere EK, Polansky M, French B, Nadkarni VM, Berg RA, Topjian AA. Association of Duration of Hypotension With Survival After Pediatric Cardiac Arrest. Pediatr Crit Care Med. 2020;21:143-149. doi: 10.1097/PCC.0000000000002119

9. Topjian AA, Sutton RM, Reeder RW, Telford R, Meert KL, Yates $A R$, Morgan RW, Berger JT, Newth CJ, Carcillo JA, McQuillen PS, Harrison RE, Moler FW, Pollack MM, Carpenter TC, Notterman DA, Holubkov R, Dean JM, Nadkarni VM, Berg RA, Zuppa AF, Graham K, Twelves C, Diliberto MA, Landis WP, Tomanio E, Kwok J, Bell MJ, Abraham A, Sapru A, Alkhouli MF, Heidemann S, Pawluszka A, Hall MW, Steele L, Shanley TP, Weber M, Dalton HJ, Bell A, Mourani PM, Malone K, Locandro C, Coleman W, Peterson A, Thelen J, Doctor A; Eunice Kennedy Shriver National Institute of Child Health and Human Development Collaborative Pediatric Critical Care Research Network (CPCCRN) Investigators. The association of immediate post cardiac arrest diastolic hypertension and survival following pediatric cardiac arrest. Resuscitation. 2019;141:88-95. doi: 10.1016/j.resuscitation.2019.05.033

10. Bennett KS, Clark AE, Meert KL, Topjian AA, Schleien CL, Shaffner DH, Dean JM, Moler FW; Pediatric Emergency Care Medicine Applied Research 


\section{Oxygenation and ventilation}

\begin{tabular}{l|c}
\hline Measure oxygenation and target normoxemia 94\%-99\% (or child's normal/appropriate oxygen saturation). & $\square$ \\
\hline $\begin{array}{l}\text { Measure and target } \mathrm{Paco}_{2} \text { appropriate to the patient's underlying condition } \\
\text { and limit exposure to severe hypercapnia or hypocapnia. }\end{array}$ & $\square$
\end{tabular}

\section{Hemodynamic monitoring}

\begin{tabular}{|l|c|}
\hline Set specific hemodynamic goals during post-cardiac arrest care and review daily. & $\square$ \\
\hline Monitor with cardiac telemetry. & $\square$ \\
\hline Monitor arterial blood pressure. & $\square$ \\
\hline Monitor serum lactate, urine output, and central venous oxygen saturation to help guide therapies. & $\square$ \\
\hline $\begin{array}{l}\text { Use parenteral fluid bolus with or without inotropes or vasopressors to maintain a } \\
\text { systolic blood pressure greater than the fifth percentile for age and sex. }\end{array}$ & $\square$ \\
\hline
\end{tabular}

\section{Targeted temperature management (TTM)}

\begin{tabular}{|l|c|}
\hline Measure and continuously monitor core temperature. & $\square$ \\
\hline Prevent and treat fever immediately after arrest and during rewarming. & $\square$ \\
\hline If patient is comatose apply TTM $\left(32^{\circ} \mathrm{C}-34^{\circ} \mathrm{C}\right)$ followed by $\left(36^{\circ} \mathrm{C}-37.5^{\circ} \mathrm{C}\right)$ or only $\operatorname{TTM}\left(36^{\circ} \mathrm{C}-37.5^{\circ} \mathrm{C}\right)$. & $\square$ \\
\hline Prevent shivering. & $\square$ \\
\hline Monitor blood pressure and treat hypotension during rewarming. & $\square$
\end{tabular}

Neuromonitoring

\begin{tabular}{|l|c|}
\hline If patient has encephalopathy and resources are available, monitor with continuous electroencephalogram. & $\square$ \\
\hline Treat seizures. & $\square$ \\
\hline Consider early brain imaging to diagnose treatable causes of cardiac arrest. & $\square$
\end{tabular}

\section{Electrolytes and glucose}

\begin{tabular}{|l|c}
\hline Measure blood glucose and avoid hypoglycemia. & $\square$ \\
\hline Maintain electrolytes within normal ranges to avoid possible life-threatening arrhythmias. & $\square$
\end{tabular}

\section{Sedation}

Treat with sedatives and anxiolytics.

\begin{tabular}{|l|c|}
\hline Prognosis & $\square$ \\
\hline Always consider multiple modalities (clinical and other) over any single predictive factor. & $\square$ \\
\hline Remember that assessments may be modified by TTM or induced hypothermia. & $\square$ \\
\hline Consider electroencephalogram in conjunction with other factors within the first 7 days after cardiac arrest. & $\square$ \\
\hline Consider neuroimaging such as magnetic resonance imaging during the first 7 days. & $\square$ \\
\hline
\end{tabular}

Figure 8. Post-cardiac arrest care checklist. 
Network. Early oxygenation and ventilation measurements after pediatric cardiac arrest: lack of association with outcome. Crit Care Med. 2013;41:1534-1542. doi: 10.1097/CCM.0b013e318287f54c

11. López-Herce J, del Castillo J, Matamoros M, Canadas S, Rodriguez-Calvo A, Cecchetti C, Rodríguez-Núnez A, Carrillo Á; Iberoamerican Pediatric Cardiac Arrest Study Network RIBEPCI. Post return of spontaneous circulation factors associated with mortality in pediatric in-hospital cardiac arrest: a prospective multicenter multinational observational study. Crit Care. 2014;18:607. doi: 10.1186/s13054-014-0607-9

12. Ferguson LP, Durward A, Tibby SM. Relationship between arterial partial oxygen pressure after resuscitation from cardiac arrest and mortality in children. Circulation. 2012;126:335-342. doi: 10.1161/ CIRCULATIONAHA. 111.085100

13. van Zellem $L$, de Jonge R, van Rosmalen J, Reiss I, Tibboel D, Buysse C. High cumulative oxygen levels are associated with improved survival of children treated with mild therapeutic hypothermia after cardiac arrest. Resuscitation. 2015;90:150-157. doi: 10.1016/j.resuscitation.2014.12.013

14. Del Castillo J, López-Herce J, Matamoros M, Cañadas S, Rodriguez-Calvo A, Cechetti C, Rodriguez-Núñez A, Alvarez AC; Iberoamerican Pediatric Cardiac Arrest Study Network RIBEPCI. Hyperoxia, hypocapnia and hypercapnia as outcome factors after cardiac arrest in children. Resuscitation. 2012;83:1456-1461. doi: 10.1016/j.resuscitation.2012.07.019

15. Herman ST, Abend NS, Bleck TP, Chapman KE, Drislane FW Emerson RG, Gerard EE, Hahn CD, Husain AM, Kaplan PW, et al. Consensus statement on continuous EEG in critically ill adults and children, part I: indications. J Clin Neurophysiol. 2015;32:87-95. doi: 10.1097/wnp.0000000000000166

16. Abend NS, Topjian A, Ichord R, Herman ST, Helfaer M, Donnelly M Nadkarni V, Dlugos DJ, Clancy RR. Electroencephalographic monitoring during hypothermia after pediatric cardiac arrest. Neurology. 2009;72:19311940. doi: 10.1212NNL.0b013e3181a82687

17. Topjian AA, Gutierrez-Colina AM, Sanchez SM, Berg RA, Friess SH, Dlugos DJ, Abend NS. Electrographic status epilepticus is associated with mortality and worse short-term outcome in critically ill children. Crit Care Med. 2013;41:215-223. doi: 10.1097/CCM.0b013e3182668035

18. Ostendorf AP, Hartman ME, Friess SH. Early Electroencephalographic Findings Correlate With Neurologic Outcome in Children Following Cardiac Arrest. Pediatr Crit Care Med. 2016;17:667-676. doi: 10.1097/PCC.0000000000000791

19. Brophy GM, Bell R, Claassen J, Alldredge B, Bleck TP, Glauser T, Laroche SM, Riviello JJ Jr, Shutter L, Sperling MR, Treiman DM, Vespa PM; Neurocritical Care Society Status Epilepticus Guideline Writing Committee. Guidelines for the evaluation and management of status epilepticus. Neurocrit Care. 2012;17:3-23. doi: 10.1007/s12028-012-9695-z

20. Topjian AA, Sánchez SM, Shults J, Berg RA, Dlugos DJ, Abend NS Early Electroencephalographic Background Features Predict Outcomes in Children Resuscitated From Cardiac Arrest. Pediatr Crit Care Med. 2016;17:547-557. doi: 10.1097/PCC.0000000000000740

\section{PROGNOSTICATION FOLLOWING CARDIAC ARREST}

Early and reliable prognostication of neurological outcome in pediatric survivors of cardiac arrest is essential to guide treatment, enable effective planning, and provide family support. Clinicians use patient and cardiac arrest characteristics, postarrest neurological examination, laboratory results, neurological imaging (eg, brain computed tomography and MRI), and EEG to guide prognostication. At this time, no single factor or validated decision rule has been identified to reliably predict either favorable or unfavorable outcome within 24 to 48 hours of ROSC. EEG, neuroimaging, and serum biomarkers when used alone predict outcome with only moderate accuracy, and more data are needed before applying these to individual patients.

\begin{tabular}{|c|c|c|}
\hline \multicolumn{2}{|c|}{ Recommendations for Prognostication Following Cardiac Arrest } \\
\hline COR & LOE & Recommendations \\
\hline 2a & B-NR & $\begin{array}{l}\text { 1. EEG in the first week post cardiac arrest can } \\
\text { be useful as 1 factor for prognostication, } \\
\text { augmented by other information. }{ }^{1-8}\end{array}$ \\
\hline 2a & B-NR & $\begin{array}{l}\text { 2. It is reasonable for providers to consider } \\
\text { multiple factors when predicting outcomes } \\
\text { in infants and children who survive cardiac } \\
\text { arrests. }{ }^{1,7,9-21}\end{array}$ \\
\hline B-NR & $\begin{array}{l}\text { 3. It is reasonable for providers to consider } \\
\text { multiple factors when predicting outcomes } \\
\text { in infants and children who survive cardiac } \\
\text { arrests after nonfatal drowning (ie, survival to } \\
\text { hospital admission). }{ }^{22-39}\end{array}$ \\
\hline
\end{tabular}

\section{Recommendation-Specific Supportive Text}

1. Eight retrospective observational studies demonstrate that EEG background patterns are associated with neurological outcomes at discharge. ${ }^{1-8}$ The presence of sleep spindles, ${ }^{3,4,8}$ normal background, ${ }^{2}$ and reactivity 7,8 is associated with favorable outcomes. Burst suppression and flat or attenuated EEG patterns are associated with unfavorable neurological outcome. ${ }^{1,2,5,8}$ However, these associations do not reach the high degrees of sensitivity and specificity needed to use EEG as a stand-alone modality for neuroprognostication.

2. Several studies demonstrate the association of clinical history, patient characteristics, physical examination, imaging, and biomarker data with neurological outcome following cardiac arrest. ${ }^{1,7,9-19}$ To date, no single factor has demonstrated sufficient accuracy to prognosticate outcome. Elevated serum lactate, $\mathrm{pH}$, or base deficit measured within the first 24 hours after cardiac arrest are associated with unfavorable outcome; $9,11,12,16-18,20,21$ however, specific cutoff values are unknown.

3. Shorter submersion times are associated with better outcomes after pediatric nonfatal drowning. ${ }^{22-25}$ There is no clear association between patient age, ${ }^{23,26-31,38}$ water type, ${ }^{30,32,33}$ water temperature, ${ }^{23,25,34,35}$ emergency medical services response times ${ }^{35,36}$ or witnessed status, ${ }^{36-39}$ and neurological outcome following nonfatal drowning. No single factor accurately predicts prognosis after nonfatal drowning.

\section{REFERENCES}

1. Brooks GA, Park JT. Clinical and Electroencephalographic Correlates in Pediatric Cardiac Arrest: Experience at a Tertiary Care Center. Neuropediatrics. 2018;49:324-329. doi: 10.1055/s-0038-1657757

2. Topjian AA, Sánchez SM, Shults J, Berg RA, Dlugos DJ, Abend NS. Early Electroencephalographic Background Features Predict Outcomes in Children Resuscitated From Cardiac Arrest. Pediatr Crit Care Med. 2016;17:547-557. doi: 10.1097/PCC.0000000000000740

3. Ostendorf AP, Hartman ME, Friess SH. Early Electroencephalographic Findings Correlate With Neurologic Outcome in Children Following Cardiac Arrest. Pediatr Crit Care Med. 2016;17:667-676. doi: 10.1097/PCC.0000000000000791 
4. Ducharme-Crevier L, Press CA, Kurz JE, Mills MG, Goldstein JL, Wainwright MS. Early Presence of Sleep Spindles on Electroencephalography Is Associated With Good Outcome After Pediatric Cardiac Arrest. Pediatr Crit Care Med. 2017;18:452-460. doi: 10.1097/PCC.0000000000001137

5. Bourgoin P, Barrault V, Joram N, Leclair Visonneau L, Toulgoat F, Anthoine $E$ Loron G, Chenouard A. The Prognostic Value of Early Amplitude-Integrated Electroencephalography Monitoring After Pediatric Cardiac Arrest. Pediatr Crit Care Med. 2020;21:248-255. doi: 10.1097/PCC.0000000000002171

6. Lee S, Zhao X, Davis KA, Topjian AA, Litt B, Abend NS. Quantitative EEG predicts outcomes in children after cardiac arrest. Neurology. 2019;92:e2329-e2338. doi: 10.1212NNNL.0000000000007504

7. Yang D, Ryoo E, Kim HJ. Combination of Early EEG, Brain CT, and Ammonia Level Is Useful to Predict Neurologic Outcome in Children Resuscitated From Cardiac Arrest. Front Pediatr. 2019;7:223. doi: 10.3389/fped.2019.00223

8. Fung FW, Topjian AA, Xiao R, Abend NS. Early EEG Features for Outcome Prediction After Cardiac Arrest in Children. J Clin Neurophysiol. 2019;36:349-357. doi: 10.1097/WNP.0000000000000591

9. Meert K, Telford R, Holubkov R, Slomine BS, Christensen JR, Berger J, Ofori-Amanfo G, Newth CJL, Dean JM, Moler FW. Paediatric in-hospital cardiac arrest: Factors associated with survival and neurobehavioural outcome one year later. Resuscitation. 2018;124:96-105. doi: 10.1016/j. resuscitation.2018.01.013

10. Ichord R, Silverstein FS, Slomine BS, Telford R, Christensen J, Holubkov R, Dean JM, Moler FW; THAPCA Trial Group. Neurologic outcomes in pediatric cardiac arrest survivors enrolled in the THAPCA trials. Neurology. 2018;91:e123-e131. doi: 10.1212MNL.0000000000005773

11. Meert KL, Telford R, Holubkov R, Slomine BS, Christensen JR, Dean JM, Moler FW; Therapeutic Hypothermia after Pediatric Cardiac Arrest (THAPCA) Trial Investigators. Pediatric Out-of-Hospital Cardiac Arrest Characteristics and Their Association With Survival and Neurobehavioral Outcome. Pediatr Crit Care Med. 2016;17:e543-e550. doi: 10.1097/PCC. 0000000000000969

12. Del Castillo J, López-Herce J, Matamoros M, Cañadas S, Rodríguez-Calvo A, Cecchetti C, Rodriguez-Núñez A, Álvarez AC; Iberoamerican Pediatric Cardiac Arrest Study Network RIBEPCI. Long-term evolution after in-hospital cardiac arrest in children: Prospective multicenter multinational study. Resuscitation. 2015;96:126-134. doi: 10.1016/j.resuscitation.2015.07.037

13. Topjian AA, Telford R, Holubkov R, Nadkarni VM, Berg RA, Dean JM, Moler FW; Therapeutic Hypothermia After Pediatric Cardiac Arrest (THAPCA) Trial Investigators. Association of Early Postresuscitation Hypotension With Survival to Discharge After Targeted Temperature Management for Pediatric Out-of-Hospital Cardiac Arrest: Secondary Analysis of a Randomized Clinical Trial. JAMA Pediatr. 2018;172:143-153. doi: 10.1001/jamapediatrics.2017.4043

14. Conlon TW, Falkensammer CB, Hammond RS, Nadkarni VM, Berg RA Topjian AA. Association of left ventricular systolic function and vasopressor support with survival following pediatric out-of-hospital cardiac arrest. Pediatr Crit Care Med. 2015;16:146-154. doi: 10.1097/pcc. 0000000000000305

15. Starling RM, Shekdar K, Licht D, Nadkarni VM, Berg RA, Topjian AA. Early Head CT Findings Are Associated With Outcomes After Pediatric Out-ofHospital Cardiac Arrest. Pediatr Crit Care Med. 2015;16:542-548. doi: 10.1097/PCC.0000000000000404

16. Alsoufi B, Awan A, Manlhiot C, Guechef A, Al-Halees Z, Al-Ahmadi M, McCrindle BW, Kalloghlian A. Results of rapid-response extracorporeal cardiopulmonary resuscitation in children with refractory cardiac arrest following cardiac surgery. Eur J Cardiothorac Surg. 2014;45:268-275. doi: 10.1093/ejcts/ezt319

17. Polimenakos AC, Rizzo V, El-Zein CF, Ilbawi MN. Post-cardiotomy Rescue Extracorporeal Cardiopulmonary Resuscitation in Neonates with Single Ventricle After Intractable Cardiac Arrest: Attrition After Hospital Discharge and Predictors of Outcome. Pediatr Cardiol. 2017;38:314-323. doi: 10.1007/s00246-016-1515-3

18. Scholefield BR, Gao F, Duncan HP, Tasker RC, Parslow RC, Draper ES, McShane P, Davies P, Morris KP. Observational study of children admitted to United Kingdom and Republic of Ireland Paediatric Intensive Care Units after out-of-hospital cardiac arrest. Resuscitation. 2015;97:122-128. doi: 10.1016/j.resuscitation.2015.07.011

19. Kramer P, Miera O, Berger F, Schmitt K. Prognostic value of serum biomarkers of cerebral injury in classifying neurological outcome after paediatric resuscitation. Resuscitation. 2018;122:113-120. doi: 10.1016/j.resuscitation.2017.09.012
20. López-Herce J, del Castillo J, Matamoros M, Canadas S, RodriguezCalvo A, Cecchetti C, Rodríguez-Núnez A, Carrillo Á; Iberoamerican Pediatric Cardiac Arrest Study Network RIBEPCI. Post return of spontaneous circulation factors associated with mortality in pediatric in-hospital cardiac arrest: a prospective multicenter multinational observational study. Crit Care. 2014;18:607. doi: 10.1186/s13054014-0607-9

21. Topjian AA, Clark AE, Casper TC, Berger JT, Schleien CL, Dean JM, Moler FW; Pediatric Emergency Care Applied Research Network. Early lactate elevations following resuscitation from pediatric cardiac arrest are associated with increased mortality*. Pediatr Crit Care Med. 2013;14:e380e387. doi: 10.1097/PCC.0b013e3182976402

22. Kyriacou DN, Arcinue EL, Peek C, Kraus JF. Effect of immediate resuscitation on children with submersion injury. Pediatrics. 1994;94(2 Pt 1):137142.

23. Suominen P, Baillie C, Korpela R, Rautanen S, Ranta S, Olkkola KT. Impact of age, submersion time and water temperature on outcome in near-drowning. Resuscitation. 2002;52:247-254. doi: 10.1016/s03009572(01)00478-6

24. Panzino F, Quintillá JM, Luaces C, Pou J. [Unintentional drowning by immersion. Epidemiological profile of victims attended in 21 Spanish emergency departments]. An Pediatr (Barc). 2013;78:178-184. doi: 10.1016/j.anpedi.2012.06.014

25. Quan L, Mack CD, Schiff MA. Association of water temperature and submersion duration and drowning outcome. Resuscitation. 2014;85:790794. doi: 10.1016/j.resuscitation.2014.02.024

26. Frates RC Jr. Analysis of predictive factors in the assessment of warmwater near-drowning in children. Am J Dis Child. 1981;135:1006-1008. doi: 10.1001/archpedi.1981.02130350010004

27. Nagel FO, Kibel SM, Beatty DW. Childhood near-drowning-factors associated with poor outcome. S Afr Med J. 1990;78:422-425.

28. Quan L, Wentz KR, Gore EJ, Copass MK. Outcome and predictors of outcome in pediatric submersion victims receiving prehospital care in King County, Washington. Pediatrics. 1990;86:586-593.

29. Niu YW, Cherng WS, Lin MT, Tsao LY. An analysis of prognostic factors for submersion accidents in children. Zhonghua Min Guo Xiao Er Ke Yi Xue Hui Za Zhi. 1992;33:81-88.

30. Mizuta R, Fujita H, Osamura T, Kidowaki T, Kiyosawa N. Childhood drownings and near-drownings in Japan. Acta Paediatr Jpn. 1993;35:186-192. doi: 10.1111/j.1442-200x.1993.tb03036.x

31. Al-Mofadda SM, Nassar A, Al-Turki A, Al-Sallounm AA. Pediatric near drowning: the experience of King Khalid University Hospital. Ann Saudi Med. 2001;21:300-303. doi: 10.5144/0256-4947.2001.300

32. Forler J, Carsin A, Arlaud K, Bosdure E, Viard L, Paut O, Camboulives J, Dubus JC. [Respiratory complications of accidental drownings in children]. Arch Pediatr. 2010;17:14-18. doi: 10.1016/j.arcped.2009.09.021

33. Al-Qurashi FO, Yousef AA, Aljoudi A, Alzahrani SM, Al-Jawder NY, Al-Ahmar AK, Al-Majed MS, Abouollo HM. A Review of Nonfatal Drowning in the Pediatric-Age Group: A 10-Year Experience at a University Hospital in Saudi Arabia. Pediatr Emerg Care. 2019;35:782-786. doi: 10.1097/PEC.0000000000001232

34. Kieboom JK, Verkade HJ, Burgerhof JG, Bierens JJ, Rheenen PF, Kneyber MC, Albers MJ. Outcome after resuscitation beyond 30 minutes in drowned children with cardiac arrest and hypothermia: Dutch nationwide retrospective cohort study. BMJ. 2015;350:h418. doi: 10.1136/bmj.h418

35. Claesson A, Lindqvist J, Ortenwall P, Herlitz J. Characteristics of lifesaving from drowning as reported by the Swedish Fire and Rescue Services 1996-2010. Resuscitation. 2012;83:1072-1077. doi: 10.1016/j.resuscitation.2012.05.025

36. Claesson A, Svensson L, Silfverstolpe J, Herlitz J. Characteristics and outcome among patients suffering out-of-hospital cardiac arrest due to drowning. Resuscitation. 2008;76:381-387. doi: 10.1016/j.resuscitation.2007.09.003

37. Dyson K, Morgans A, Bray J, Matthews B, Smith K. Drowning related outof-hospital cardiac arrests: characteristics and outcomes. Resuscitation. 2013;84:1114-1118. doi: 10.1016/j.resuscitation.2013.01.020

38. Nitta M, Kitamura $T$, Iwami $T$, Nadkarni VM, Berg RA, Topjian AA, Okamoto Y, Nishiyama C, Nishiuchi T, Hayashi Y, Nishimoto Y, Takasu A. Out-of-hospital cardiac arrest due to drowning among children and adults from the Utstein Osaka Project. Resuscitation. 2013;84:1568-1573. doi: 10.1016/j.resuscitation.2013.06.017

39. Claesson A, Lindqvist J, Herlitz J. Cardiac arrest due to drowningchanges over time and factors of importance for survival. Resuscitation. 2014;85:644-648. doi: 10.1016/j.resuscitation.2014.02.006 


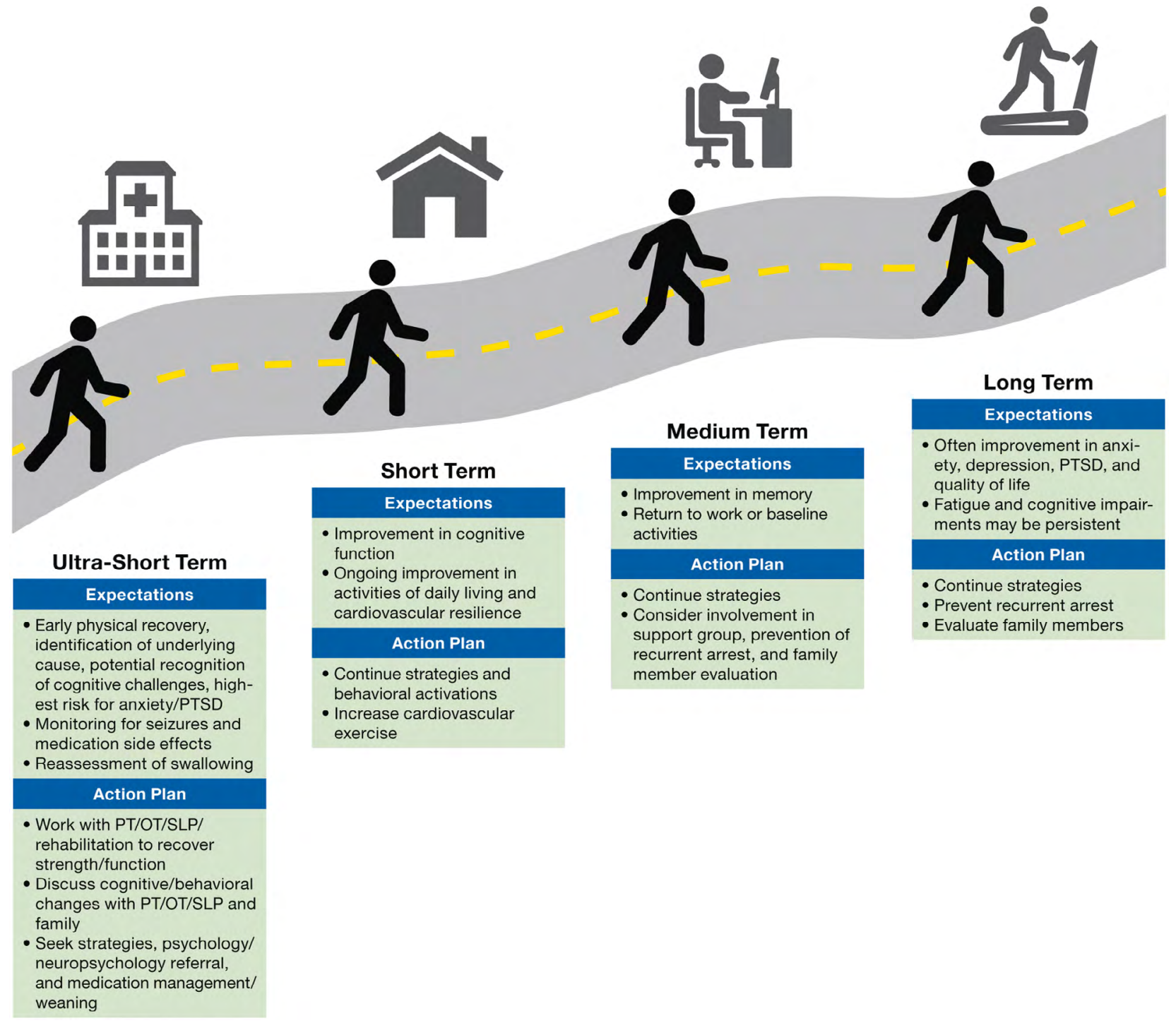

Figure 9. Road map to recovery. ${ }^{3}$

\section{POST-CARDIAC ARREST RECOVERY}

Survivors are at significant risk for both short-term and long-term physical, neurological, cognitive, emotional, and social morbidity. ${ }^{3}$ Many children who survive a cardiac arrest with a grossly "favorable outcome" have more subtle and sustained neuropsychological impairment. ${ }^{4}$ The full impact of brain injury on children's development may not be fully appreciated until months to years after the cardiac arrest. Furthermore, because children are raised by caregivers, the impact of morbidity following cardiac arrest affects not only the child but also the family.

Recovery has been introduced as the sixth link in the Chain of Survival to acknowledge that survivors of cardiac arrest may require ongoing integrated medical, rehabilitative, caregiver, and community support in the months to years after their cardiac arrest (see Figure 9). ${ }^{3}$

Recent scientific statements from the AHA and ILCOR highlight the importance of studying long-term neurological and health-related quality-of-life outcomes. 5,6

\begin{tabular}{|c|c|l|}
\hline \multicolumn{2}{|c|}{ Recommendations for Post-Cardiac Arrest Recovery } \\
\hline COR & LOE & Recommendations \\
\hline 1 & C-LD & $\begin{array}{l}\text { 1. It is recommended that pediatric cardiac } \\
\text { arrest survivors be evaluated for rehabilitation } \\
\text { services., } \text {, }^{-11}\end{array}$ \\
\hline 2a & C-LD & $\begin{array}{l}\text { 2. It is reasonable to refer pediatric cardiac } \\
\text { arrest survivors for ongoing neurological } \\
\text { evaluation for at least the first year after cardiac } \\
\text { arrest. }{ }^{3,5,10-15}\end{array}$ \\
\hline
\end{tabular}

\section{Recommendation-Specific Supportive Text}

1. Two randomized controlled trials of TTM for comatose children after IHCA or OHCA with a primary outcome of neurobehavioral outcome at 1 year ${ }^{7,8}$ showed that new morbidity is common. ${ }^{9-11}$ Many children who survived to 1 year with a 
favorable neurobehavioral outcome on Vineland Adaptive Behavior Scales-II (VABS-II) had global cognitive impairment or selective neuropsychological deficits. ${ }^{4}$

2. Two randomized controlled trials of TTM for pediatric cardiac arrest demonstrated that neurological function improves for some survivors during the first year after cardiac arrest. ${ }^{10,11}$ Several case series of longer-term outcomes (more than 1 year after cardiac arrest) demonstrate ongoing cognitive, physical, and neuropsychological impairments. ${ }^{12-14}$ Recent statements from the AHA highlight the importance of follow-up after discharge, because patient recovery continues during the first year after cardiac arrest. $3,5,6,15$ It is unclear what impact ongoing childhood development has on recovery following pediatric cardiac arrest.

\section{REFERENCES}

1. Deleted in proof

2. Deleted in proof

3. Sawyer KN, Camp-Rogers TR, Kotini-Shah P, Del Rios M, Gossip MR Moitra VK, Haywood KL, Dougherty CM, Lubitz SA, Rabinstein AA, Rittenberger JC, Callaway CW, Abella BS, Geocadin RG, Kurz MC; American Heart Association Emergency Cardiovascular Care Committee; Council on Cardiovascular and Stroke Nursing; Council on Genomic and Precision Medicine; Council on Quality of Care and Outcomes Research; and Stroke Council. Sudden Cardiac Arrest Survivorship: A Scientific Statement From the American Heart Association. Circulation. 2020;141:e654e685. doi: 10.1161/CIR.0000000000000747

4. Slomine BS, Silverstein FS, Christensen JR, Page K, Holubkov R, Dean JM, Moler FW. Neuropsychological Outcomes of Children 1 Year After Pediatric Cardiac Arrest: Secondary Analysis of 2 Randomized Clinical Trials. JAMA Neurol. 2018;75:1502-1510. doi: 10.1001/jamaneurol.2018.2628

5. Geocadin RG, Callaway CW, Fink EL, Golan E, Greer DM, Ko NU, Lang E, Licht DJ, Marino BS, McNair ND, Peberdy MA, Perman SM, Sims DB, Soar J, Sandroni C; American Heart Association Emergency Cardiovascular Care Committee. Standards for Studies of Neurological Prognostication in Comatose Survivors of Cardiac Arrest: A Scientific Statement From the American Heart Association. Circulation. 2019;140:e517-e542. doi: 10.1161/CIR.0000000000000702

6. Topjian AA, Scholefield BR, Pinto NP, Fink EL, Buysse CMP, Haywood K, Maconochie I, Nadkarni VM, de Caen A, Escalante-Kanashiro R, Ng K-C, Nuthall G, Reis AG, Van de Voorde P, Suskauer SJ, Schexnayder SM, Hazinski MF, Slomine BS. P-COSCA (Pediatric Core Outcome Set for Cardiac Arrest) in children: an advisory statement from the International Liaison Committee on Resuscitation. Circulation. 2020;142:e000-e000. doi: 10.1161/CIR.0000000000000911

7. Moler FW, Silverstein FS, Holubkov R, Slomine BS, Christensen JR, Nadkarni VM, Meert KL, Clark AE, Browning B, Pemberton VL, Page $K$, Shankaran S, Hutchison JS, Newth CJ, Bennett KS, Berger JT, Topjian A, Pineda JA, Koch JD, Schleien CL, Dalton HJ, Ofori-Amanfo G, Goodman DM, Fink EL, McQuillen P, Zimmerman JJ, Thomas NJ, van der Jagt EW, Porter MB, Meyer MT, Harrison R, Pham N, Schwarz AJ, Nowak JE, Alten J, Wheeler DS, Bhalala US, Lidsky K, Lloyd E, Mathur M, Shah S, Wu T, Theodorou AA, Sanders RC Jr, Dean JM; THAPCA Trial Investigators. Therapeutic hypothermia after out-of-hospital cardiac arrest in children. N Engl J Med. 2015;372:1898-1908. doi: 10.1056/NEJMoa1411480

8. Moler FW, Silverstein FS, Holubkov R, Slomine BS, Christensen JR, Nadkarni VM, Meert KL, Browning B, Pemberton VL, Page K, et al; on behalf of the THAPCA Trial Investigators. Therapeutic hypothermia after in-hospital cardiac arrest in children. N Engl J Med. 2017;376:318-329. doi: 10.1056/NEJMoa1610493

9. Slomine BS, Silverstein FS, Page K, Holubkov R, Christensen JR, Dean JM, Moler FW; Therapeutic Hypothermia after Pediatric Cardiac Arrest (THAPCA) Trial Investigators. Relationships between three and twelve month outcomes in children enrolled in the therapeutic hypothermia after pediatric cardiac arrest trials. Resuscitation. 2019;139:329-336. doi: 10.1016/j.resuscitation.2019.03.020

10. Slomine BS, Silverstein FS, Christensen JR, Holubkov R, Telford R, Dean JM, Moler FW; Therapeutic Hypothermia after Paediatric Cardiac Arrest (THAPCA) Trial Investigators. Neurobehavioural outcomes in children after In-Hospital cardiac arrest. Resuscitation. 2018;124:80-89. doi: 10.1016/j.resuscitation.2018.01.002

11. Slomine BS, Silverstein FS, Christensen JR, Holubkov R, Page K, Dean JM, Moler FW; on behalf of the THAPCA Trial Group. Neurobehavioral outcomes in children after out-of-hospital cardiac arrest. Pediatrics. 2016;137:e20153412. doi: 10.1542/peds.2015-3412

12. van Zellem L, Buysse C, Madderom M, Legerstee JS, Aarsen F, Tibboel D, Utens EM. Long-term neuropsychological outcomes in children and adolescents after cardiac arrest. Intensive Care Med. 2015;41:1057-1066. doi: 10.1007/s00134-015-3789-y

13. van Zellem L, Utens EM, Legerstee JS, Cransberg K, Hulst JM, Tibboel D, Buysse C. Cardiac Arrest in Children: Long-Term Health Status and HealthRelated Quality of Life. Pediatr Crit Care Med. 2015;16:693-702. doi: 10.1097/PCC.0000000000000452

14. van Zellem L, Utens EM, Madderom M, Legerstee JS, Aarsen F, Tibboel D, Buysse C. Cardiac arrest in infants, children, and adolescents: long-term emotional and behavioral functioning. Eur J Pediatr. 2016;175:977-986. doi: 10.1007/s00431-016-2728-4

15. Topjian AA, de Caen A, Wainwright MS, Abella BS, Abend NS, Atkins DL, Bembea MM, Fink EL, Guerguerian AM, Haskell SE, Kilgannon JH, Lasa JJ, Hazinski MF. Pediatric Post-Cardiac Arrest Care: A Scientific Statement From the American Heart Association. Circulation. 2019;140:e194-e233. doi: 10.1161/CIR.0000000000000697

\section{FAMILY PRESENCE DURING RESUSCITATION}

Over the past 20 years, the practice of maintaining family presence during resuscitation has increased. Most parents surveyed indicate that they would desire to be present during their child's resuscitation. Older data suggest a lower incidence of anxiety and depression and more constructive grief behaviors among parents who were present when their child died. ${ }^{1}$

\begin{tabular}{|c|c|c|}
\hline \multicolumn{1}{|c|}{ Recommendations for Family Presence During Resuscitation } \\
\hline COR & LOE & Recommendations \\
\hline 1 & B-NR & $\begin{array}{l}\text { 1. Whenever possible, provide family members } \\
\text { with the option of being present during the } \\
\text { resuscitation of their infant or child. }{ }^{2-10}\end{array}$ \\
\hline 1 & B-NR & $\begin{array}{l}\text { 2. When family members are present during } \\
\text { resuscitation, it is beneficial for a designated } \\
\text { team member to provide comfort, answer } \\
\text { questions, and support the family. }{ }^{11,12}\end{array}$ \\
\hline C-LD & $\begin{array}{l}\text { 3. If the presence of family members is } \\
\text { considered detrimental to the resuscitation, } \\
\text { family members should be asked in a } \\
\text { respectful manner to leave. }{ }^{13,14}\end{array}$ \\
\hline
\end{tabular}

\section{Recommendation-Specific Supportive Text}

1. Qualitative studies generally show that there can be benefits for families if they are permitted to be present during the resuscitation of their children. Parents stated that they believed their presence brought their child comfort and that it helped them to adjust to the loss of their child. ${ }^{2}$ Other surveys of parents reported that they desired to be present to understand what was happening, to know that all that could be done was being done, and to 
keep physical contact with their child. ${ }^{3,4}$ However, not all parents who were present for their child's resuscitation would choose to do so again. ${ }^{5}$ Some concerns have been raised about family presence during resuscitation, such as trauma for the family, interference with procedures, impact on technical performance, and concern for teaching and clinical decision-making, but these have not been supported by the available evidence..$^{6-8}$ Experienced providers are more likely than trainees to support family presence. ${ }^{9,10}$

2. The presence of a facilitator to support the family is helpful. ${ }^{11,12}$ It is important that the family have a dedicated team member during the resuscitation to help process the traumatic event, but this is not always feasible. Lack of an available facilitator should not prevent family presence at the resuscitation.

3. Most surveys indicate family presence is not disruptive during resuscitation, although some providers feel increased stress. ${ }^{13}$ Providers with significant experience with family presence acknowledge occasional negative experiences. ${ }^{14}$

\section{REFERENCES}

1. Robinson SM, Mackenzie-Ross S, Campbell Hewson GL, Egleston CV, Prevost AT. Psychological effect of witnessed resuscitation on bereaved relatives. Lancet. 1998;352:614-617. doi: 10.1016/s01406736(97)12179-1

2. Tinsley C, Hill JB, Shah J, Zimmerman G, Wilson M, Freier $K$, Abd-Allah $\mathrm{S}$. Experience of families during cardiopulmonary resuscitation in a pediatric intensive care unit. Pediatrics. 2008;122:e799-e804. doi: 10.1542/peds.2007-3650

3. Maxton FJ. Parental presence during resuscitation in the PICU: the parents' experience. Sharing and surviving the resuscitation: a phenomenological study. J Clin Nurs. 2008;17:3168-3176. doi: 10.1111/j.13652702.2008.02525.x

4. Stewart SA. Parents' Experience During a Child's Resuscitation: Getting Through It. J Pediatr Nurs. 2019;47:58-67. doi: 10.1016/j.pedn 2019.04.019

5. Curley MA, Meyer EC, Scoppettuolo LA, McGann EA, Trainor BP Rachwal CM, Hickey PA. Parent presence during invasive procedures and resuscitation: evaluating a clinical practice change. Am J Respir Crit Care Med. 2012;186:1133-1139. doi: 10.1164/rccm.201205-09150C

6. McClenathan BM, Torrington KG, Uyehara CF. Family member presence during cardiopulmonary resuscitation: a survey of US and international critical care professionals. Chest. 2002;122:2204-2211. doi: 10.1378/chest.122.6.2204

7. Vavarouta A, Xanthos T, Papadimitriou L, Kouskouni E, lacovidou N. Family presence during resuscitation and invasive procedures: physicians' and nurses' attitudes working in pediatric departments in Greece. Resuscitation. 2011;82:713-716. doi: 10.1016/j.resuscitation.2011.02.011

8. Pasek TA, Licata J. Parent Advocacy Group for Events of Resuscitation. Crit Care Nurse. 2016;36:58-64. doi: 10.4037/ccn2016759

9. Fein JA, Ganesh J, Alpern ER. Medical staff attitudes toward family presence during pediatric procedures. Pediatr Emerg Care. 2004;20:224-227. doi: 10.1097/01.pec.0000121241.99242.3b

10. Bradford KK, Kost S, Selbst SM, Renwick AE, Pratt A. Family member presence for procedures: the resident's perspective. Ambul Pediatr. 2005;5:294-297. doi: 10.1367/A04-024R1.1

11. Jarvis AS. Parental presence during resuscitation: attitudes of staff on a paediatric intensive care unit. Intensive Crit Care Nurs. 1998;14:3-7. doi 10.1016/s0964-3397(98)80029-3

12. Zavotsky KE, McCoy J, Bell G, Haussman K, Joiner J, Marcoux KK, Magarelli K Mahoney K, Maldonado L, Mastro KA, Milloria A, Tamburri LM, Tortajada D.
Resuscitation team perceptions of family presence during CPR. Adv Emerg Nurs J. 2014;36:325-334. doi: 10.1097/TME.0000000000000027

13. Kuzin JK, Yborra JG, Taylor MD, Chang AC, Altman CA, Whitney GM, Mott AR. Family-member presence during interventions in the intensive care unit: perceptions of pediatric cardiac intensive care providers. Pediatrics. 2007;120:e895-e901. doi: 10.1542/peds.2006-2943

14. Fulbrook P, Latour JM, Albarran JW. Paediatric critical care nurses' attitudes and experiences of parental presence during cardiopulmonary resuscitation: a European survey. Int J Nurs Stud. 2007;44:1238-1249. doi: 10.1016/j.jinurstu.2006.05.006

\section{EVALUATION OF SUDDEN UNEXPLAINED CARDIAC ARREST}

Hypertrophic cardiomyopathy, coronary artery anomalies, and arrhythmias are common causes of sudden unexplained cardiac arrest in infants and children. Up to one third of young patients who do not survive sudden unexplained cardiac arrest have no abnormalities found on gross and microscopic autopsy. ${ }^{1-4}$ Postmortem genetic evaluation ("molecular autopsy") is increasingly used to inform etiology of sudden unexplained cardiac arrest. ${ }^{5}$ In addition to providing an explanation for the arrest, genetic diagnosis can identify inheritable cardiac disease, such as channelopathy and cardiomyopathy, enabling screening and preventive measures for relatives.

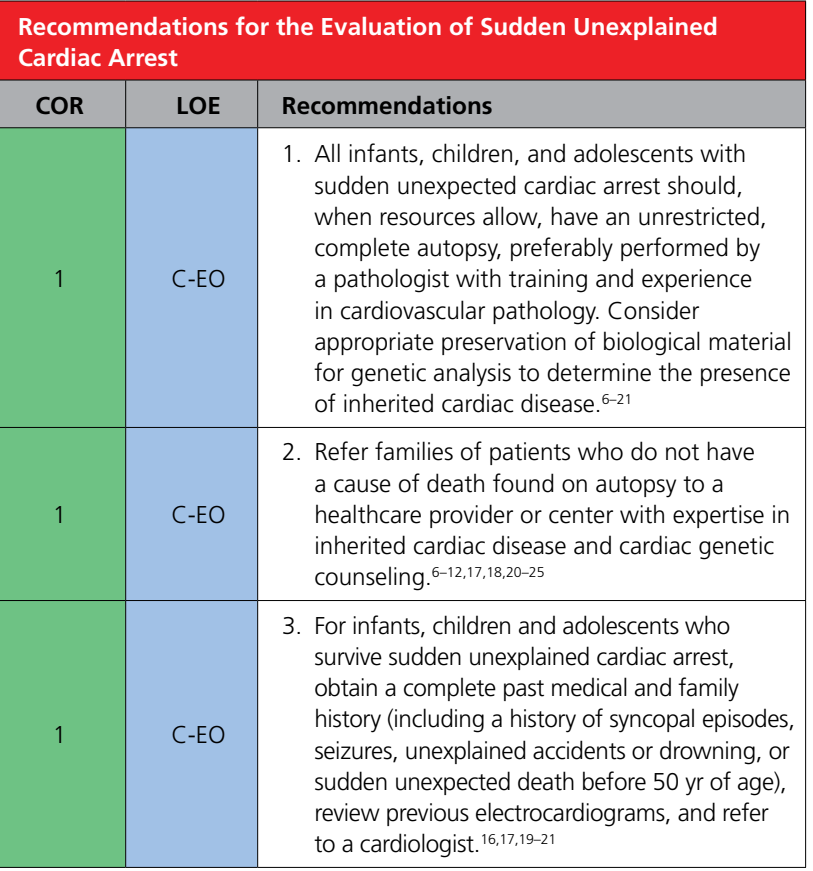

\section{Recommendation-Specific Supportive Text}

1. In 7 cohort studies, mutations causing channelopathies were identified in $2 \%$ to $10 \%$ of infants with sudden infant death syndrome. ${ }^{6-12}$ Among children and adolescents with sudden unexplained cardiac arrest and a normal autopsy, 9 cohort studies report identification of genetic mutations associated with channelopathy or cardiomyopathy. ${ }^{13-21}$ 
2. In 7 cohort studies ${ }^{17,18,20,22-25}$ and 1 population-based study ${ }^{21}$ of screening using clinical and laboratory (electrocardiographic, molecular genetic screening) investigations, $14 \%$ to $53 \%$ of first- and seconddegree relatives of patients with sudden unexplained cardiac arrest had inherited, arrhythmogenic disorders. In 7 cohort studies, mutations causing channelopathies were identified in $2 \%$ to $10 \%$ of infants with sudden infant death syndrome. ${ }^{6-12}$

3. Several cohort studies report the utility of obtaining a complete past medical and family history after sudden unexplained cardiac arrest as well as review of prior electrocardiograms. A small case series suggested that specific genetic screening of family members was directed by the clinical history. ${ }^{20}$ Three small cohort studies and 1 population-based study reported relevant clinical symptoms or medical comorbidities, such as seizure, syncope, palpitations, chest pain, left arm pain, and shortness of breath, among patients who had a sudden unexplained cardiac arrest and their family members. ${ }^{16,17,19,21}$

\section{REFERENCES}

1. Doolan A, Langlois N, Semsarian C. Causes of sudden cardiac death in young Australians. Med J Aust. 2004;180:110-112.

2. Eckart RE, Scoville SL, Campbell CL, Shry EA, Stajduhar KC, Potter RN, Pearse LA, Virmani R. Sudden death in young adults: a 25-year review of autopsies in military recruits. Ann Intern Med. 2004;141:829-834. doi: 10.7326/0003-4819-141-11-200412070-00005

3. Ong ME, Stiell I, Osmond MH, Nesbitt L, Gerein R, Campbell S, McLellan B; OPALS Study Group. Etiology of pediatric out-of-hospital cardiac arrest by coroner's diagnosis. Resuscitation. 2006;68:335-342. doi: 10.1016/j.resuscitation.2005.05.026

4. Puranik R, Chow CK, Duflou JA, Kilborn MJ, McGuire MA. Sudden death in the young. Heart Rhythm. 2005;2:1277-1282. doi: 10.1016/j.hrthm.2005.09.008

5. Torkamani A, Muse ED, Spencer EG, Rueda M, Wagner GN, Lucas JR, Topol EJ. Molecular Autopsy for Sudden Unexpected Death. JAMA. 2016; 316:1492-1494. doi: 10.1001/jama.2016.11445

6. Ackerman MJ, Siu BL, Sturner WQ, Tester DJ, Valdivia CR, Makielski JC, Towbin JA. Postmortem molecular analysis of SCN5A defects in sudden infant death syndrome. JAMA. 2001;286:2264-2269. doi: 10.1001/jama. 286.18.2264

7. Arnestad M, Crotti L, Rognum TO, Insolia R, Pedrazzini M, Ferrandi $C$, Vege A, Wang DW, Rhodes TE, George AL Jr, Schwartz PJ. Prevalence of long-QT syndrome gene variants in sudden infant death syndrome. Circulation. 2007;115:361-367. doi: 10.1161/CIRCULATIONAHA.106.658021

8. Cronk LB, Ye B, Kaku T, Tester DJ, Vatta M, Makielski JC, Ackerman MJ. Novel mechanism for sudden infant death syndrome: persistent late sodium current secondary to mutations in caveolin-3. Heart Rhythm. 2007;4:161-166. doi: 10.1016/j.hrthm.2006.11.030

9. Millat G, Kugener B, Chevalier $P$, Chahine M, Huang $H$, Malicier D, Rodriguez-Lafrasse C, Rousson R. Contribution of long-QT syndrome genetic variants in sudden infant death syndrome. Pediatr Cardiol. 2009;30:502-509. doi: 10.1007/s00246-009-9417-2

10. Otagiri T, Kijima K, Osawa M, Ishii K, Makita N, Matoba $R$ Umetsu K, Hayasaka K. Cardiac ion channel gene mutations in sudden infant death syndrome. Pediatr Res. 2008;64:482-487. doi: 10.1203/PDR. Ob013e3181841eca

11. Plant LD, Bowers PN, Liu Q, Morgan T, Zhang T, State MW, Chen $W_{\text {, }}$ Kittles RA, Goldstein SA. A common cardiac sodium channel variant associated with sudden infant death in African Americans, SCN5A S1103Y. J Clin Invest. 2006;116:430-435. doi: 10.1172/JCI25618

12. Tester DJ, Dura M, Carturan E, Reiken S, Wronska A, Marks AR, Ackerman MJ. A mechanism for sudden infant death syndrome (SIDS) stress-induced leak via ryanodine receptors. Heart Rhythm. 2007;4:733739. doi: 10.1016/j.hrthm.2007.02.026

13. Albert CM, Nam EG, Rimm EB, Jin HW, Hajjar RJ, Hunter DJ, MacRae CA, Ellinor PT. Cardiac sodium channel gene variants and sudden cardiac death in women. Circulation. 2008;117:16-23. doi: 10.1161/ CIRCULATIONAHA.107.736330

14. Chugh SS, Senashova O, Watts A, Tran PT, Zhou Z, Gong Q, Titus JL, Hayflick SJ. Postmortem molecular screening in unexplained sudden death. J Am Coll Cardiol. 2004;43:1625-1629. doi: 10.1016/j.jacc.2003.11.052

15. Tester DJ, Spoon DB, Valdivia HH, Makielski JC, Ackerman MJ. Targeted mutational analysis of the RyR2-encoded cardiac ryanodine receptor in sudden unexplained death: a molecular autopsy of 49 medical examiner/coroner's cases. Mayo Clin Proc. 2004;79:1380-1384. doi: 10.4065/79.11.1380

16. Scheiper S, Ramos-Luis E, Blanco-Verea A, Niess C, Beckmann BM, Schmidt U, Kettner M, Geisen C, Verhoff MA, Brion M, Kauferstein S. Sudden unexpected death in the young - Value of massive parallel sequencing in postmortem genetic analyses. Forensic Sci Int. 2018;293:7076. doi: 10.1016/j.forsciint.2018.09.034

17. Hellenthal N, Gaertner-Rommel A, Klauke B, Paluszkiewicz L, Stuhr M, Kerner T, Farr M, Püschel K, Milting H. Molecular autopsy of sudden unexplained deaths reveals genetic predispositions for cardiac diseases among young forensic cases. Europace. 2017;19:1881-1890. doi: 10.1093/europace/euw247

18. Jiménez-Jáimez J, Alcalde Martínez $V$, Jiménez Fernández $M$, Bermúdez Jiménez F, Rodríguez Vázquez Del Rey MDM, Perin F, Oyonarte Ramírez JM, López Fernández S, de la Torre I, García Orta R, González Molina M, Cabrerizo EM, Álvarez Abril B, Álvarez M, Macías Ruiz R, Correa C, Tercedor L. Clinical and Genetic Diagnosis of Nonischemic Sudden Cardiac Death. Rev Esp Cardiol (Engl Ed). 2017;70:808-816. doi: 10.1016/j.rec. 2017.04.024

19. Lahrouchi N, Raju H, Lodder EM, Papatheodorou E, Ware JS, Papadakis M, Tadros R, Cole D, Skinner JR, Crawford J, Love DR, Pua CJ, Soh BY, Bhalshankar JD, Govind R, Tfelt-Hansen J, Winkel BG, van derWerfC, Wijeyeratne YD, Mellor G, Till J, Cohen MC, Tome-Esteban M, Sharma S, Wilde AAM, Cook SA, Bezzina CR, Sheppard MN, Behr ER. Utility of PostMortem Genetic Testing in Cases of Sudden Arrhythmic Death Syndrome. J Am Coll Cardiol. 2017;69:2134-2145. doi: 10.1016/j.jacc.2017.02.046

20. Anastasakis A, Papatheodorou E, Ritsatos K, Protonotarios N, Rentoumi V, GatzoulisK,AntoniadesL,AgapitosE, KoutsaftisP, SpiliopoulouC, TousoulisD. Sudden unexplained death in the young: epidemiology, aetiology and value of the clinically guided genetic screening. Europace. 2018;20:472480. doi: 10.1093/europace/euw362

21. Hendrix A, Borleffs CJ, Vink A, Doevendans PA, Wilde AA, van Langen IM, van der Smagt JJ, Bots ML, Mosterd A. Cardiogenetic screening of first-degree relatives after sudden cardiac death in the young: a population-based approach. Europace. 2011;13:716-722. doi: 10.1093/europace/euq460

22. Behr E, Wood DA, Wright M, Syrris P, Sheppard MN, Casey A, Davies MJ, McKenna W; Sudden Arrhythmic Death Syndrome Steering Group. Cardiological assessment of first-degree relatives in sudden arrhythmic death syndrome. Lancet. 2003;362:1457-1459. doi: 10.1016/s01406736(03)14692-2

23. Behr ER, Dalageorgou C, Christiansen M, Syrris P, Hughes S, Tome Esteban MT, Rowland E, Jeffery S, McKenna WJ. Sudden arrhythmic death syndrome: familial evaluation identifies inheritable heart disease in the majority of families. Eur Heart J. 2008;29:1670-1680. doi: 10.1093/eurheartj/ehn219

24. Hofman N, Tan HL, Clur SA, Alders M, van Langen IM, Wilde AA. Contribution of inherited heart disease to sudden cardiac death in childhood. Pediatrics. 2007;120:e967-e973. doi: 10.1542/peds.2006-3751

25. Tan HL, Hofman N, van Langen IM, van der Wal AC, Wilde AA. Sudden unexplained death: heritability and diagnostic yield of cardiological and genetic examination in surviving relatives. Circulation. 2005;112:207213. doi: 10.1161/CIRCULATIONAHA.104.522581

\section{RESUSCITATING THE PATIENT IN SHOCK}

Shock is the failure of oxygen delivery to meet tissue metabolic demands and can be life threatening. The most common type of pediatric shock is hypovolemic, 
including shock due to hemorrhage. Distributive, cardiogenic, and obstructive shock occur less frequently. Often, multiple types of shock can occur simultaneously; thus, providers should be vigilant. Cardiogenic shock in its early stages can be difficult to diagnose, so a high index of suspicion is warranted.

Shock progresses over a continuum of severity, from a compensated to a decompensated (hypotensive) state. Compensatory mechanisms include tachycardia and increased systemic vascular resistance (vasoconstriction) in an effort to maintain cardiac output and end-organ perfusion. As compensatory mechanisms fail, hypotension and signs of inadequate end-organ perfusion develop, such as depressed mental status, decreased urine output, lactic acidosis, and weak central pulses.

Early administration of intravenous fluids t o t reat septic shock has been widely accepted based on limited evidence. Mortality from pediatric sepsis has declined in recent years, concurrent with implementation of guidelines emphasizing the role of early antibiotic and fluid administration. ${ }^{1}$ Controversies in the management of septic shock include volume of fluid administration and how to assess the patient's response, the timing and choice of vasopressor agents, the use of corticosteroids, and modifications to treatment algorithms for patients in sepsis-related cardiac arrest. Previous AHA guidelines ${ }^{2}$ have considered large studies of patients with malaria, sickle cell anemia, and dengue shock syndrome; however, these patients require special consideration that make generalization of results from these studies problematic.

Resuscitation guidance for children with hemorrhagic shock is evolving, as crystalloid-then-blood paradigms are being challenged by resuscitation protocols using blood products early in resuscitation. However, the ideal resuscitation strategy for a given type of injury is often unknown.

\section{Fluid Resuscitation in Shock}

\begin{tabular}{|c|c|c|}
\hline \multicolumn{2}{|c|}{ Recommendations for Fluid Resuscitation in Shock } \\
\hline COR & LOE & Recommendations \\
\hline 1 & C-LD & $\begin{array}{l}\text { 1. Providers should reassess the patient after every } \\
\text { fluid bolus to assess for fluid responsiveness } \\
\text { and for signs of volume overload. }{ }^{3-5}\end{array}$ \\
\hline 2a & B-R & $\begin{array}{l}\text { 2. Either isotonic crystalloids or colloids can } \\
\text { be effective as the initial fluid choice for } \\
\text { resuscitation. }\end{array}$ \\
\hline 2a & B-NR & $\begin{array}{l}\text { 3. Either balanced or unbalanced solutions } \\
\text { can be effective as the fluid choice for } \\
\text { resuscitation. }{ }^{7-9}\end{array}$ \\
\hline 2a & C-LD & $\begin{array}{l}\text { 4. In patients with septic shock, it is reasonable } \\
\text { to administer fluid in 10-mL/kg or 20-mL/kg } \\
\text { aliquots with frequent reassessment. }{ }^{4}\end{array}$ \\
\hline
\end{tabular}

\section{Recommendation-Specific Supportive Text}

1. Although fluids r emain the $m$ ainstay i nitial therapy for infants and children in shock, especially in hypovolemic and septic shock, fluid overload can lead to increased morbidity. ${ }^{3}$ In 2 randomized trials of patients with septic shock, those who received higher fluid volumes ${ }^{4}$ or faster fluid resuscitation ${ }^{5}$ were more likely to develop clinically significant fluid overload characterized by increased rates of mechanical ventilation and worsening oxygenation.

2. In a systematic review, 12 relevant studies were identified, though 11 assessed colloid or crystalloid fluid resuscitation in patients with malaria, dengue shock syndrome, or "febrile illness" in sub-Saharan Africa. ${ }^{6}$ There was no clear benefit to crystalloid or colloid solutions as first-line fluid therapy in any of the identified studies.

3. One pragmatic, randomized controlled trial compared the use of balanced (lactated Ringer's solution) to unbalanced $(0.9 \%$ saline $)$ crystalloid solutions as the initial resuscitation fluid and showed no difference in relevant clinical outcomes. ${ }^{7}$ A matched retrospective cohort study of pediatric patients with septic shock showed no difference in outcomes, ${ }^{8}$ though a propensity-matched database study showed an association with increased 72-hour mortality and vasoactive infusion days with unbalanced crystalloid fluid resuscitation. ${ }^{9}$

4. In a small, randomized controlled study, there were no significant differences in outcomes with the use of $20 \mathrm{~mL} / \mathrm{kg}$ as the initial fluid bolus volume (compared with $10 \mathrm{~mL} / \mathrm{kg}$ ); however, the study was limited by a small sample size. ${ }^{4}$

\section{Resuscitating a Patient in Septic Shock}

\begin{tabular}{|c|c|l|}
\hline \multicolumn{2}{|c|}{ Recommendations for Resuscitating a Patient in Septic Shock } \\
\hline COR & LOE & Recommendations \\
\hline $2 a$ & C-LD & $\begin{array}{l}\text { 1. In infants and children with fluid-refractory } \\
\text { septic shock, it is reasonable to use either } \\
\text { epinephrine or norepinephrine as an initial } \\
\text { vasoactive infusion. }{ }^{1,10-14}\end{array}$ \\
\hline $2 a$ & C-EO & $\begin{array}{l}\text { 2. For infants and children with cardiac arrest } \\
\text { and sepsis, it is reasonable to apply the } \\
\text { standard pediatric advanced life support } \\
\text { algorithm compared with any unique } \\
\text { approach for sepsis-associated cardiac } \\
\text { arrest. }{ }^{15}\end{array}$ \\
\hline $2 b$ & B-NR & $\begin{array}{l}\text { 3. For infants and children with septic shock } \\
\text { unresponsive to fluids and requiring } \\
\text { vasoactive support, it may be reasonable to } \\
\text { consider stress-dose corticosteroids. }{ }^{12,16-19}\end{array}$ \\
\hline $2 b$ & C-LD & $\begin{array}{l}\text { 4. In infants and children with fluid- } \\
\text { refractory septic shock, if epinephrine or } \\
\text { norepinephrine are unavailable, dopamine } \\
\text { may be considered. }{ }^{10-12}\end{array}$ \\
\hline
\end{tabular}

\section{Recommendation-Specific Supportive Text}

1. Two randomized controlled trials comparing escalating doses of dopamine or epinephrine demonstrated improvement in timing of resolution of shock ${ }^{10}$ and 28-day mortality ${ }^{11}$ with the use of epinephrine 
over dopamine. Both studies were conducted in resource-limited settings, and the doses of inotropes used may not have been directly comparable, limiting conclusions from the studies. Medications that increase systemic vascular resistance, such as norepinephrine, may also be a reasonable initial vasopressor therapy in septic shock patients. ${ }^{1,12-14}$ Recent international sepsis guidelines recommend the choice of the medications to be guided by patient physiology and clinician preferences. ${ }^{1}$

2. No studies support deviations from standard lifesupport algorithms to improve outcomes in patients with sepsis-associated cardiac arrest. Sepsisassociated cardiac arrest is associated with worse outcomes than other causes of cardiac arrest. ${ }^{15}$

3. A meta-analysis ${ }^{20}$ showed no change in survival with corticosteroid use in pediatric septic shock, though a more recent randomized controlled trial suggested a shorter time to reversal of shock with steroid use. ${ }^{17}$ Two observational studies ${ }^{18,19}$ suggested there may be specific subpopulations, based on genomics, that would either benefit or experience harm from steroid administration, though these subpopulations are difficult to identify clinically. Patients at risk for adrenal insufficiency (eg, those on chronic steroids, patients with purpura fulminans) are more likely to benefit from steroid therapy.12

4. In situations when epinephrine or norepinephrine are not available, dopamine is a reasonable alternative initial vasoactive infusion in patients with fluidrefractory septic shock. ${ }^{10,11}$ Patients with vasodilatory shock may require a higher dose of dopamine. ${ }^{12}$

\section{Resuscitating the Patient in Cardiogenic Shock}

\begin{tabular}{|c|c|c|}
\hline \multicolumn{2}{|c|}{ Recommendations for Resuscitating the Patient in Cardiogenic Shock } \\
\hline COR & LOE & Recommendations \\
\hline 1 & C-EO & $\begin{array}{l}\text { 1. For infants and children with cardiogenic } \\
\text { shock, early expert consultation is } \\
\text { recommended. }\end{array}$ \\
\hline $2 b$ & C-EO & $\begin{array}{l}\text { 2. For infants and children with cardiogenic } \\
\text { shock, it may be reasonable to use } \\
\text { epinephrine, dopamine, dobutamine, or } \\
\text { milrinone as an inotropic infusion. }\end{array}$ \\
\hline
\end{tabular}

\section{Recommendation-Specific Supportive Text}

1 and 2. Cardiogenic shock in infants and children is uncommon and associated with high mortality rates. No studies were identified comparing outcomes between vasoactive medications. For patients with hypotension, medications such as epinephrine may be more appropriate as an initial inotropic therapy. Because of the rarity and complexity of these presentations, expert consultation is recommended when managing infants and children in cardiogenic shock.

\section{Resuscitating the Patient in Traumatic Hemorrhagic Shock}

Recommendation for Resuscitating the Patient in Traumatic Hemorrhagic Shock

\begin{tabular}{|c|c|l|}
\hline COR & LOE & Recommendation \\
\hline $2 a$ & C-EO & $\begin{array}{l}\text { 1. Among infants and children with hypotensive } \\
\text { hemorrhagic shock following trauma, it is } \\
\text { reasonable to administer blood products, } \\
\text { when available, instead of crystalloid for } \\
\text { ongoing volume resuscitation. }{ }^{21-27}\end{array}$ \\
\hline
\end{tabular}

\section{Recommendation-Specific Supportive Text}

1. There are no prospective pediatric data comparing the administration of early blood products versus early crystalloid for traumatic hemorrhagic shock. A scoping review identified 6 recent retrospective studies that compared patient outcomes with the total volume of crystalloid resuscitation received in the first 24 to 48 hours among children with hemorrhagic shock ${ }^{21-25,28}$ Four studies reported no differences in survival to 24 hours, survival at 30 days with good neurological outcome, or survival to discharge. ${ }^{21,24,25,28}$ Large-volume resuscitation was associated with increased hospital//CU length of stay in 5 of the 6 studies. ${ }^{22-25,28}$ One study reported lower survival to hospital discharge among children who received more than $60 \mathrm{~mL} / \mathrm{kg}$ crystalloid compared to lower volume groups. ${ }^{22}$ Despite limited pediatric data, recent guidelines for adults from the Eastern Association for the Surgery of Trauma, ${ }^{26}$ the American College of Surgeons, and the National Institute for Health and Care Excellence ${ }^{27}$ suggest the early use of balanced ratios of packed red blood cells, fresh frozen plasma, and platelets for traumarelated hemorrhagic shock. ${ }^{29}$

\section{REFERENCES}

1. Weiss SL, Peters MJ, Alhazzani W, Agus MSD, Flori HR, Inwald DP, Nadel S, Schlapbach LJ, Tasker RC, Argent AC, Brierley J, Carcillo J, Carrol ED, Carroll CL, Cheifetz IM, Choong K, Cies JJ, Cruz AT, De Luca D, Deep A, Faust SN, De Oliveira CF, Hall MW, Ishimine P, Javouhey E, Joosten KFM, Joshi P, Karam O, Kneyber MCJ, Lemson J, MacLaren G, Mehta NM, Møller MH, Newth CJL, Nguyen TC, Nishisaki A, Nunnally ME, Parker MM, Paul RM, Randolph AG, Ranjit S, Romer LH, Scott HF, Tume LN, Verger JT, Williams EA, Wolf J, Wong HR, Zimmerman JJ, Kissoon N, Tissieres P. Surviving Sepsis Campaign International Guidelines for the Management of Septic Shock and Sepsis-Associated Organ Dysfunction in Children. Pediatr Crit Care Med. 2020;21:e52-e106. doi: 10.1097/PCC.0000000000002198

2. de Caen AR, Berg MD, Chameides L, Gooden CK, Hickey RW, Scott HF, Sutton RM, Tijssen JA, Topjian A, van der Jagt EW, et al. Part 12: pediatric advanced life support: 2015 American Heart Association Guidelines Update for Cardiopulmonary Resuscitation and Emergency Cardiovascular Care. Circulation. 2015;132(suppl 2):S526-S542. doi: 10.1161/CIR.0000000000000266

3. van Paridon BM, Sheppard C, Garcia Guerra G, Joffe AR; on behalf of the Alberta Sepsis Network. Timing of antibiotics, volume, and vasoactive infusions in children with sepsis admitted to intensive care. Crit Care. 2015;19:293. doi: 10.1186/s13054-015-1010-x

4. Inwald DP, Canter R, Woolfall K, Mouncey P, Zenasni Z, O'Hara C, Carter A, Jones N, Lyttle MD, Nadel S, et al; on behalf of PERUKI (Paediatric Emergency Research in the UK and Ireland) and PICS SG (Paediatric 
Intensive Care Society Study Group). Restricted fluid bolus volume in early septic shock: results of the Fluids in Shock pilot trial. Arch Dis Child. 2019;104:426-431. doi: 10.1136/archdischild-2018-314924

5. Sankar J, Ismail J, Sankar MJ, C P S, Meena RS. Fluid Bolus Over 15-20 Versus 5-10 Minutes Each in the First Hour of Resuscitation in Children With Septic Shock: A Randomized Controlled Trial. Pediatr Crit Care Med. 2017;18:e435-e445. doi: 10.1097/PCC.0000000000001269

6. Medeiros DN, Ferranti JF, Delgado AF, de Carvalho WB. Colloids for the Initial Management of Severe Sepsis and Septic Shock in Pediatric Patients: A Systematic Review. Pediatr Emerg Care. 2015;31:e11-e16. doi: 10.1097/PEC.0000000000000601

7. Balamuth F, Kittick M, McBride P, Woodford AL, Vestal N, Casper TC Metheney M, Smith K, Atkin NJ, Baren JM, Dean JM, Kuppermann N, Weiss SL. Pragmatic Pediatric Trial of Balanced Versus Normal Saline Fluid in Sepsis: The PRoMPT BOLUS Randomized Controlled Trial Pilot Feasibility Study. Acad Emerg Med. 2019;26:1346-1356. doi: 10.1111/acem.13815

8. Weiss SL, Keele L, Balamuth F, Vendetti N, Ross R, Fitzgerald JC, Gerber JS. Crystalloid Fluid Choice and Clinical Outcomes in Pediatric Sepsis: A Matched Retrospective Cohort Study. J Pediatr. 2017;182:304-310. e10. doi: 10.1016/j.jpeds.2016.11.075

9. Emrath ET, Fortenberry JD, Travers C, McCracken CE, Hebbar KB. Resuscitation With Balanced Fluids Is Associated With Improved Survival in Pediatric Severe Sepsis. Crit Care Med. 2017;45:1177-1183. doi: 10.1097/CCM.0000000000002365

10. Ventura AM, Shieh HH, Bousso A, Góes PF, de Cássia F O Fernandes I, de Souza DC, Paulo RL, Chagas F, Gilio AE. Double-Blind Prospective Randomized Controlled Trial of Dopamine Versus Epinephrine as First-Line Vasoactive Drugs in Pediatric Septic Shock. Crit Care Med. 2015;43:22922302. doi: 10.1097/CCM.0000000000001260

11. Ramaswamy KN, Singhi S, Jayashree M, Bansal A, Nallasamy K. DoubleBlind Randomized Clinical Trial Comparing Dopamine and Epinephrine in Pediatric Fluid-Refractory Hypotensive Septic Shock. Pediatr Crit Care Med. 2016;17:e502-e512. doi: 10.1097/PCC.0000000000000954

12. Davis AL, Carcillo JA, Aneja RK, Deymann AJ, Lin JC, Nguyen TC, Okhuysen-Cawley RS, Relvas MS, Rozenfeld RA, Skippen PW, StojadinovicBJ, WilliamsEA, YehTS, BalamuthF, BrierleyJ, deCaenAR, CheifetzIM, ChoongK, Conway E Jr, Cornell T, Doctor A, Dugas MA, Feldman JD, Fitzgerald JC, Flori HR, Fortenberry JD, Graciano AL, Greenwald BM, Hall MW, Han YY, Hernan LJ, Irazuzta JE, Iselin E, van der Jagt EW, Jeffries HE, Kache S, Katyal C, Kissoon N, Kon AA, Kutko MC, MacLaren G, Maul T, Mehta R, Odetola F, Parbuoni K, Paul R, Peters MJ, Ranjit S, Reuter-Rice KE, Schnitzler EJ, Scott HF, Torres A Jr, Weingarten-Arams J, Weiss SL, Zimmerman JJ, Zuckerberg AL. American College of Critical Care Medicine Clinical Practice Parameters for Hemodynamic Support of Pediatric and Neonatal Septic Shock. Crit Care Med. 2017;45:1061-1093. doi: 10.1097/CCM.0000000000002425

13. Lampin ME, Rousseaux J, Botte A, Sadik A, Cremer R, Leclerc F. Noradrenaline use for septic shock in children: doses, routes of administration and complications. Acta Paediatr. 2012;101:e426-e430. doi: 10.1111/j.1651-2227.2012.02725.x

14. Deep A, Goonasekera CD, Wang Y, Brierley J. Evolution of haemodynamics and outcome of fluid-refractory septic shock in children. Intensive Care Med. 2013;39:1602-1609. doi: 10.1007/s00134-013-3003-z

15. Del Castillo J, López-Herce J, Cañadas S, Matamoros M, Rodríguez-NúnezA Rodríguez-Calvo A, Carrillo A; Iberoamerican Pediatric Cardiac Arrest Study Network RIBEPCI. Cardiac arrest and resuscitation in the pediatric intensive care unit: a prospective multicenter multinational study. Resuscitation. 2014;85:1380-1386. doi: 10.1016/j.resuscitation.2014.06.024

16. Menon K, Ward RE, Lawson ML, Gaboury I, Hutchison JS, Hébert PC Canadian Critical Care Trials Group. A prospective multicenter study of adrenal function in critically ill children. Am J Respir Crit Care Med. 2010;182:246-251. doi: 10.1164/rccm.200911-17380C

17. El-Nawawy A, Khater D, Omar H, Wali Y. Evaluation of Early Corticosteroid Therapy in Management of Pediatric Septic Shock in Pediatric Intensive Care Patients: A Randomized Clinical Study. Pediatr Infect Dis J. 2017:36:155-159. doi: 10.1097/INF.0000000000001380

18. Wong HR, Atkinson SJ, Cvijanovich NZ, Anas N, Allen GL, Thomas NJ, Bigham MT, Weiss SL, Fitzgerald JC, Checchia PA, et al. Combining prognostic and predictive enrichment strategies to identify children with septic shock responsive to corticosteroids. Crit Care Med. 2016;44:e1000 e1003. doi: 10.1097/CCM.0000000000001833

19. Wong HR, Cvijanovich NZ, Anas N, Allen GL, Thomas NJ, Bigham MT, Weiss SL, Fitzgerald JC, Checchia PA, Meyer K, et al. Endotype transitions during the acute phase of pediatric septic shock reflect changing risk and treatment response. Crit Care Med. 2018;46:e242-e249. doi 10.1097/CCM.0000000000002932
20. Menon K, McNally D, Choong K, Sampson M. A systematic review and meta-analysis on the effect of steroids in pediatric shock. Pediatr Crit Care Med. 2013;14:474-480. doi: 10.1097/PCC.0b013e31828a8125

21. Hussmann $B$, Lefering $R$, Kauther MD, Ruchholtz $S$, Moldzio $P$, Lendemans S; and the TraumaRegister DGU. Influence of prehospital volume replacement on outcome in polytraumatized children. Crit Care. 2012;16:R201. doi: 10.1186/cc11809

22. Acker SN, Ross JT, Partrick DA, DeWitt P, Bensard DD. Injured children are resistant to the adverse effects of early high volume crystalloid resuscitation. J Pediatr Surg. 2014;49:1852-1855. doi: 10.1016/j.jpedsurg.2014.09.034

23. Edwards MJ, Lustik MB, Clark ME, Creamer KM, Tuggle D. The effects of balanced blood component resuscitation and crystalloid administration in pediatric trauma patients requiring transfusion in Afghanistan and Iraq 2002 to 2012. J Trauma Acute Care Surg. 2015;78:330-335. doi: 10.1097/TA.0000000000000469

24. Coons BE, Tam S, Rubsam J, Stylianos S, Duron V. High volume crystalloid resuscitation adversely affects pediatric trauma patients. J Pediatr Surg 2018;53:2202-2208. doi: 10.1016/j.jpedsurg.2018.07.009

25. Elkbuli A, Zajd S, Ehrhardt JD Jr, McKenney M, Boneva D. Aggressive crystalloid resuscitation outcomes in low-severity pediatric trauma. J Surg Res. 2020;247:350-355. doi: 10.1016/j.jss.2019.10.009

26. Cannon JW, Khan MA, Raja AS, Cohen MJ, Como JJ, Cotton BA, Dubose JJ, Fox EE, Inaba K, Rodriguez CJ, Holcomb JB, Duchesne JC. Damage control resuscitation in patients with severe traumatic hemorrhage: A practice management guideline from the Eastern Association for the Surgery of Trauma. J Trauma Acute Care Surg. 2017;82:605-617. doi: 10.1097/TA.0000000000001333

27. Kanani AN, Hartshorn S. NICE clinical guideline NG39: Major trauma: assessment and initial management. Arch Dis Child Educ Pract Ed. 2017;102:20-23. doi: 10.1136/archdischild-2016-310869

28. Zhu H, Chen B, Guo C. Aggressive crystalloid adversely affects outcomes in a pediatric trauma population. Eur J Trauma Emerg Surg. 2019:Epub ahead of print. doi: 10.1007/s00068-019-01134-0

29. Henry S. ATLS Advanced Trauma Life Support. 10th Edition Student Course Manual. Chicago, IL: American College of Surgeons; 2018.

\section{TREATMENT OF RESPIRATORY FAILURE}

Respiratory failure occurs when a patient's breathing becomes inadequate and results in ineffective oxygenation and ventilation. This can occur due to disordered control of breathing, upper airway obstruction, lower airway obstruction, respiratory muscle failure, or parenchymal lung disease. Providing assisted ventilation when breathing is absent or inadequate, relieving foreign body airway obstruction (FBAO), and administering naloxone in opioid overdose can be lifesaving.

Suffocation (eg, FBAO) and poisoning are leading causes of death in infants and children. Balloons, foods (eg, hot dogs, nuts, grapes), and small household objects are the most common causes of FBAO in children, ${ }^{1-3}$ whereas liquids are common among infants. ${ }^{4}$ It is important to differentiate between mild FBAO (the patient is coughing and making sounds) and severe FBAO (the patient cannot make sounds). Patients with mild FBAO can attempt to clear the obstruction by coughing, but intervention is required in severe obstruction.

In the United States in 2017, opioid overdose caused 79 deaths in children less than 15 years old and 4094 deaths in people age 15 to 24 years. ${ }^{5}$ Naloxone reverses the respiratory depression of narcotic overdose, ${ }^{6}$ and, in 2014, the US Food and Drug Administration approved the use of a naloxone autoinjector by lay rescuers and 
healthcare providers. Naloxone intranasal delivery devices are also available.

\section{Treatment of Inadequate Breathing With a Pulse}

\begin{tabular}{|c|c|c|}
\hline \multicolumn{2}{|c|}{ Recommendations for Treatment of Inadequate Breathing With a Pulse } \\
\hline COR & LOE & Recommendations \\
\hline 1 & C-EO & $\begin{array}{r}\text { 1. For infants and children with a pulse but } \\
\text { absent or inadequate respiratory effort, } \\
\text { provide rescue breathing. }\end{array}$ \\
\hline 2a & C-EO & $\begin{array}{l}\text { 2. For infants and children with a pulse but } \\
\text { absent or inadequate respiratory effort, it is } \\
\text { reasonable to give } 1 \text { breath every } 2 \text { to } 3 \mathrm{~s} \\
\text { (20-30 breaths/min). }{ }^{7}\end{array}$ \\
\hline
\end{tabular}

\section{Recommendation-Specific Supportive Text}

1 and 2. There are no pediatric-specific clinical studies evaluating the effect of different ventilation rates on outcomes in inadequate breathing with a pulse. One multicenter observational study found that high ventilation rates (at least $30 / \mathrm{min}$ in children younger than 1 year of age, at least 25/min in children older than 1 year) during CPR with an advanced airway for cardiac arrest were associated with improved ROSC and survival. ${ }^{7}$ For the ease of training, the suggested respiratory rate for the patient with inadequate breathing and a pulse has been increased from 1 breath every 3 to 5 seconds to 1 breath every 2 to 3 seconds to be consistent with the new CPR guideline recommendation for ventilation in patients with an advanced airway.

\section{Foreign Body Airway Obstruction}

\begin{tabular}{|c|c|c|}
\hline \multicolumn{3}{|c|}{ Recommendations for Foreign Body Airway Obstruction } \\
\hline COR & LOE & Recommendations \\
\hline 1 & C-LD & $\begin{array}{l}\text { 1. If the child has mild FBAO, allow the victim to } \\
\text { clear the airway by coughing while observing } \\
\text { for signs of severe FBAO. } 4,8,9\end{array}$ \\
\hline 1 & C-LD & $\begin{array}{l}\text { 2. For a child with severe FBAO, perform } \\
\text { abdominal thrusts until the object is expelled } \\
\text { or the victim becomes unresponsive. } .^{4,8,9}\end{array}$ \\
\hline 1 & C-LD & $\begin{array}{l}\text { 3. For an infant with severe FBAO, deliver repeated } \\
\text { cycles of } 5 \text { back blows (slaps) followed by } 5 \\
\text { chest compressions until the object is expelled or } \\
\text { the victim becomes unresponsive., }{ }^{4,9-12}\end{array}$ \\
\hline 1 & C-LD & $\begin{array}{l}\text { 4. If the infant or child with severe FBAO } \\
\text { becomes unresponsive, start CPR beginning } \\
\text { with chest compressions (do not perform } \\
\text { pulse check). After } 2 \text { min of CPR, activate } \\
\text { the emergency response system if no one } \\
\text { has done so. }{ }^{11}\end{array}$ \\
\hline 1 & C-LD & $\begin{array}{l}\text { 5. For the infant or child with FBAO receiving } \\
\text { CPR, remove any visible foreign body when } \\
\text { opening the airway to provide breaths. }{ }^{13-15}\end{array}$ \\
\hline 3: Harm & C-LD & 6. Do not perform blind finger sweeps. ${ }^{13-15}$ \\
\hline
\end{tabular}

\section{Recommendation-Specific Supportive Text}

1 and 2. There are no high-quality data to support recommendations regarding $\mathrm{FBAO}$ in children. Many FBAOs are relieved by allowing the patient to cough or, if severe, are treated by bystanders using abdominal thrusts. ${ }^{4,8,9}$

3. Observational data primarily from case series support the use of back blows ${ }^{4,9,10}$ or chest compressions ${ }^{10,11}$ for infants. Abdominal thrusts are not recommended for infants given the potential to cause abdominal organ injury. ${ }^{12}$

4. Once the victim is unconscious, observational data support immediate provision of chest compressions whether or not the patient has a pulse. ${ }^{11}$

5 and 6 . Observational data suggest that the risk of blind finger sweeps outweighs any potential benefit in the management of FBAO. ${ }^{13-15}$

\section{Opioid-Related Respiratory and Cardiac Arrest}

Recommendations for Opioid-Related Respiratory and Cardiac Arrest

\begin{tabular}{|c|c|c|}
\hline COR & LOE & Recommendations \\
\hline 1 & C-LD & $\begin{array}{l}\text { 1. For patients in respiratory arrest, rescue } \\
\text { breathing or bag-mask ventilation should } \\
\text { be maintained until spontaneous breathing } \\
\text { returns, and standard pediatric basic or } \\
\text { advanced life support measures should } \\
\text { continue if return of spontaneous breathing } \\
\text { does not occur. }{ }^{17,18}\end{array}$ \\
\hline 1 & C-EO & $\begin{array}{l}\text { 2. For patients known or suspected to be in } \\
\text { cardiac arrest, in the absence of a proven } \\
\text { benefit from the use of naloxone, standard } \\
\text { resuscitative measures should take priority over } \\
\text { naloxone administration, with a focus on high- } \\
\text { quality CPR (compressions plus ventilation). } .^{19,20}\end{array}$ \\
\hline 1 & C-EO & $\begin{array}{l}\text { 3. Lay and trained responders should not delay } \\
\text { activating emergency response systems while } \\
\text { awaiting the patient's response to naloxone or } \\
\text { other interventions. } .^{21,22}\end{array}$ \\
\hline $2 a$ & B-NR & $\begin{array}{l}\text { 4. For a patient with suspected opioid overdose } \\
\text { who has a definite pulse but no normal } \\
\text { breathing or only gasping (ie, a respiratory } \\
\text { arrest), in addition to providing standard } \\
\text { pediatric basic life support or advanced } \\
\text { life support, it is reasonable for responders } \\
\text { to administer intramuscular or intranasal } \\
\text { naloxone. }{ }^{23-36}\end{array}$ \\
\hline
\end{tabular}

\section{Recommendation-Specific Supportive Text}

1. Initial management should focus on support of the patient's airway and breathing. This begins with opening the airway followed by delivery of rescue breaths, ideally with the use of a bag-mask or barrier device. ${ }^{17,18}$ Provision of life support should continue if return of spontaneous breathing does not occur.

2. Because there are no studies demonstrating improvement in patient outcomes from administration of naloxone during cardiac arrest, provision of 


\section{Opioid-Associated Emergency for Lay Responders Algorithm}

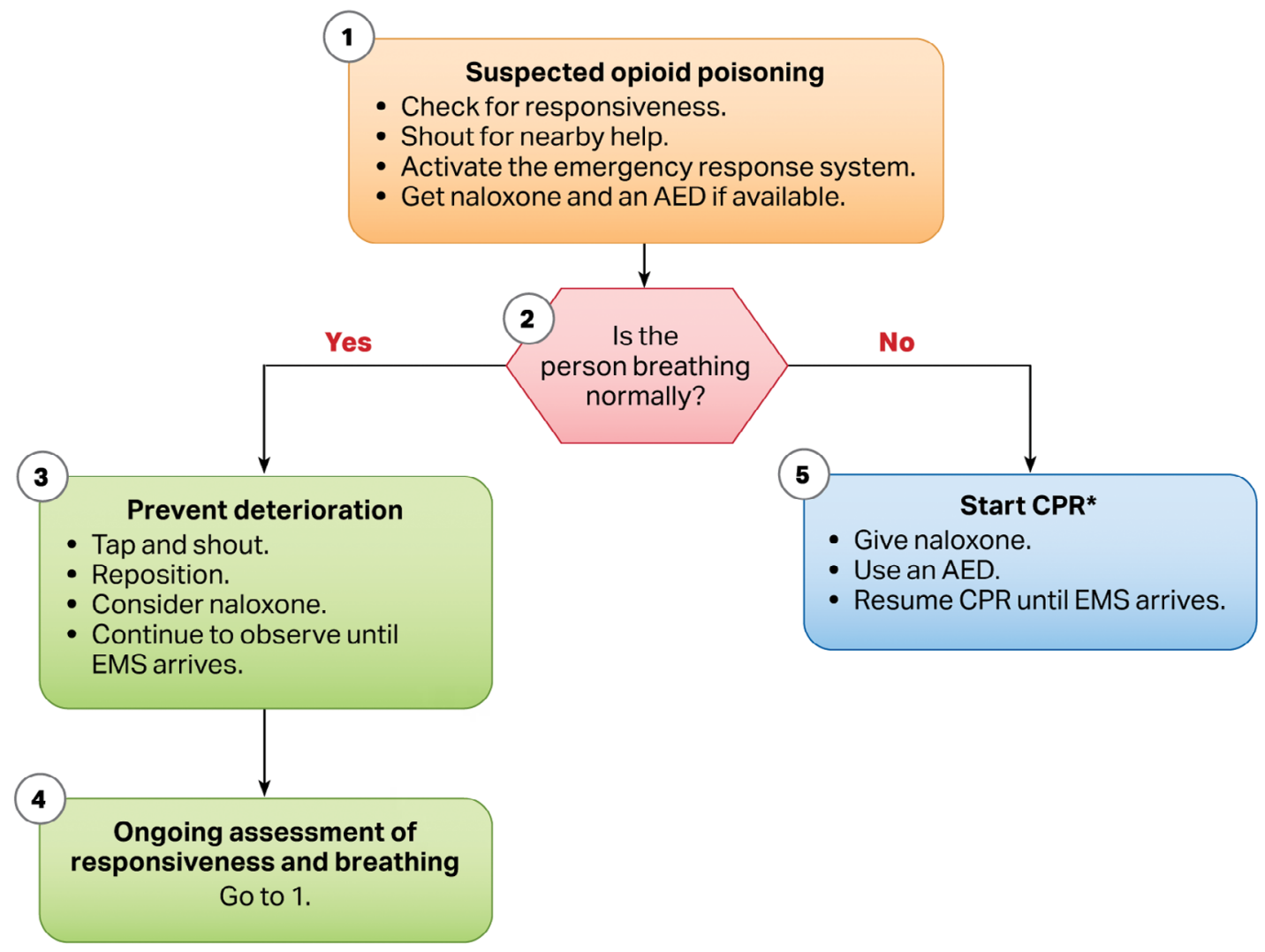

*For adult and adolescent victims, responders should perform compressions and rescue breaths for opioid-associated emergencies if they are trained and perform Hands-Only CPR if not trained to perform rescue breaths. For infants and children, CPR should include compressions with rescue breaths.

(C) 2020 American Heart Association

Figure 10. Opioid-Associated Emergency for Lay Responders Algorithm.

AED indicates automated external defibrillator; CPR, cardiopulmonary resuscitation; and EMS, emergency medical services.

CPR should be the focus of initial care. ${ }^{20}$ Naloxone can be administered along with standard advanced cardiovascular life support care if it does not delay components of high-quality CPR.

3. Early activation of the emergency response system is critical for patients with suspected opioid overdose. Rescuers cannot be certain that the person's clinical condition is due to opioid-induced respiratory depression alone. This is particularly true in first aid and BLS, where determination of the presence of a pulse is unreliable. ${ }^{21,22}$ Naloxone is ineffective in other medical conditions, including overdose involving nonopioids and cardiac arrest from any cause. Patients who respond to naloxone administration may develop recurrent central nervous system and/ or respiratory depression and require longer periods of observation before safe discharge. ${ }^{37-40}$

4. Twelve studies examined the use of naloxone in respiratory arrest, of which 5 compared intramuscular, intravenous, and/or intranasal routes of naloxone administration (2 RCT 23,24 and 3 non-RCT ${ }^{25-27}$ ) and 9 assessed the safety of naloxone use or were observational studies of naloxone use. ${ }^{28-36}$ These studies report that naloxone is safe and effective in treatment of opioid-induced respiratory depression and that complications are rare and dose related.

These recommendations were taken from Part 3: Adult Basic and Advanced Life Support ${ }^{41}$ and further supported by a 2020 ILCOR evidence update..$^{42}$ There were no pediatric data supporting these recommendations; however, due to the urgency of the opioid crisis, the adult recommendations should be applied to children.

Figures 10 and 11 are algorithms for opioid-associated emergencies for lay responders and healthcare providers.

\section{REFERENCES}

1. Morley RE, Ludemann JP, Moxham JP, Kozak FK, Riding KH. Foreign body aspiration in infants and toddlers: recent trends in British Columbia. J Otolaryngol. 2004;33:37-41. doi: 10.2310/7070.2004.00310 


\section{Opioid-Associated Emergency for Healthcare Providers Algorithm}

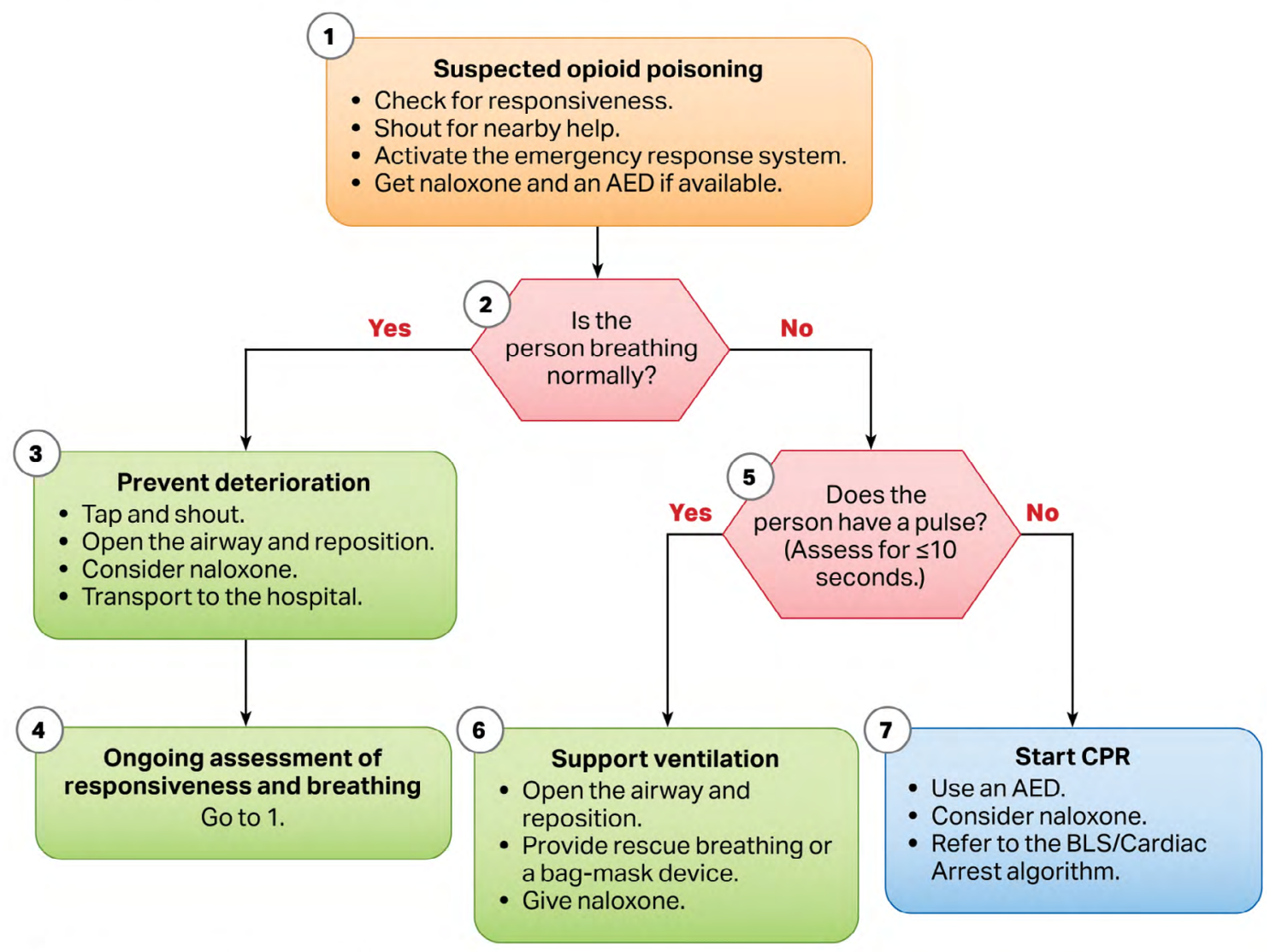

(c) 2020 American Heart Association

Figure 11. Opioid-Associated Emergency for Healthcare Providers Algorithm.

AED indicates automated external defibrillator; BLS, basic life support; and CPR, cardiopulmonary resuscitation.

2. Harris CS, Baker SP, Smith GA, Harris RM. Childhood asphyxiation by food A national analysis and overview. JAMA. 1984;251:2231-2235.

3. Rimell FL, Thome A Jr, Stool S, Reilly JS, Rider G, Stool D, Wilson CL. Characteristics of objects that cause choking in children. JAMA. 1995;274:17631766.

4. Vilke GM, Smith AM, Ray LU, Steen PJ, Murrin PA, Chan TC. Airway obstruction in children aged less than 5 years: the prehospital experience. Prehosp Emerg Care. 2004;8:196-199. doi: 10.1016/j.prehos.2003.12.014

5. Scholl L, Seth P, Kariisa M, Wilson N, Baldwin G. Drug and opioid-involved overdose deaths-United States, 2013-2017. MMWR Morb Mortal Wkly Rep. 2018;67:1419-1427. doi: 10.15585/mmwr.mm675152e1

6. Fischer CG, Cook DR. The respiratory and narcotic antagonistic effects of naloxone in infants. Anesth Analg. 1974;53:849-852. doi: 10.1213/00000539-197453060-00007

7. Sutton RM, ReederRW, LandisWP, MeertKL, YatesAR, Morgan RW, Berger JT, Newth CJ, Carcillo JA, McQuillen PS, Harrison RE, Moler FW, Pollack MM, Carpenter TC, Notterman DA, Holubkov R, Dean JM, Nadkarni VM, Berg RA; Eunice Kennedy Shriver National Institute of Child Health and Human Development Collaborative Pediatric Critical Care Research Network (CPCCRN). Ventilation Rates and Pediatric In-Hospital Cardiac Arrest Survival Outcomes. Crit Care Med. 2019;47:1627-1636. doi: 10.1097/CCM.0000000000003898

8. Heimlich HJ. A life-saving maneuver to prevent food-choking. JAMA 1975;234:398-401.

9. Sternbach G, Kiskaddon RT. Henry Heimlich: a life-saving maneuver for food choking. J Emerg Med. 1985;3:143-148. doi: 10.1016/0736-4679(85)90047-2

10. Redding JS. The choking controversy: critique of evidence on the Heimlich maneuver. Crit Care Med. 1979;7:475-479.
11. Kinoshita K, Azuhata T, Kawano D, Kawahara Y. Relationships between pre-hospital characteristics and outcome in victims of foreign body airway obstruction during meals. Resuscitation. 2015;88:63-67. doi: 10.1016/j.resuscitation.2014.12.018

12. Lee SL, Kim SS, Shekherdimian S, Ledbetter DJ. Complications as a result of the Heimlich maneuver. J Trauma. 2009;66:E34-E35. doi: 10.1097/01.ta.0000219291.27245.90

13. Abder-Rahman HA. Infants choking following blind finger sweep. J Pediatr (Rio J). 2009;85:273-275. doi: 10.2223/JPED.1892

14. Hartrey R, Bingham RM. Pharyngeal trauma as a result of blind finger sweeps in the choking child. J Accid Emerg Med. 1995;12:52-54. doi: 10.1136/emj.12.1.52

15. Kabbani M, Goodwin SR. Traumatic epiglottis following blind finger sweep to remove a pharyngeal foreign body. Clin Pediatr (Phila). 1995;34:495497. doi: $10.1177 / 000992289503400908$

16. Deleted in proof

17. Guildner CW. Resuscitation-opening the airway: a comparative study of techniques for opening an airway obstructed by the tongue. JACEP. 1976;5:588-590. doi: 10.1016/s0361-1124(76)80217-1

18. Wenzel V, Keller C, Idris AH, Dörges V, Lindner KH, Brimacombe JR. Effects of smaller tidal volumes during basic life support ventilation in patients with respiratory arrest: good ventilation, less risk? Resuscitation. 1999;43:25-29. doi: 10.1016/s0300-9572(99)00118-5

19. Saybolt MD, Alter SM, Dos Santos F, Calello DP, Rynn KO, Nelson DA, Merlin MA. Naloxone in cardiac arrest with suspected opioid overdoses. Resuscitation. 2010;81:42-46. doi: 10.1016/j.resuscitation.2009.09.016

20. Dezfulian C, Orkin AM, Maron BA, Elmer J, Girota S, Gladwin MT, Merchant RM, Panchal AR, Perman SM, Starks M, et al; on behalf of the American Heart Association Council on Cardiopulmonary, Critical Care, 
Perioperative and Resuscitation; Council on Arteriosclerosis, Thrombosis and Vascular Biology; Council on Cardiovascular and Stroke Nursing; and Council on Clinical Cardiology. Opioid-associated out-of-hospital cardiac arrest: distinctive clinical features and implications for healthcare and public responses: a scientific statement from the American Heart Association. Circulation. In press.

21. Bahr J, Klingler H, Panzer W, Rode H, Kettler D. Skills of lay people in checking the carotid pulse. Resuscitation. 1997;35:23-26. doi 10.1016/s0300-9572(96)01092-1

22. Eberle B, Dick WF, Schneider T, Wisser G, Doetsch S, Tzanova I. Checking the carotid pulse check: diagnostic accuracy of first responders in patients with and without a pulse. Resuscitation. 1996;33:107-116. doi 10.1016/s0300-9572(96)01016-7

23. Kelly AM, Kerr D, Dietze P, Patrick I, Walker T, Koutsogiannis Z. Randomised trial of intranasal versus intramuscular naloxone in prehospital treatment for suspected opioid overdose. Med J Aust. 2005;182:24-27.

24. Kerr D, Kelly AM, Dietze P, Jolley D, Barger B. Randomized controlled trial comparing the effectiveness and safety of intranasal and intramuscular naloxone for the treatment of suspected heroin overdose. Addiction. 2009;104:2067-2074. doi: 10.1111/j.1360-0443.2009.02724.x

25. Wanger K, Brough L, Macmillan I, Goulding J, MacPhail I, Christenson JM Intravenous vs subcutaneous naloxone for out-of-hospital management of presumed opioid overdose. Acad Emerg Med. 1998;5:293-299. doi: 10.1111/j.1553-2712.1998.tb02707.x

26. Barton ED, Colwell CB, Wolfe T, Fosnocht D, Gravitz C, Bryan T, Dunn W, Benson J, Bailey J. Efficacy of intranasal naloxone as a needleless alternative for treatment of opioid overdose in the prehospital setting. J Emerg Med. 2005;29:265-271. doi: 10.1016/j.jemermed.2005.03.007

27. Robertson TM, Hendey GW, Stroh G, Shalit M. Intranasal naloxone is a viable alternative to intravenous naloxone for prehospital narcotic overdose. Prehosp Emerg Care. 2009;13:512-515. doi: 10.1080/10903120903144866

28. Cetrullo C, Di Nino GF, Melloni C, Pieri C, Zanoni A. [Naloxone antagonism toward opiate analgesic drugs. Clinical experimental study]. Minerva Anestesiol. 1983;49:199-204

29. Osterwalder JJ. Naloxone-for intoxications with intravenous heroin and heroin mixtures-harmless or hazardous? A prospective clinical study. J Toxicol Clin Toxicol. 1996;34:409-416. doi: 10.3109/15563659609013811

30. Sporer KA, Firestone J, Isaacs SM. Out-of-hospital treatment of opioid overdoses in an urban setting. Acad Emerg Med. 1996;3:660-667. doi: 10.1111/j.1553-2712.1996.tb03487.x

31. Stokland O, Hansen TB, Nilsen JE. [Prehospital treatment of heroin intoxication in Oslo in 1996]. Tidsskr Nor Laegeforen. 1998;118:3144-3146.

32. Buajordet I, Naess AC, Jacobsen D, Brørs O. Adverse events after naloxone treatment of episodes of suspected acute opioid overdose. Eur J Emerg Med. 2004;11:19-23. doi: 10.1097/00063110-200402000-00004

33. Cantwell K, Dietze $P$, Flander $L$. The relationship between naloxone dose and key patient variables in the treatment of non-fatal heroin overdose in the prehospital setting. Resuscitation. 2005;65:315-319. doi 10.1016/j.resuscitation.2004.12.012

34. Boyd JJ, Kuisma MJ, Alaspää AO, Vuori E, Repo JV, Randell TT. Recurrent opioid toxicity after pre-hospital care of presumed heroin overdose patients. Acta Anaesthesiol Scand. 2006;50:1266-1270. doi: 10.1111/j.13996576.2006.01172.x

35. Nielsen K, Nielsen SL, Siersma V, Rasmussen LS. Treatment of opioid overdose in a physician-based prehospital EMS: frequency and long-term prognosis. Resuscitation. 2011;82:1410-1413. doi: 10.1016/j.resuscitation.2011.05.027

36. Wampler DA, Molina DK, McManus J, Laws P, Manifold CA. No deaths associated with patient refusal of transport after naloxonereversed opioid overdose. Prehosp Emerg Care. 2011;15:320-324. doi 10.3109/10903127.2011.569854

37. Clarke SF, Dargan PI, Jones AL. Naloxone in opioid poisoning: walking the tightrope. Emerg Med J. 2005;22:612-616. doi: 10.1136/emj. 2003.009613

38. Etherington J, Christenson J, Innes G, Grafstein E, Pennington S, Spinelli JJ, Gao M, Lahiffe B, Wanger K, Fernandes C. Is early discharge safe after naloxone reversal of presumed opioid overdose? CJEM. 2000;2:156-162. doi: $10.1017 / \mathrm{s} 1481803500004863$

39. Zuckerman M, Weisberg SN, Boyer EW. Pitfalls of intranasal naloxone Prehosp Emerg Care. 2014;18:550-554. doi: 10.3109/10903127. 2014.896961
40. Heaton JD, Bhandari B, Faryar KA, Huecker MR. Retrospective Review of Need for Delayed Naloxone or Oxygen in Emergency Department Patients Receiving Naloxone for Heroin Reversal. J Emerg Med. 2019;56:642-651. doi: 10.1016/j.jemermed.2019.02.015

41. Panchal AR, Bartos JA, Cabañas JG, Donnino MW, Drennan IR, Hirsch KG, Kudenchuk PJ, Kurz MC, Lavonas EJ, Morley PT, et al; on behalf of the Adult Basic and Advanced Life Support Writing Group. Part 3: adult basic and advanced life support: 2020 American Heart Association Guidelines for Cardiopulmonary Resuscitation and Emergency Cardiovascular Care. Circulation. 2020;142(suppl 2):S366-\$468 doi: 10.1161/ CIR.0000000000000916

42. Olasveengen TM, Mancini ME, Perkins GD, Avis S, Brooks S, Castrén M, Chung SP, Considine J, Couper K, Escalante R, et al; on behalf of the Adult Basic Life Support Collaborators. Adult basic life support: 2020 International Consensus on Cardiopulmonary Resuscitation and Emergency Cardiovascular Care Science With Treatment Recommendations. Circulation. 2020;142(suppl 1):S41-S91. doi: 10.1161/CIR.0000000000000892

\section{INTUBATION}

It is important to select appropriate equipment and medications for pediatric intubation. Uncuffed ETTs were historically preferred for young children because the normal pediatric airway narrows below the vocal cords, creating an anatomic seal around the distal tube. In the acute setting and with poor pulmonary compliance, uncuffed ETTs may need to be changed to cuffed ETTS. Cuffed tubes improve capnography accuracy, reduce the need for ETT changes (resulting in high-risk reintubations or delayed compressions), and improve pressure and tidal volume delivery. However, high pressure in the cuff can cause airway mucosal damage. Although several studies have identified that cuffed tube use may actually decrease airway trauma by decreasing tube changes, attention must be made to selecting the correct tube size and cuff inflation pressure. ${ }^{1}$ ETT cuff pressures are dynamic during transport at altitude ${ }^{2}$ and with increasing airway edema.

Intubation is a high-risk procedure. Depending on the patient's hemodynamics, respiratory mechanics, and airway status, the patient can be at increased risk for cardiac arrest during intubation. Therefore, it is important to provide adequate resuscitation before intubation.

Cricoid pressure during bag-mask ventilation and intubation has historically been used to minimize the risk of gastric contents refluxing into the airway, but there are concerns that tracheal compression may impede effective bag-mask ventilation and intubation success.

Confirmation of ETT placement in patients with a perfusing rhythm is not reliably achieved by auscultation of breath sounds, mist in the tube, or chest rise. Either colorimetric detector or capnography $\left(\mathrm{ETCO}_{2}\right)$ can be used to assess initial ETT placement. In patients with decreased pulmonary blood flow from low cardiac output or cardiac arrest, $\mathrm{ETCO}_{2}$ may not be as reliable. 


\section{Use of Cuffed Endotracheal Tubes for Intubation}

\begin{tabular}{|c|c|c|}
\hline COR & LOE & Recommendations \\
\hline 1 & C-EO & $\begin{array}{l}\text { 1. When a cuffed ETT is used, attention should } \\
\text { be paid to ETT size, position, and cuff inflation } \\
\text { pressure (usually }<20-25 \mathrm{~cm} \mathrm{H}_{2} \mathrm{O} \text { ). }{ }^{3}\end{array}$ \\
\hline $2 a$ & C-LD & $\begin{array}{l}\text { 2. It is reasonable to choose cuffed ETTs over } \\
\text { uncuffed ETTs for intubating infants and } \\
\text { children. }{ }^{4-15}\end{array}$ \\
\hline
\end{tabular}

Recommendation-Specific Supportive Text

1. A retrospective study including 2953 children noted that, with $25 \mathrm{~cm} \mathrm{H}_{2} \mathrm{O}$ of pressure to the airway and a slight leak around the ETT, there were no cases of clinically significant subglottic stenosis, and the incidence of stridor requiring reintubation was less than $1 \%{ }^{3}$

2. Three systematic reviews, 2 randomized controlled trials, and 2 retrospective reviews support the safety of cuffed ETTs and the decreased need for ETT changes. ${ }^{4-10}$ These studies were almost entirely performed in the perioperative patient population, and intubation was performed by highly skilled airway providers. Thus, ETT duration may have been shorter than in critically ill patients. The use of cuffed ETTs is associated with lower reintubation rates, more successful ventilation, and improved accuracy of capnography without increased risk of complications., ${ }^{7,-13}$ Cuffed ETTs may decrease the risk of aspiration. ${ }^{14,15}$

\section{The Use of Cricoid Pressure During Intubation}

\begin{tabular}{|c|c|c|}
\hline \multicolumn{2}{|c|}{ Recommendations for the Use of Cricoid Pressure During Intubation } \\
\hline COR & LOE & Recommendations \\
\hline 2b & C-LD & $\begin{array}{l}\text { 1. Cricoid pressure during bag-mask ventilation } \\
\text { may be considered to reduce gastric } \\
\text { insufflation. }{ }^{16,17}\end{array}$ \\
\hline $\begin{array}{c}\text { 3: No } \\
\text { Benefit }\end{array}$ & C-LD & $\begin{array}{l}\text { 2. Routine use of cricoid pressure is not } \\
\text { recommended during endotracheal intubation } \\
\text { of pediatric patients. }{ }^{16,17}\end{array}$ \\
\hline 3: Harm & C-LD & $\begin{array}{l}\text { 3. If cricoid pressure is used, discontinue if it } \\
\text { interferes with ventilation or the speed or } \\
\text { ease of intubation. }{ }^{16,17}\end{array}$ \\
\hline
\end{tabular}

\section{Recommendation-Specific Supportive Text}

1,2 , and 3. A retrospective, propensity score-matched study from a large pediatric ICU intubation registry showed that cricoid pressure during induction and bag-mask ventilation before tracheal intubation was not associated with lower rates of regurgitation. ${ }^{17}$ A study from the same pediatric ICU database reported external laryngeal manipulation was associated with lower initial tracheal intubation success. ${ }^{16}$

\section{Atropine Use for Intubation}

\begin{tabular}{|c|c|c|}
\hline \multicolumn{2}{|c|}{ Recommendations for Atropine Use for Intubation } \\
\hline COR & LOE & Recommendations \\
\hline 2b & C-LD & $\begin{array}{l}\text { 1. It may be reasonable for practitioners to } \\
\text { use atropine as a premedication to prevent } \\
\text { bradycardia during emergency intubations } \\
\text { when there is higher risk of bradycardia (eg, } \\
\text { when giving succinylcholine). }{ }^{18,19}\end{array}$ \\
\hline 2b & C-LD & $\begin{array}{l}\text { 2. When atropine is used as a premedication for } \\
\text { emergency intubation, a dose of 0.02 mg/kg } \\
\text { of atropine, with no minimum dose, may be } \\
\text { considered. }{ }^{20}\end{array}$ \\
\hline
\end{tabular}

\section{Recommendation-Specific Supportive Text}

1. The 2019 French Society of Anesthesia and Intensive Care Medicine guidelines state that atropine "should probably" be used as a preintubation drug in children 28 days to 8 years with septic shock, with hypovolemia, or with succinylcholine administration. 18,19

2. One nonrandomized, single-center intervention study did not identify an association between atropine dosing less than $0.1 \mathrm{mg}$ and bradycardia or arrhythmias. ${ }^{20}$

\section{Monitoring Exhaled $\mathrm{CO}_{2}$ in Patients With Advanced Airways}

\begin{tabular}{|c|c|c|}
\hline COR & LOE & Recommendations \\
\hline 1 & C-LD & $\begin{array}{l}\text { 1. In all settings, for infants and children with a } \\
\text { perfusing rhythm, use exhaled } \mathrm{CO}_{2} \text { detection } \\
\text { (colorimetric detector or capnography) for } \\
\text { confirmation of ETT placement. }{ }^{21-27}\end{array}$ \\
\hline $2 a$ & C-LD & $\begin{array}{l}\text { 2. In infants and children with a perfusing } \\
\text { rhythm, it is beneficial to monitor exhaled } \\
\mathrm{CO}_{2} \text { (colorimetric detector or capnography) } \\
\text { during out-of-hospital and intra/interhospital } \\
\text { transport. }{ }^{21,22,28-30}\end{array}$ \\
\hline
\end{tabular}

\section{Recommendation-Specific Supportive Text}

1. Although there are no randomized controlled trials linking use of $\mathrm{ETCO}_{2}$ detection with clinical outcomes, the Fourth National Audit Project of the Royal College of Anesthetists and Difficult Airway Society concluded that the failure to use or inability to properly interpret capnography contributed to adverse events, including ICU-related deaths (mixed adult and pediatric data). ${ }^{21,22}$ One small randomized study showed that capnography was faster than clinical assessment in premature newborns intubated in the delivery room. ${ }^{23}$ There was no difference in patient outcomes between qualitative (colorimetric) and quantitative (capnography or numeric display) $\mathrm{ETCO}_{2}$ detectors. ${ }^{24-27}$

2. Adult literature suggests monitoring and correct interpretation of capnography in intubated patients may prevent adverse events. 21,22,28 This 
has been demonstrated in simulated pediatric scenarios, in which capnography increased provider recognition of possible ETT dislodgement. ${ }^{29,30}$

\section{REFERENCES}

1. Tobias JD. Pediatric airway anatomy may not be what we thought: implications for clinical practice and the use of cuffed endotracheal tubes. Paediatr Anaesth. 2015;25:9-19. doi: 10.1111/pan.12528

2. Orsborn J, Graham J, Moss M, Melguizo M, Nick T, Stroud M. Pediatric Endotracheal Tube Cuff Pressures During Aeromedical Transport. Pediatr Emerg Care. 2016;32:20-22. doi: 10.1097/PEC.0000000000000365

3. Black AE, Hatch DJ, Nauth-Misir N. Complications of nasotracheal intubation in neonates, infants and children: a review of 4 years' experience in a children's hospital. Br J Anaesth. 1990;65:461-467. doi: 10.1093/bja/65.4.461

4. Chen L, Zhang J, Pan G, Li X, Shi T, He W. Cuffed versus uncuffed endotracheal tubes in pediatrics: a meta-analysis. Open Med (Wars) 2018;13:366-373. doi: 10.1515/med-2018-0055

5. Shi F, Xiao Y, Xiong W, Zhou Q, Huang X. Cuffed versus uncuffed endotracheal tubes in children: a meta-analysis. J Anesth. 2016;30:3-11. doi: 10.1007/s00540-015-2062-4

6. De Orange FA, Andrade RG, Lemos A, Borges PS, Figueiroa JN, Kovatsis PG. Cuffed versus uncuffed endotracheal tubes for general anaesthesia in children aged eight years and under. Cochrane Database Syst Rev. 2017;11:CD011954. doi: 10.1002/14651858.CD011954.pub2

7. Chambers NA, Ramgolam A, Sommerfield D, Zhang G, Ledowski T, Thurm M, Lethbridge M, Hegarty M, von Ungern-Sternberg BS. Cuffed vs. uncuffed tracheal tubes in children: a randomised controlled trial comparing leak, tidal volume and complications. Anaesthesia. 2018;73:160-168. doi: 10.1111/anae.14113

8. de Wit M, Peelen LM, van Wolfswinkel L, de Graaff JC. The incidence of postoperative respiratory complications: A retrospective analysis of cuffed vs uncuffed tracheal tubes in children 0-7 years of age. Paediatr Anaesth 2018;28:210-217. doi: 10.1111/pan.13340

9. Schweiger C, Marostica PJ, Smith MM, Manica D, Carvalho PR, Kuhl G. Incidence of post-intubation subglottic stenosis in children: prospective study. J Laryngol Otol. 2013;127:399-403. doi: 10.1017/S002221511300025X

10. Dorsey DP, Bowman SM, Klein MB, Archer D, Sharar SR. Perioperative use of cuffed endotracheal tubes is advantageous in young pediatric burn patients. Burns. 2010;36:856-860. doi: 10.1016/j.burns.2009.11.011

11. Khine $H H$, Corddry DH, Kettrick RG, Martin TM, McCloskey JJ, Rose JB, Theroux MC, Zagnoev M. Comparison of cuffed and uncuffed endotracheal tubes in young children during general anesthesia. Anesthesiology. 1997;86:627-31; discussion 27A. doi: 10.1097/00000542199703000-00015

12. Weiss M, Dullenkopf A, Fischer JE, Keller C, Gerber AC; European Paediatric Endotracheal Intubation Study Group. Prospective randomized controlled multi-centre trial of cuffed or uncuffed endotracheal tubes in small children. Br J Anaesth. 2009;103:867-873. doi: 10.1093/bja/aep290

13. James I. Cuffed tubes in children. Paediatr Anaesth. 2001;11:259-263. doi: 10.1046/j.1460-9592.2001.00675.x

14. Gopalareddy V, He Z, Soundar S, Bolling L, Shah M, Penfil S, McCloskey JJ, Mehta DI. Assessment of the prevalence of microaspiration by gastric pep$\sin$ in the airway of ventilated children. Acta Paediatr. 2008;97:55-60. doi: 10.1111/j.1651-2227.2007.00578.x

15. Browning DH, Graves SA. Incidence of aspiration with endotracheal tubes in children. J Pediatr. 1983;102:582-584. doi: 10.1016/s00223476(83)80191-7

16. Kojima T, Laverriere EK, Owen EB, Harwayne-Gidansky I, Shenoi AN, Napolitano N, Rehder KJ, Adu-Darko MA, Nett ST, Spear D, et al; and the National Emergency Airway Registry for Children (NEAR4KIDS) Collaborators and Pediatric Acute Lung Injury and Sepsis Investigators (PALISI). Clinical impact of external laryngeal manipulation during laryngoscopy on tracheal intubation success in critically ill children. Pediatr Crit Care Med. 2018;19:106-114. doi: 10.1097/PCC.0000000000001373

17. Kojima T, Harwayne-Gidansky I, Shenoi AN, Owen EB, Napolitano N, Rehder KJ, Adu-Darko MA, Nett ST, Spear D, Meyer K, Giuliano JS Jr, Tarquinio KM, Sanders RC Jr, Lee JH, Simon DW, Vanderford PA, Lee AY, Brown CAIII, Skippen PW, Breuer RK, Toedt-Pingell, Parsons SJ, Gradidge EA Glater LB, Culver K, Nadkarni VM, Nishisaki A; National Emergency Airway Registry for Children (NEAR4KIDS) and Pediatric Acute Lung Injury and Sepsis Investigators (PALISI). Cricoid Pressure During Induction for Tracheal
Intubation in Critically III Children: A Report From National Emergency Airway Registry for Children. Pediatr Crit Care Med. 2018;19:528-537. doi: 10.1097/PCC.0000000000001531

18. Quintard $H$, l'Her $E$, Pottecher J, Adnet $F$, Constantin JM, De Jong A, Diemunsch P, Fesseau R, Freynet A, Girault C, Guitton C, Hamonic Y, Maury E, Mekontso-Dessap A, Michel F, Nolent P, Perbet S, Prat G, Roquilly A, Tazarourte K, Terzi N, Thille AW, Alves M, Gayat E, Donetti L. Experts' guidelines of intubation and extubation of the ICU patient of French Society of Anaesthesia and Intensive Care Medicine (SFAR) and French-speaking Intensive Care Society (SRLF): In collaboration with the pediatric Association of French-speaking Anaesthetists and Intensivists (ADARPEF), French-speaking Group of Intensive Care and Paediatric emergencies (GFRUP) and Intensive Care physiotherapy society (SKR). Ann Intensive Care. 2019;9:13. doi: 10.1186/s13613-019-0483-1

19. Jones P, Ovenden N, Dauger S, Peters MJ. Estimating 'lost heart beats' rather than reductions in heart rate during the intubation of critically-ill children. PLoS One. 2014;9:e86766. doi: 10.1371/journal.pone.0086766

20. Eisa L, Passi Y, Lerman J, Raczka M, Heard C. Do small doses of atropine $(<0.1 \mathrm{mg})$ cause bradycardia in young children? Arch Dis Child. 2015;100:684-688. doi: 10.1136/archdischild-2014-307868

21. Cook TM, Woodall N, Harper J, Benger J; on behalf of the Fourth National Audit Project. Major complications of airway management in the UK: results of the Fourth National Audit Project of the Royal College of Anaesthetists and the Difficult Airway Society, part 2: intensive care and emergency departments. Br J Anaesth. 2011;106:632-642. doi: 10.1093/bja/aer059

22. Cook TM. Strategies for the prevention of airway complications - a narrative review. Anaesthesia. 2018;73:93-111. doi: 10.1111/anae.14123

23. Hosono S, Inami I, Fujita H, Minato M, Takahashi S, Mugishima H. A role of end-tidal $\mathrm{CO}(2)$ monitoring for assessment of tracheal intubations in very low birth weight infants during neonatal resuscitation at birth. J Perinat Med. 2009;37:79-84. doi: 10.1515/JPM.2009.017

24. Hawkes GA, Finn D, Kenosi M, Livingstone V, O'Toole JM, Boylan GB, O'Halloran KD, Ryan AC, Dempsey EM. A Randomized Controlled Trial of End-Tidal Carbon Dioxide Detection of Preterm Infants in the Delivery Room. J Pediatr. 2017;182:74-78.e2. doi: 10.1016/j.jpeds.2016.11.006

25. Hunt KA, Yamada Y, Murthy V, Srihari Bhat P, Campbell M, Fox GF, Milner AD, Greenough A. Detection of exhaled carbon dioxide following intubation during resuscitation at delivery. Arch Dis Child Fetal Neonatal Ed. 2019;104:F187-F191. doi: 10.1136/archdischild-2017-313982

26. Langhan ML, Emerson BL, Nett S, Pinto M, Harwayne-Gidansky I, Rehder KJ, Krawiec C, Meyer K, Giuliano JS Jr, Owen EB, Tarquinio KM, Sanders RC Jr, ShepherdM, Bysani GK, ShenoiAN, NapolitanoN, GangadharanS, ParsonsSJ, Simon DW, Nadkarni VM, Nishisaki A; for Pediatric Acute Lung Injury and Sepsis Investigators (PALISI) and National Emergency Airway Registry for Children (NEAR4KIDS) Investigators. End-Tidal Carbon Dioxide Use for Tracheal Intubation: Analysis From the National Emergency Airway Registry for Children (NEAR4KIDS) Registry. Pediatr Crit Care Med. 2018;19:98105. doi: 10.1097/PCC.0000000000001372

27. Hawkes GA, Kenosi M, Ryan CA, Dempsey EM. Quantitative or qualitative carbon dioxide monitoring for manual ventilation: a mannequin study. Acta Paediatr. 2015;104:e148-e151. doi: 10.1111/apa.12868

28. Fanara B, Manzon C, Barbot O, Desmettre T, Capellier G. Recommendations for the intra-hospital transport of critically ill patients. Crit Care. 2010;14:R87. doi: 10.1186/cc9018

29. Langhan ML, Ching K, Northrup V, Alletag M, Kadia P, Santucci K, Chen L. A randomized controlled trial of capnography in the correction of simulated endotracheal tube dislodgement. Acad Emerg Med. 2011;18:590596. doi: 10.1111/j.1553-2712.2011.01090.x

30. Langhan ML, Auerbach M, Smith AN, Chen L. Improving detection by pediatric residents of endotracheal tube dislodgement with capnography: a randomized controlled trial. J Pediatr. 2012;160:1009-14.e1. doi: 10.1016/j.jpeds.2011.12.012

\section{MANAGEMENT OF BRADYCARDIA}

Bradycardia associated with hemodynamic compromise, even with a palpable pulse, may be a harbinger for cardiac arrest. As such, bradycardia with a heart rate of less than 60 beats per minute requires emergent evaluation for cardiopulmonary compromise. If cardiopulmonary compromise is present, the initial management in the 
pediatric patient requires simultaneous assessment of the etiology and treatment by supporting airway, ventilation, and oxygenation. If bradycardia with cardiopulmonary compromise is present despite effective oxygenation and ventilation, CPR should be initiated immediately. Outcomes are better for children who receive CPR for bradycardia before progressing to pulseless arrest. ${ }^{1}$ Correctable factors that contribute to bradycardia (ie, hypoxia, hypotension, hypoglycemia, hypothermia, acidosis, or toxic ingestions) should be identified and treated immediately.

\section{Recommendations for the Management of Bradycardia}

\begin{tabular}{|c|c|c|}
\hline COR & LOE & Recommendations \\
\hline 1 & C-LD & $\begin{array}{l}\text { 1. If bradycardia is due to increased vagal tone } \\
\text { or primary atrioventricular conduction block } \\
\text { (ie, not secondary to factors such as hypoxia), } \\
\text { give atropine. }{ }^{2,4,6,7}\end{array}$ \\
\hline 1 & C-LD & $\begin{array}{l}\text { 2. If the heart rate is }<60 \text { beats/min with } \\
\text { cardiopulmonary compromise despite } \\
\text { effective ventilation with oxygen, start CPR. } .^{1,10}\end{array}$ \\
\hline 1 & C-EO & $\begin{array}{l}\text { 3. If bradycardia persists after correction of } \\
\text { other factors (eg, hypoxia) or responds only } \\
\text { transiently, give epinephrine IV/IO. If IV/IO } \\
\text { access is not available, give endotracheally if } \\
\text { present. }{ }^{1,11}\end{array}$ \\
\hline $2 b$ & C-LD & $\begin{array}{l}\text { 4. Emergency transcutaneous pacing may be } \\
\text { considered if bradycardia is due to complete } \\
\text { heart block or sinus node dysfunction } \\
\text { unresponsive to ventilation, oxygenation, } \\
\text { chest compressions, and medications, } \\
\text { especially in children with congenital or } \\
\text { acquired heart disease. }{ }^{12-16}\end{array}$ \\
\hline
\end{tabular}

\section{Recommendation-Specific Supportive Text}

1. Two adult studies ${ }^{2,4}$ and 2 pediatric studies ${ }^{6,7}$ demonstrate that atropine is effective to treat bradycardia due to vagal stimulation, atrioventricular block, and intoxication. There is no evidence that atropine should be used for bradycardia due to other causes.

2. Two retrospective analyses from the same database showed children who received CPR for bradycardia and poor perfusion had better outcomes than children who suffered pulseless cardiac arrest and received CPR. ${ }^{1,10}$ The longer the time between the initiation of CPR for bradycardia and the loss of a pulse, the lower the chance of survival.

3. There are limited pediatric data regarding the treatment of bradycardia. A recent retrospective, propensity-matched study of pediatric patients with bradycardia with a pulse found that patients who received epinephrine had worse outcomes than patients who did not receive epinephrine. ${ }^{11}$ However, due to limitations of the study, further research on the impact of epinephrine on patients with bradycardia and a pulse is required.

4. There are limited data about transcutaneous pacing for refractory bradycardia in children. ${ }^{12-16}$ In patients with complete heart block or sinus node dysfunction, especially when caused by congenital or acquired heart disease, emergency transcutaneous pacing may be considered. Pacing is not useful for asystole or bradycardia due to postarrest hypoxic or ischemic myocardial insult or respiratory failure.

Figure 12 shows the algorithm for pediatric bradycardia with a pulse.

\section{REFERENCES}

1. Khera R, Tang $Y$, Girotra S, Nadkarni VM, Link MS, Raymond TT, Guerguerian AM, Berg RA, Chan PS; on behalf of the American Heart Association's Get With the Guidelines-Resuscitation Investigators. Pulselessness after initiation of cardiopulmonary resuscitation for bradycardia in hospitalized children. Circulation. 2019;140:370-378. doi: 10.1161/CIRCULATIONAHA.118.039048

2. Smith I, Monk TG, White PF. Comparison of transesophageal atrial pacing with anticholinergic drugs for the treatment of intraoperative bradycardia. Anesth Analg. 1994;78:245-252. doi: 10.1213/00000539-199402000-00009

3. Deleted in proof

4. Brady WJ, Swart G, DeBehnke DJ, Ma OJ, Aufderheide TP. The efficacy of atropine in the treatment of hemodynamically unstable bradycardia and atrioventricular block: prehospital and emergency department considerations. Resuscitation. 1999;41:47-55. doi: 10.1016/s0300-9572(99)00032-5

5. Deleted in proof

6. Zimmerman G, Steward DJ. Bradycardia delays the onset of action of intravenous atropine in infants. Anesthesiology. 1986;65:320-322

7. Fullerton DA, St Cyr JA, Clarke DR, Campbell DN, Toews WH, See WM. Bezold-Jarisch reflex in postoperative pediatric cardiac surgical patients. Ann Thorac Surg. 1991;52:534-536. doi: 10.1016/0003-4975(91)90919-h

8. Deleted in proof

9. Deleted in proof

10. Donoghue A, Berg RA, Hazinski MF, Praestgaard AH, Roberts $K$, Nadkarni VM; American Heart Association National Registry of CPR Investigators. Cardiopulmonary resuscitation for bradycardia with poor perfusion versus pulseless cardiac arrest. Pediatrics. 2009;124:1541-1548. doi: 10.1542/peds.2009-0727

11. Holmberg MJ, Ross CE, Yankama T, Roberts JS, Andersen LW; on behalf of the American Heart Association's Get With The Guidelines-Resuscitation Investigators. Epinephrine in children receiving cardiopulmonary resuscitation for bradycardia with poor perfusion. Resuscitation. 2020:180-190. doi: 10.1016/j.resuscitation.2019.12.032

12. Pirasath S, Arulnithy K. Yellow oleander poisoning in eastern province: an analysis of admission and outcome. Indian J Med Sci. 2013;67:178-183. doi: 10.4103/0019-5359.125879

13. Singh HR, Batra AS, Balaji S. Pacing in children. Ann Pediatr Cardiol. 2013;6:46-51. doi: 10.4103/0974-2069.107234

14. Kugler JD, Danford DA. Pacemakers in children: an update. Am Heart J. 1989;117:665-679. doi: 10.1016/0002-8703(89)90743-6

15. Bolourchi M, Silver ES, Liberman L. Advanced heart block in children with Lyme disease. Pediatr Cardiol. 2019;40:513-517. doi: 10.1007/s00246018-2003-8

16. Nazif TM, Vazquez J, Honig LS, Dizon JM. Anti-N-methyl-D-aspartate receptor encephalitis: an emerging cause of centrally mediated sinus node dysfunction. Europace. 2012;14:1188-1194. doi: 10.1093/europace/eus014

\section{TACHYARRHYTHMIAS}

Regular, narrow-complex tachyarrhythmias (QRS duration 0.09 seconds or less) are most commonly caused by re-entrant circuits, although other mechanisms (eg, ectopic atrial tachycardia, atrial fibrillation) sometimes occur. Regular, wide-complex tachyarrhythmias (greater than 0.09 seconds) can have multiple mechanisms, including supraventricular tachycardia (SVT) with aberrant conduction or ventricular tachycardia.

The hemodynamic impact of SVT in the pediatric patient can be variable, with cardiovascular compromise 


\section{Pediatric Bradycardia With a Pulse Algorithm}

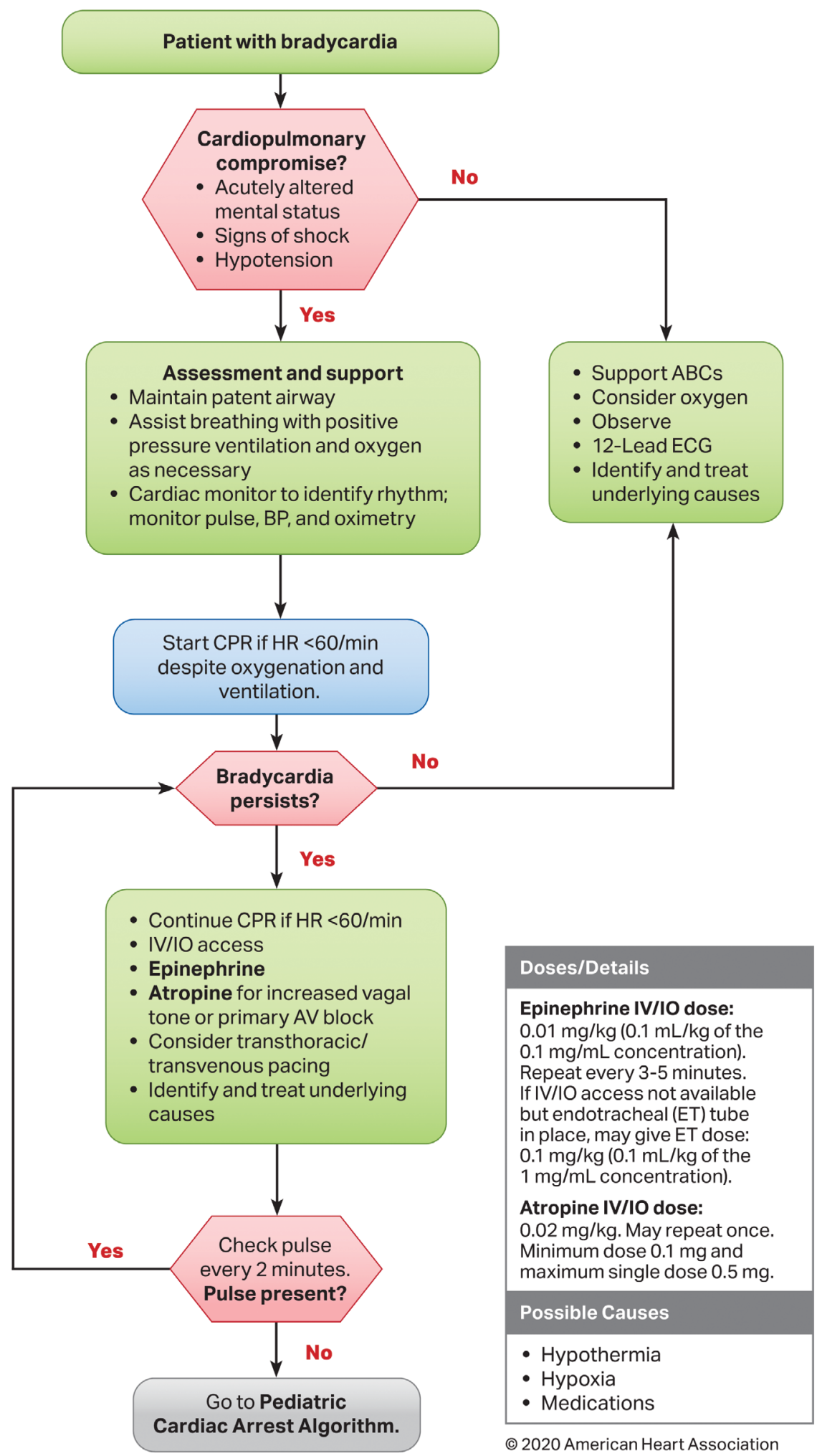

Figure 12. Pediatric Bradycardia With a Pulse Algorithm.

$A B C$ indicates airway, breathing, and circulation; AV, atrioventricular; BP, blood pressure; CPR, cardiopulmonary resuscitation; ECG, electrocardiogram; HR, heart rate; IO, intraosseous; and IV, intravenous. 
(ie, altered mental status, signs of shock, hypotension) occurring in the minority of patients. In hemodynamically stable patients, re-entrant SVT can often be terminated with vagal maneuvers. ${ }^{1,2}$ Adenosine remains the preferred medication to treat SVT in infants and children with a palpable pulse who do not respond to vagal maneuvers. For patients with hemodynamically stable widecomplex tachycardia and those in whom SVT recurs after initial successful treatment, expert consultation is important to diagnose etiology and customize treatment.

In hemodynamically unstable patients with SVT or wide-complex tachycardia, synchronized cardioversion should be considered.

\section{Treatment of Supraventricular Tachycardia With A Pulse}

\begin{tabular}{|c|c|c|}
\hline COR & LOE & Recommendations \\
\hline 1 & C-LD & $\begin{array}{l}\text { 1. If IV/IO access is readily available, adenosine is } \\
\text { recommended for the treatment of SVT. }{ }^{3-9}\end{array}$ \\
\hline 1 & C-EO & $\begin{array}{l}\text { 2. For hemodynamically stable patients whose } \\
\text { SVT is unresponsive to vagal maneuvers } \\
\text { and/or IV adenosine, expert consultation is } \\
\text { recommended. } .^{5-15,17}\end{array}$ \\
\hline $2 a$ & C-LD & $\begin{array}{l}\text { 3. It is reasonable to attempt vagal stimulation } \\
\text { first, unless the patient is hemodynamically } \\
\text { unstable or it will delay chemical or electric } \\
\text { synchronized cardioversion. } .^{1,2,4}\end{array}$ \\
\hline $2 a$ & C-LD & $\begin{array}{l}\text { 4. If the patient with SVT is hemodynamically } \\
\text { unstable with evidence of cardiovascular } \\
\text { compromise (ie. altered mental status, signs } \\
\text { of shock, hypotension) it is reasonable to } \\
\text { perform electric synchronized cardioversion } \\
\text { starting with a dose of } 0.5 \text { to } 1 \mathrm{~J} / \mathrm{kg} \text {. If } \\
\text { unsuccessful, increase the dose to } 2 \mathrm{~J} / \mathrm{kg} .{ }^{5,8,15}\end{array}$ \\
\hline $2 b$ & C-LD & $\begin{array}{l}\text { 5. For a patient with unstable SVT unresponsive } \\
\text { to vagal maneuvers, IV adenosine, electric } \\
\text { synchronized cardioversion and for whom } \\
\text { expert consultation is not available, it may be } \\
\text { reasonable to consider either procainamide } \\
\text { or amiodarone. }{ }^{12,15}\end{array}$ \\
\hline
\end{tabular}

\section{Recommendation-Specific Supportive Text}

1. Intravenous adenosine remains generally effective for terminating re-entrant SVT within the first 2 doses. $^{3-6}$ Of 5 retrospective observational studies on the management of tachyarrhythmias (4 single center, 1 multicenter), none directly compared adenosine to other drugs. ${ }^{6-9,17}$

2. For patients with hemodynamically stable SVT that is refractory to vagal maneuvers or adenosine, consideration of alternative second-line agents should be guided by expert consultation, given potential proarrhythmic and life-threatening hemodynamic collapse with the administration of multiple antiarrhythmic agents. Multiple medications have been used as second-line agents for the management of adenosine-refractory SVT, including intravenous verapamil, $\beta$-blockers, amiodarone, procainamide, and sotalol. ${ }^{5-15,17}$ Few comparative studies exist.

3. Vagal maneuvers are noninvasive, have few adverse effects, and effectively terminate SVT in many cases; exact success rates for each type of maneuver (ie, ice water to face, postural modification) are unknown. ${ }^{4}$ Although improved success rates have been reported with a postural modification to the standard Valsalva maneuver in adults, ${ }^{1}$ published pediatric experience with this technique is very limited. Upside-down positioning may be an additional form of a vagal maneuver that is effective in children. ${ }^{2}$

4. Direct current synchronized cardioversion remains the treatment of choice for patients with hemodynamically unstable SVT (ie, with cardiovascular compromise characterized by altered mental status, signs of shock, or hypotension) and those with SVT unresponsive to standard measures. However, these cases are uncommon, and there are few data reporting outcomes from cardioversion of SVT. $5,8,15$ Consider administering sedation prior to synchronized cardioversion if resources are available and definitive therapy is not delayed.

5. Procainamide and amiodarone are moderately effective treatments for adenosine-resistant SVT. ${ }^{12}$ There may be a small efficacy advantage favoring procainamide; adverse effects are frequent with both therapies. Intravenous sotalol was approved by the US Food and Drug Administration for the treatment of SVT in 2009. Only 3 reports describe its use in acute or subacute supraventricular tachyarrhythmias, with a $60 \%$ to $100 \%$ termination rate of SVT and atrial tachyarrhythmias. ${ }^{9,13,14}$ In the aforementioned studies, IV sotalol was administered under the guidance of pediatric electrophysiologists in the critical care or pediatric cardiology unit. Due to its potential proarrhythmic properties, it is unknown whether IV sotalol can be safely given in other settings. There is currently insufficient evidence in support for or against the use of IV sotalol for refractory SVT.

\section{Treatment of Wide-Complex Tachycardia With a Pulse}

\begin{tabular}{|c|c|c|}
\hline COR & LOE & Recommendations \\
\hline 1 & C-LD & $\begin{array}{l}\text { 1. If the patient with a wide-complex tachycardia } \\
\text { is hemodynamically stable, expert consultation } \\
\text { is recommended prior to administration of } \\
\text { antiarrhythmic agents. }{ }^{18}\end{array}$ \\
\hline $2 a$ & C-EO & $\begin{array}{l}\text { 2. If the patient with a wide-complex tachycardia } \\
\text { is hemodynamically unstable with evidence } \\
\text { of cardiovascular compromise (ie, altered } \\
\text { mental status, signs of shock, hypotension), it } \\
\text { is reasonable to perform electric synchronized } \\
\text { cardioversion starting with a dose of } 0.5-1 \mathrm{~J} / \mathrm{kg} \text {. } \\
\text { If unsuccessful, increase the dose to } 2 \mathrm{~J} / \mathrm{kg} \text {. }\end{array}$ \\
\hline
\end{tabular}




\section{Recommendation-Specific Supportive Text}

1. The occurrence of wide-complex tachycardia (QRS duration more than $0.09 \mathrm{~s}$ ) with a pulse is rare in children and may originate from either the ventricle (ventricular tachycardia) or atria (SVT with aberrant conduction). ${ }^{18}$ Both pediatric and adult studies have identified potential populations at risk of proarrhythmic complications from antiarrhythmic therapies, including patients with underlying cardiomyopathies, long-QT syndrome, Brugada syndrome, and Wolff-Parkinson-White syndrome. ${ }^{19-23}$

2. Electric direct current synchronized cardioversion should be provided urgently for the treatment of children with wide-complex tachycardia of either atrial or ventricular origin who are hemodynamically unstable with a pulse. Cardiovascular compromise is a key factor in determining the use of electric therapy instead of primary pharmacological management. There is insufficient evidence describing the incidence of wide-complex tachycardias with a pulse and hemodynamic stability, and there is no support for or against the use of specific antiarrhythmic drugs in the management of children with wide-complex tachycardia with a pulse.

Figure 13 shows the algorithm for pediatric tachycardia with a pulse.

\section{REFERENCES}

1. Appelboam A, Reuben A, Mann C, Gagg J, Ewings P, Barton A, Lobban T, Dayer M, Vickery J, Benger J; REVERT trial collaborators. Postural modification to the standard Valsalva manoeuvre for emergency treatment of supraventricular tachycardias (REVERT): a randomised controlled trial. Lancet. 2015;386:1747-1753. doi: 10.1016/S0140-6736(15)61485-4

2. Bronzetti G, Brighenti M, Mariucci E, Fabi M, Lanari M, Bonvicini M Gargiulo G, Pession A. Upside-down position for the out of hospital management of children with supraventricular tachycardia. Int J Cardiol. 2018;252:106-109. doi: 10.1016/j.ijcard.2017.10.120

3. Losek JD, Endom E, Dietrich A, Stewart G, Zempsky W, Smith K. Adenos ine and pediatric supraventricular tachycardia in the emergency department: multicenter study and review. Ann Emerg Med. 1999;33:185-191. doi: 10.1016/s0196-0644(99)70392-6

4. Campbell M, Buitrago SR. BET 2: Ice water immersion, other vagal manoeuvres or adenosine for SVT in children. Emerg Med J. 2017;34:58-60. doi: 10.1136/emermed-2016-206487.2

5. Clausen H, Theophilos T, Jackno K, Babl FE. Paediatric arrhythmias in the emergency department. Emerg Med J. 2012;29:732-737. doi: 10.1136/emermed-2011-200242

6. Díaz-Parra S, Sánchez-Yañez P, Zabala-Argüelles I, Picazo-Angelin B, Conejo-Muñoz L, Cuenca-Peiró V, Durán-Hidalgo I, García-Soler P. Use of adenosine in the treatment of supraventricular tachycardia in a pediatric emergency department. Pediatr Emerg Care. 2014;30:388-393. doi: 10.1097/PEC.0000000000000144

7. Chu PY, Hill KD, Clark RH, Smith PB, Hornik CP. Treatment of supraventricular tachycardia in infants: Analysis of a large multicenter database. Early Hum Dev. 2015;91:345-350. doi: 10.1016/j.earlhumdev.2015.04.001

8. Lewis J, Arora G, Tudorascu DL, Hickey RW, Saladino RA, Manole MD. Acute management of refractory and unstable pediatric supraventricular tachycardia. J Pediatr. 2017;181;177.e2-182.e2. doi: 10.1016/j.jpeds.2016.10.051

9. Borquez AA, Aljohani OA, Williams MR, Perry JC. Intravenous sotalol in the young. J Am Coll Cardiol EP. 2020;6:425-432. doi: 10.1016/j.jacep.2019.11.019

10. Lim SH, Anantharaman V, Teo WS, Chan YH. Slow infusion of calcium channel blockers compared with intravenous adenosine in the emergency treatment of supraventricular tachycardia. Resuscitation. 2009;80:523528. doi: 10.1016/j.resuscitation.2009.01.017

11. Lapage MJ, Bradley DJ, Dick M II. Verapamil in infants: an exaggerated fear? Pediatr Cardiol. 2013;34:1532-1534. doi: 10.1007/s00246-013-0739-8

12. Chang PM, Silka MJ, Moromisato DY, Bar-Cohen Y. Amiodarone versus procainamide for the acute treatment of recurrent supraventricular tachycardia in pediatric patients. Circ Arrhythm Electrophysiol. 2010;3:134140. doi: 10.1161/CIRCEP.109.901629

13. Li $X$, Zhang $Y$, Liu $H$, Jiang $H$, Ge $H$, Zhang $Y$. Efficacy of intravenous sotalol for treatment of incessant tachyarrhythmias in children. Am J Cardiol. 2017;119:1366-1370. doi: 10.1016/j.amjcard.2017.01.034

14. Valdés SO, Landstrom AP, Schneider AE, Miyake CY, de la Uz CM, Kim JJ. Intravenous sotalol for the management of postoperative junctional ectopic tachycardia. HeartRhythm Case Rep. 2018;4:375-377. doi: 10.1016/j. hrcr.2018.05.007

15. Sacchetti A, Moyer V, Baricella R, Cameron J, Moakes ME. Primary cardiac arrhythmias in children. Pediatr Emerg Care. 1999;15:95-98. doi: 10.1097/00006565-199904000-00004

16. Deleted in proof

17. Chandler SF, Chu E, Whitehill RD, Bevilacqua LM, Bezzerides VJ, DeWitt ES, Alexander ME, Abrams DJ, Triedman JK, Walsh EP, et al. Adverse event rate during inpatient sotalol initiation for the management of supraventricular and ventricular tachycardia in the pediatric and young adult population. Heart Rhythm. 2020;17:984-990. doi: 10.1016/j.hrthm.2020.01.022

18. Brady WJ, Mattu A, Tabas J, Ferguson JD. The differential diagnosis of wide QRS complex tachycardia. Am J Emerg Med. 2017;35:1525-1529. doi: 10.1016/j.ajem.2017.07.056

19. Ramusovic S, Läer S, Meibohm B, Lagler FB, Paul T. Pharmacokinetics of intravenous amiodarone in children. Arch Dis Child. 2013;98:989-993. doi: 10.1136/archdischild-2013-304483

20. Sarganas G, Garbe E, Klimpel A, Hering RC, Bronder E, Haverkamp W. Epidemiology of symptomatic drug-induced long QT syndrome and Torsade de Pointes in Germany. Europace. 2014;16:101-108. doi: 10.1093/europace/eut214

21. Chen S, Motonaga KS, Hollander SA, Almond CS, Rosenthal DN, Kaufman BD, May LJ, Avasarala K, Dao DT, Dubin AM, Ceresnak SR. Electrocardiographic repolarization abnormalities and increased risk of lifethreatening arrhythmias in children with dilated cardiomyopathy. Heart Rhythm. 2016;13:1289-1296. doi: 10.1016/j.hrthm.2016.02.014

22. Coughtrie AL, Behr ER, Layton D, Marshall V, Camm AJ, Shakir SAW. Drugs and life-threatening ventricular arrhythmia risk: results from the DARE study cohort. BMJ Open. 2017;7:e016627. doi: 10.1136/bmjopen-2017-016627

23. Ortiz M, Martín A, Arribas F, Coll-Vinent B, Del Arco C, Peinado R, Almendral J; PROCAMIO Study Investigators. Randomized comparison of intravenous procainamide vs. intravenous amiodarone for the acute treatment of tolerated wide QRS tachycardia: the PROCAMIO study. Eur Heart J. 2017;38:1329-1335. doi: 10.1093/eurheartj/ehw230

\section{TREATMENT OF MYOCARDITIS AND CARDIOMYOPATHY}

Fulminant myocarditis can result in decreased cardiac output with end-organ compromise; conduction system disease, including complete heart block; and persistent supraventricular or ventricular arrhythmias, which can ultimately result in cardiac arrest. ${ }^{1}$ Because patients can present with nonspecific symptoms such as abdominal pain, diarrhea, vomiting, or fatigue, myocarditis can be confused with other, more common disease presentations. Outcomes can be optimized by early diagnosis and prompt intervention, including ICU monitoring and therapy. Sudden onset of heart block and multifocal ventricular ectopy in the patient with fulminant myocarditis should be considered a prearrest state. Treatment with external or intracardiac pacing or antiarrhythmic drugs may not be successful, and early transfer to a center capable of providing extracorporeal life support (ECLS) or mechanical 


\section{Pediatric Tachycardia With a Pulse Algorithm}

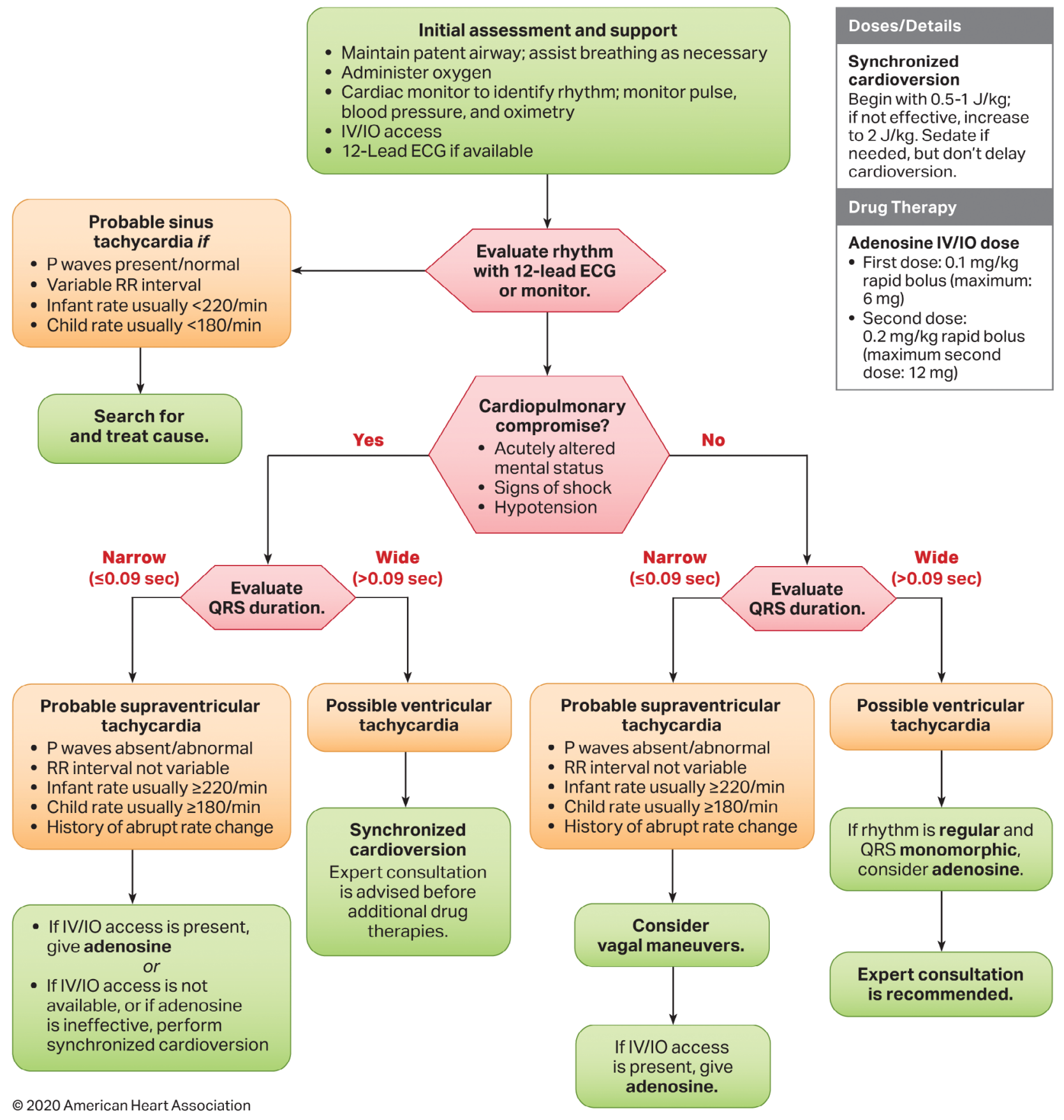

Figure 13. Pediatric Tachycardia With a Pulse Algorithm.

CPR indicates cardiopulmonary resuscitation; ECG, electrocardiogram; IO, intraosseous; and IV, intravenous. 
circulatory support (MCS), such as temporary or implanted ventricular assist devices, is recommended. . $^{2,3}$

Noninfectious causes of cardiomyopathy in children include dilated cardiomyopathy, hypertrophic cardiomyopathy, restrictive cardiomyopathy, and miscellaneous (rare) forms of cardiomyopathy that include arrhythmogenic right ventricular dysplasia and mitochondrial and left ventricular noncompaction cardiomyopathies. Cardiomyopathy patients who present in acute decompensated heart failure refractory to mechanical ventilation and vasoactive administration have undergone preemptive MCS in the form of ECMO, short-term percutaneous ventricular assist device, or long-term implantable ventricular assist device prior to or during cardiac arrest. ${ }^{4,5}$

For patients who have worsening clinical status or incessant ventricular arrhythmias, ECLS can be lifesaving when initiated prior to cardiac arrest. ECLS also offers an opportunity to wean inotropic support, assist myocardial recovery, and serve as a bridge to cardiac transplantation if needed. The use of ECLS and MCS have improved outcomes from acute myocarditis, with a high possibility of partial or complete recovery of myocardial function. ${ }^{2,6}$

Recommendations for Treatment of Myocarditis and Cardiomyopathy

\begin{tabular}{|c|c|c|}
\hline COR & LOE & Recommendations \\
\hline 1 & C-LD & $\begin{array}{l}\text { 1. Given the high risk of cardiac arrest in children } \\
\text { with acute myocarditis who demonstrate } \\
\text { arrhythmias, heart block, ST-segment changes, } \\
\text { and/or low cardiac output, early consideration } \\
\text { of transfer to ICU monitoring and therapy is } \\
\text { recommended. }{ }^{1.7,8}\end{array}$ \\
\hline 2a & B-NR & $\begin{array}{l}\text { 2. For children with myocarditis or } \\
\text { cardiomyopathy and refractory low cardiac } \\
\text { output, prearrest use of ECLS or MCS can be } \\
\text { beneficial to provide end-organ support and } \\
\text { prevent cardiac arrest. } 9.10\end{array}$ \\
\hline 2a & B-NR & $\begin{array}{l}\text { 3. Given the challenges to successful } \\
\text { resuscitation of children with myocarditis and } \\
\text { cardiomyopathy, once cardiac arrest occurs, } \\
\text { early consideration of ECPR can be beneficial. }\end{array}$ \\
\hline
\end{tabular}

\section{Recommendation-Specific Supportive Text}

1. Three retrospective studies have evaluated predictors of worse outcome in fulminant myocarditis, noting increased incidence of cardiac arrest and the need for ECLS in this high-risk population. ${ }^{1,7,8}$ In 1 study, nearly half of fulminant myocarditis patients required CPR, and nearly one third received $\mathrm{MCS}^{7}$ Even modest decreases in left ventricular ejection fraction are associated with the need for invasive circulatory support. ${ }^{8}$

2. The prognosis for patients with fulminant myocarditis who receive ECLS or MCS can be good. In 1 study, 13 (46\%) of 28 children requiring MCS survived without transplant. ${ }^{9}$ One study noted that outcomes for ECPR patients cannulated with a diagnosis of myocarditis are superior to other arrest and illness categories leading to ECPR (ie, patients without congenital heart disease), noting myocarditis as a precannulation factor associated with improved survival. ${ }^{10}$ In the pre-cardiac arrest cardiomyopathy patient, newer forms of temporary circulatory support devices provide alternate and potentially improved support for decompensated heart failure requiring bridge to transplantation. These devices may provide a survival benefit over ECMO. 4,5

3. In 1 study, $95 \%$ of children with myocarditis who were placed on ECLS $(n=15)$ or MCS $(n=1)$ after cardiac arrest were alive 6 months later. ${ }^{9}$

\section{REFERENCES}

1. Miyake CY, Teele SA, Chen L, Motonaga KS, Dubin AM, Balasubramanian S, Balise RR, Rosenthal DN, Alexander ME, Walsh EP, Mah DY. In-hospital arrhythmia development and outcomes in pediatric patients with acute myocarditis. Am J Cardiol. 2014;113:535-540. doi: 10.1016/j.amjcard.2013.10.021

2. Wilmot I, Morales DL, Price JF, Rossano JW, Kim JJ, Decker JA, McGarry MC, Denfield SW, Dreyer WJ, Towbin JA, Jefferies JL. Effectiveness of mechanical circulatory support in children with acute fulminant and persistent myocarditis. J Card Fail. 2011;17:487-494. doi: 10.1016/j.cardfail.2011.02.008

3. Teele SA, Allan CK, Laussen PC, Newburger JW, Gauvreau K, Thiagarajan RR. Management and outcomes in pediatric patients presenting with acute fulminant myocarditis. J Pediatr. 2011;158:638-643.e1. doi: 10.1016/j.jpeds.2010.10.015

4. Lorts A, Eghtesady P, Mehegan M, Adachi I, Villa C, Davies R, Gossett JG, Kanter K, Alejos J, Koehl D, Cantor RS, Morales DLS. Outcomes of children supported with devices labeled as "temporary" or short term: A report from the Pediatric Interagency Registry for Mechanical Circulatory Support. J Heart Lung Transplant. 2018;37:54-60. doi: 10.1016/j.healun.2017.10.023

5. Yarlagadda VV, Maeda K, Zhang Y, Chen S, Dykes JC, Gowen MA, ShuttleworthP,MurrayJM, ShinAY, ReinhartzO, RosenthalDN, McElhinneyDB, Almond CS. Temporary Circulatory Support in U.S. Children Awaiting Heart Transplantation. JAm CollCardiol. 2017;70:2250-2260. doi: 10.1016/j.jacc. 2017.08.072

6. Rajagopal SK, Almond CS, Laussen PC, Rycus PT, Wypij D, Thiagarajan RR. Extracorporeal membrane oxygenation for the support of infants, children, and young adults with acute myocarditis: a review of the Extracorporeal Life Support Organization registry. Crit Care Med. 2010;38:382387. doi: 10.1097/CCM.0b013e3181bc8293

7. Casadonte JR, Mazwi ML, Gambetta KE, Palac HL, McBride ME, Eltayeb OM, Monge MC, Backer CL, Costello JM. Risk Factors for Cardiac Arrest or Mechanical Circulatory Support in Children with Fulminant Myocarditis. Pediatr Cardiol. 2017;38:128-134. doi: 10.1007/s00246-016-1493-5

8. Wu HP, Lin MJ, Yang WC, Wu KH, Chen CY. Predictors of Extracorporeal Membrane Oxygenation Support for Children with Acute Myocarditis. Biomed Res Int. 2017;2017:2510695. doi: 10.1155/2017/2510695

9. Schubert S, Opgen-Rhein B, Boehne M, Weigelt A, Wagner R, Müller G, Rentzsch A, Zu Knyphausen E, Fischer M, Papakostas K, Wiegand G, Ruf B, Hannes T, Reineker K, Kiski D, Khalil M, Steinmetz M, Fischer G, Pickardt T, Klingel K, Messroghli DR, Degener F; MYKKE consortium. Severe heart failure and the need for mechanical circulatory support and heart transplantation in pediatric patients with myocarditis: Results from the prospective multicenter registry "MYKKE". Pediatr Transplant. 2019;23:e13548. doi: 10.1111/petr.13548

10. Conrad SJ, Bridges BC, Kalra Y, Pietsch JB, Smith AH. Extracorporeal Cardiopulmonary Resuscitation Among Patients with Structurally Normal Hearts. ASAIO J. 2017;63:781-786. doi: 10.1097/MAT.0000000000000568 


\section{RESUSCITATION OF THE PATIENT WITH A SINGLE VENTRICLE}

The complexity and variability in pediatric congenital heart disease pose unique challenges during resuscitation. Children with single-ventricle heart disease typically undergo a series of staged palliative operations. The objectives of the first palliative procedure, typically performed during the neonatal period, are (1) to create unobstructed systemic blood flow, (2) to create an effective atrial communication to allow for atrial level mixing, and (3) to regulate pulmonary blood flow to prevent overcirculation and decrease the volume load on the systemic ventricle (Figure 14). During the second stage of palliation, a superior cavopulmonary anastomosis, or bidirectional Glenn/hemi-Fontan operation, is performed to create an anastomosis, which aids in the redistribution of systemic venous return directly to the pulmonary circulation (Figure 15). The Fontan is the final palliation, in which inferior vena caval blood flow is baffled directly to the pulmonary circulation, thereby making the single (systemic) ventricle preload dependent on passive flow a cross the pulmonary vascular bed (Figure 16).

Neonates and infants with single-ventricle physiology have an increased risk of cardiac arrest as a result of (1) increased myocardial work as a consequence of volume overload, (2) imbalances in relative systemic (Qs) and pulmonary (Qp) blood flow, and (3) potential shunt occlusion. ${ }^{1,2}$ Depending on the stage of repair, resuscitation may require control of pulmonary vascular resistance, oxygenation, systemic vascular resistance, or ECLS.

\section{Preoperative and Postoperative Stage I Palliation (Norwood/Blalock-Taussig Shunt or Sano Shunt)}

Recommendations for the Treatment of Preoperative and

Postoperative Stage I Palliation (Norwood/Blalock-Taussig Shunt or Sano Shunt)

\begin{tabular}{|c|c|c|}
\hline COR & LOE & Recommendations \\
\hline $2 a$ & B-NR & $\begin{array}{l}\text { 1. Direct (superior vena cava catheter) and/or } \\
\text { indirect (near infrared spectroscopy) oxygen } \\
\text { saturation monitoring can be beneficial to } \\
\text { trend and direct management in the critically } \\
\text { ill neonate after stage I Norwood palliation or } \\
\text { shunt placement. }\end{array}$ \\
\hline $2 a$ & C-LD & $\begin{array}{l}\text { 2. In the patient with an appropriately restrictive } \\
\text { shunt, manipulation of pulmonary vascular } \\
\text { resistance may have little effect, whereas } \\
\text { lowering systemic vascular resistance with the use } \\
\text { of systemic vasodilators ( } \alpha \text {-adrenergic antagonists } \\
\text { and/or phosphodiesterase type III inhibitors), with } \\
\text { or without the use of oxygen, can be useful to } \\
\text { increase systemic oxygen delivery }\left(\mathrm{DO}_{2}\right) .{ }^{4,5}\end{array}$ \\
\hline $2 a$ & $C-L D$ & $\begin{array}{l}\text { 3. For neonates prior to stage I repair with } \\
\text { pulmonary overcirculation and symptomatic } \\
\text { low systemic cardiac output and delivery of } \\
\text { oxygen }\left(\mathrm{DO}_{2}\right) \text {, it is reasonable to target a } \mathrm{Paco}_{2} \\
\text { of } 50-60 \mathrm{~mm} \mathrm{Hg} \text {. This can be achieved during } \\
\text { mechanical ventilation by reducing minute } \\
\text { ventilation or by administering analgesia/ } \\
\text { sedation with or without neuromuscular } \\
\text { blockade. }\end{array}$ \\
\hline $2 a$ & C-LD & $\begin{array}{l}\text { 4. ECLS after Stage I Norwood palliation can be } \\
\text { useful to treat low systemic } \mathrm{DO}_{2}{ }^{8,9}\end{array}$ \\
\hline $2 a$ & $C-E O$ & $\begin{array}{l}\text { 5. In the situation of known or suspected shunt } \\
\text { obstruction, it is reasonable to administer } \\
\text { oxygen, vasoactive agents to increase shunt } \\
\text { perfusion pressure, and heparin (50-100 U/kg } \\
\text { bolus) while preparing for catheter-based or } \\
\text { surgical intervention. }{ }^{2}\end{array}$ \\
\hline
\end{tabular}

Aortic Arch Reconstruction
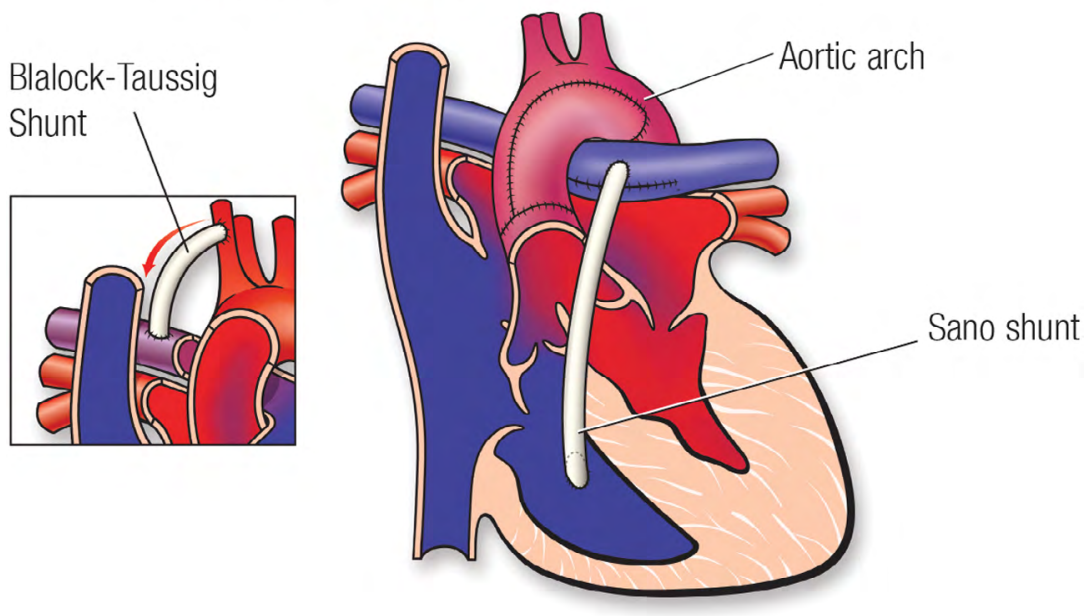

Figure 14. Stage I palliation for single ventricle with a Norwood repair and either a Blalock-Taussig Shunt from the right subclavian artery to the right pulmonary artery or a Sano shunt from the right ventricle to pulmonary artery. 


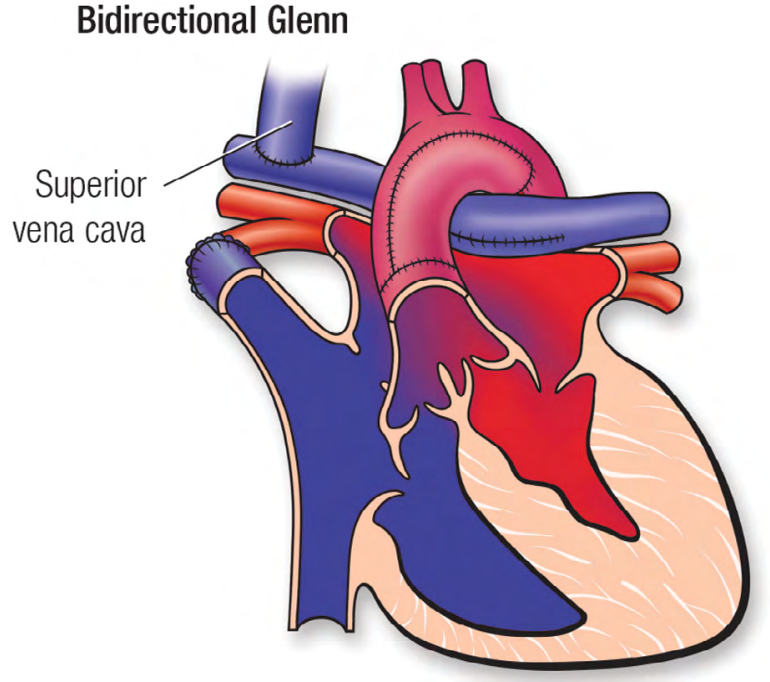

Figure 15. Stage II palliation for single ventricle with a bidirectional Glenn shunt connecting the superior vena cava to the right pulmonary artery.

\section{Recommendation-Specific Supportive Text}

1. In the early postoperative period, noninvasively measured regional cerebral and somatic saturations, via near infrared spectroscopy, can predict outcomes of early mortality and ECLS use following stage I Norwood palliation. There are retrospective data that postoperative near infrared spectroscopy measures may be targets for goaldirected interventions. ${ }^{3}$

2. Afterload reduction using vasodilators (sodium nitroprusside or phentolamine), with or without a phosphodiesterase type III inhibitor (eg, milrinone), reduces systemic vascular resistance, serum lactate, arterial venous oxygen difference,

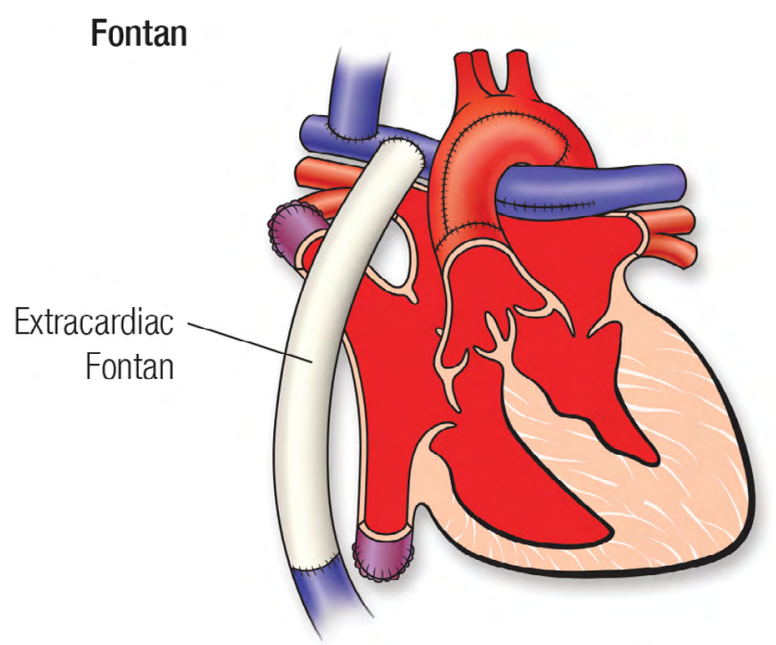

Figure 16. Stage III Fontan single ventricle palliation with an extracardiac conduit connecting the inferior vena cava to the right pulmonary artery. and the need for ECPR in the postoperative period for shunt-dependent single-ventricle patients. ${ }^{4,5}$

3. In the period before single-ventricle palliation, cautious use of controlled hypoventilation can reduce Qp:Qs by increasing pulmonary vascular resistance, narrowing the arterial-venous oxygen difference, and increasing cerebral oxygen delivery. Simple hypoventilation can also increase the pulmonary vascular resistance but can be associated with unwanted atelectasis or respiratory acidosis..$^{6,7}$

4. For cardiac arrest before or after Stage I palliation repair, the use of ECPR is associated with improved survival. In 2 observational studies, 32\% to 54\% of neonates requiring ECPR survived, and, in 1 study, the odds of survival improved in cardiac arrest patients managed with ECPR. ${ }^{8,9}$

5. Treatment of acute shunt obstruction can include administration of oxygen, vasoactive agents (eg, phenylephrine, norepinephrine, epinephrine) to maximize shunt perfusion pressure, anticoagulation with heparin (50-100 U/kg bolus), shunt intervention by catheterization or surgery, and ECLS. ${ }^{2}$

\section{Postoperative Stage II (Bidirectional Glenn/ Hemi-Fontan) and III (Fontan) Palliation}

\begin{tabular}{|c|c|c|}
\hline COR & LOE & Recommendations \\
\hline $2 a$ & B-NR & $\begin{array}{l}\text { 1. For patients in a prearrest state with superior } \\
\text { cavopulmonary anastomosis physiology } \\
\text { and severe hypoxemia due to inadequate } \\
\text { Qp, ventilatory strategies that target a mild } \\
\text { respiratory acidosis and a minimum mean } \\
\text { airway pressure without atelectasis can be } \\
\text { useful to increase cerebral and systemic } \\
\text { arterial oxygenation. }^{10}\end{array}$ \\
\hline $2 b$ & B-NR & $\begin{array}{l}\text { 2. ECLS in patients with superior cavopulmonary } \\
\text { anastomosis or Fontan circulation may be } \\
\text { considered to treat low } \mathrm{DO}_{2} \text { from reversible } \\
\text { causes or as a bridge to a ventricular assist } \\
\text { device or surgical revision. }{ }^{11}\end{array}$ \\
\hline
\end{tabular}

\section{Recommendation-Specific Supportive Text}

1. In patients immediately following bidirectional Glenn placement, a ventilation strategy with higher $\mathrm{PaCO}_{2}$ improved oxygenation. ${ }^{10}$

2. In 1 retrospective analysis of the Extracorporeal Life Support Organization database, among infants in whom a bidirectional Glenn had been placed and in whom ECLS was required, survival was similar in patients who had cardiac arrest before ECLS $(16 / 39,41 \%)$ and those who did not $(26 / 64,41 \%) .{ }^{11}$

These topics were reviewed previously in "Cardiopulmonary Resuscitation in Infants and Children With Cardiac Disease: A Scientific Statement From the American Heart Association." 12 


\section{REFERENCES}

1. Feinstein JA, Benson DW, Dubin AM, Cohen MS, Maxey DM, Mahle WT, Pahl E, Villafañe J, Bhatt $A B$, Peng $L F$, et al. Hypoplastic left heart syndrome: current considerations and expectations. J Am Coll Cardiol. 2012;59(suppl 1):S1-S42. doi: 10.1016/j.jacc.2011.09.022

2. Marino BS, Tibby SM, Hoffman GM. Resuscitation of the patient with the functionally univentricular heart. Curr Pediatr Rev. 2013;9:148-157. doi: 10.2174/1573396311309020008

3. Hoffman GM, Ghanayem NS, ScottJP, Tweddell JS, Mitchell ME, MussattoKA Postoperative Cerebral and Somatic Near-Infrared Spectroscopy Saturations and Outcome in Hypoplastic Left Heart Syndrome. Ann Thorac Surg. 2017;103:1527-1535. doi: 10.1016/j.athoracsur.2016.09.100

4. Mills KI, Kaza AK, Walsh BK, Bond HC, Ford M, Wypij D Thiagarajan RR, Almodovar MC, Quinonez LG, Baird CW, et al. Phosphodiesterase inhibitor-based vasodilation improves oxygen delivery and clinical outcomes following stage 1 palliation. J Am Heart Assoc. 2016;5 doi: 10.1161/JAHA.116.003554

5. Hansen JH, Schlangen J, Voges I, Jung O, Wegmann A, Scheewe J, Kramer $\mathrm{HH}$. Impact of afterload reduction strategies on regional tissue oxygenation after the Norwood procedure for hypoplastic left heart syndrome. Eur J Cardiothorac Surg. 2014;45:e13-e19. doi: 10.1093/ejcts/ezt538

6. Ramamoorthy C, Tabbutt S, Kurth CD, Steven JM, Montenegro LM, Durning S, Wernovsky G, Gaynor JW, Spray TL, Nicolson SC. Effects of inspired hypoxic and hypercapnic gas mixtures on cerebral oxygen saturation in neonates with univentricular heart defects. Anesthesiology. 2002;96:283-288. doi: 10.1097/00000542-200202000-00010

7. Tabbutt S, Ramamoorthy C, Montenegro LM, Durning SM, Kurth CD, Steven JM, Godinez RI, Spray TL, Wernovsky G, Nicolson SC. Impact of inspired gas mixtures on preoperative infants with hypoplastic left heart syndrome during controlled ventilation. Circulation. 2001;104(suppl 1):I159-I164. doi: 10.1161/hc37t1.094818

8. Alsoufi B, Awan A, Manlhiot C, Guechef A, Al-Halees Z, Al-Ahmadi M, McCrindle BW, Kalloghlian A. Results of rapid-response extracorporeal cardiopulmonary resuscitation in children with refractory cardiac arrest following cardiac surgery. Eur J Cardiothorac Surg. 2014;45:268-275. doi: 10.1093/ejcts/ezt319

9. Alsoufi B, Awan A, Manlhiot C, Al-Halees Z, Al-Ahmadi M, McCrindle BW Alwadai $A$. Does single ventricle physiology affect survival of children requiring extracorporeal membrane oxygenation support following cardiac surgery? World J Pediatr Congenit Heart Surg. 2014;5:7-15. doi: $10.1177 / 2150135113507292$

10. Zhu L, Xu Z, Gong X, Zheng J, Sun Y, Liu L, Han L, Zhang H, Xu Z, Liu J, et al. Mechanical ventilation after bidirectional superior cavopulmonary anastomosis for single-ventricle physiology: a comparison of pressure support ventilation and neurally adjusted ventilatory assist. Pediatr Cardiol. 2016;37:1064-1071. doi: 10.1007/s00246-016-1392-9

11. Jolley $M$, Thiagarajan RR, Barrett CS, Salvin JW, Cooper DS, Rycus PT, Teele SA. Extracorporeal membrane oxygenation in patients undergoing superior cavopulmonary anastomosis. J Thorac Cardiovasc Surg. 2014;148:1512-1518. doi: 10.1016/j.jtcvs.2014.04.028

12. Marino BS, Tabbutt S, MacLaren G, Hazinski MF, Adatia I, Atkins DL, Checchia PA, DeCaen A, Fink EL, Hoffman GM, Jefferies JL, Kleinman M, Krawczeski CD, LichtDJ, Macrae D, Ravishankar C, Samson RA, Thiagarajan RR, Toms R, Tweddell J, Laussen PC; American Heart Association Congenital Cardiac Defects Committee of the Council on Cardiovascular Disease in the Young; Council on Clinical Cardiology; Council on Cardiovascular and Stroke Nursing; Council on Cardiovascular Surgery and Anesthesia; and Emergency Cardiovascular Care Committee. Cardiopulmonary Resuscitation in Infants and Children With Cardiac Disease: A Scientific Statement From the American Heart Association. Circulation. 2018;137:e691-e782. doi: 10.1161/CIR.0000000000000524

\section{RECOMMENDATION FOR TREATMENT OF THE CHILD WITH PULMONARY HYPERTENSION}

Pulmonary hypertension is a rare disease in infants and children that is associated with significant morbidity and mortality. In the majority of pediatric patients, pulmonary hypertension is idiopathic or associated with chronic lung disease; congenital heart disease; and, rarely, other conditions, such as connective tissue or thromboembolic disease. ${ }^{1}$ Pulmonary hypertension occurs in $2 \%$ to $20 \%$ of patients following congenital heart disease surgery, with substantial morbidity and mortality. ${ }^{2}$ Pulmonary hypertension occurs in $2 \%$ to $5 \%$ of pediatric patients after cardiac surgery, ${ }^{3}$ and $0.7 \%$ to $5 \%$ of all cardiovascular surgical patients experience postoperative pulmonary hypertensive crises. ${ }^{4}$ Pulmonary hypertensive crises are acute rapid increases in pulmonary artery pressure accompanied by right-sided (or single-ventricle) heart failure. During pulmonary hypertensive crises, the right ventricle fails, and the increased afterload on the right ventricle produces increased myocardial oxygen demand at the same time that the coronary perfusion pressure and coronary blood flow decrease. The elevated left ventricle and right ventricle pressures lead to a fall in pulmonary blood flow and left-sided heart filling, with a resultant fall in cardiac output. Inotropic agents can be administered to improve right ventricle function, and vasopressors can be administered to treat systemic hypotension and improve coronary artery perfusion pressure. Once cardiac arrest has occurred, outcomes can be improved in the presence of an anatomic rightto-left shunt that permits left ventricle preload to be maintained without pulmonary blood flow. ${ }^{2}$ These crises are life threatening and may lead to systemic hypotension, myocardial ischemia, cardiac arrest, and death. Because acidosis and hypoxemia are both potent pulmonary vasoconstrictors, careful monitoring and management of these conditions are critical in the management of pulmonary hypertension. Treatment should also include the provision of adequate analgesics, sedatives, and muscle relaxants. Pulmonary vasodilators, including inhaled nitric oxide, inhaled prostacyclin, inhaled and intravenous prostacyclin analogs, and intravenous and oral phosphodiesterase type $\mathrm{V}$ inhibitors (eg, sildenafil) are used to prevent and treat pulmonary hypertensive crises. ${ }^{5-8}$ 


\begin{tabular}{|c|c|c|}
\hline COR & LOE & Recommendations \\
\hline 1 & $B-R$ & $\begin{array}{l}\text { 1. Inhaled nitric oxide or prostacyclin should be } \\
\text { used as the initial therapy to treat pulmonary } \\
\text { hypertensive crises or acute right-sided heart } \\
\text { failure secondary to increased pulmonary } \\
\text { vascular resistance. } .^{7,-12}\end{array}$ \\
\hline 1 & B-NR & $\begin{array}{l}\text { 2. Provide careful respiratory management and } \\
\text { monitoring to avoid hypoxia and acidosis } \\
\text { in the postoperative care of the child with } \\
\text { pulmonary hypertension. }{ }^{13-15}\end{array}$ \\
\hline 1 & C-EO & $\begin{array}{l}\text { 3. For pediatric patients who are at high } \\
\text { risk for pulmonary hypertensive crises, } \\
\text { provide adequate analgesics, sedatives, and } \\
\text { neuromuscular blocking agents., }{ }^{2,11,16,17}\end{array}$ \\
\hline $2 a$ & C-LD & $\begin{array}{l}\text { 4. For the initial treatment of pulmonary } \\
\text { hypertensive crises, oxygen administration and } \\
\text { induction of alkalosis through hyperventilation } \\
\text { or alkali administration can be useful } \\
\text { while pulmonary-specific vasodilators are } \\
\text { administered. } \text {. }^{13-15}\end{array}$ \\
\hline $2 b$ & C-LD & $\begin{array}{l}\text { 5. For children who develop refractory } \\
\text { pulmonary hypertension, including signs of } \\
\text { low cardiac output or profound respiratory } \\
\text { failure despite optimal medical therapy, ECLS } \\
\text { may be considered. }{ }^{11,18-23}\end{array}$ \\
\hline
\end{tabular}

\section{Recommendation-Specific Supportive Text}

1. Treatment with inhaled nitric oxide reduces the frequency of pulmonary hypertensive crises and shortens time to extubation. ${ }^{9}$ In patients with atrioventricular septal defect repair and severe postoperative pulmonary hypertension, inhaled nitric oxide administration is associated with reduced mortality. 710 Inhaled prostacyclin transiently produces pulmonary vasodilation and improves oxygenation, but the alkalinity of the drug can irritate airways, and precise dosing can be complicated by drug loss in the nebulization circuit. ${ }^{11,12}$

2. Two physiological reviews and 1 randomized clinical trial have demonstrated that hypercarbia, hypoxemia, acidosis, atelectasis, and ventilationperfusion mismatch can all lead to increases in pulmonary vascular resistance and, hence, elevation of pulmonary artery pressures in the immediate postoperative period. ${ }^{13-15}$

3. Two observational studies looking at select high-risk postoperative cardiac patients found an attenuation in the stress response in those patients receiving fentanyl in the postoperative period. 2,11,16,17

4. Two physiological reviews and 1 randomized clinical trial have demonstrated that hypercarbia, hypoxemia, acidosis, atelectasis, and ventilationperfusion mismatch can all lead to increases in pulmonary vascular resistance and, hence, elevation of pulmonary artery pressures in the immediate postoperative period. ${ }^{13-15}$

5. ECLS has been used in children with pulmonary vascular disease after cardiopulmonary collapse or low cardiac output. ${ }^{18,19}$ Although outcomes remain poor in certain populations, ${ }^{20}$ advances in technology of extracorporeal devices may allow for bridging to MCS or to transplantation. ${ }^{21}$ Although patients with pulmonary hypertension who require ECLS have a high mortality rate, provision of ECLS can be lifesaving. ${ }^{11,22,23}$

These topics were reviewed previously in "Cardiopulmonary Resuscitation in Infants and Children With Cardiac Disease: A Scientific Statement From the American Heart Association" 2 and "Pediatric Pulmonary Hypertension: Guidelines From the American Heart Association and American Thoracic Society." 11

\section{REFERENCES}

1. Ivy DD, Abman SH, Barst RJ, Berger RM, Bonnet $D$, Fleming $T R$, Haworth SG, Raj JU, Rosenzweig EB, Schulze Neick I, et al. Pediatric pulmonary hypertension. J Am Coll Cardiol. 2013;62(suppl):D117-D126. doi: 10.1016/j.jacc.2013.10.028

2. Marino BS, Tabbutt S, MacLaren G, Hazinski MF, Adatia I, Atkins DL, Checchia PA, DeCaen A, Fink EL, Hoffman GM, Jefferies JL, Kleinman M, Krawczeski CD, Licht DJ, Macrae D, Ravishankar C, Samson RA, Thiagarajan RR, Toms R, Tweddell J, Laussen PC; American Heart Association Congenital Cardiac Defects Committee of the Council on Cardiovascular Disease in the Young; Council on Clinical Cardiology; Council on Cardiovascular and Stroke Nursing; Council on Cardiovascular Surgery and Anesthesia; and Emergency Cardiovascular Care Committee. Cardiopulmonary Resuscitation in Infants and Children With Cardiac Disease: A Scientific Statement From the American Heart Association. Circulation. 2018;137:e691-e782. doi: 10.1161/CIR.0000000000000524

3. Bando K, Turrentine MW, Sharp TG, Sekine Y, Aufiero TX, Sun K, Sekine E, Brown JW. Pulmonary hypertension after operations for congenital heart disease: analysis of risk factors and management. J Thorac Cardiovasc Surg. 1996;112:1600-7; discussion 1607. doi: 10.1016/S0022-5223(96)70019-3

4. Lindberg L, Olsson AK, Jögi P, Jonmarker C. How common is severe pulmonary hypertension after pediatric cardiac surgery? J Thorac Cardiovasc Surg. 2002;123:1155-1163. doi: 10.1067/mtc.2002.121497

5. Avila-Alvarez A, Del Cerro Marin MJ, Bautista-Hernandez V. Pulmonary Vasodilators in the Management of Low Cardiac Output Syndrome After Pediatric Cardiac Surgery. Curr Vasc Pharmacol. 2016;14:37-47. doi: 10.2174/1570161113666151014124912

6. Sabri MR, Bigdelian H, Hosseinzadeh M, Ahmadi A, Ghaderian M, Shoja M. Comparison of the therapeutic effects and side effects of tadalafil and sildenafil after surgery in young infants with pulmonary arterial hypertension due to systemic-to-pulmonary shunts. Cardiol Young. 2017;27:16861693. doi: 10.1017/S1047951117000981

7. Bizzarro M, Gross I, Barbosa FT. Inhaled nitric oxide for the postoperative management of pulmonary hypertension in infants and children with congenital heart disease. Cochrane Database Syst Rev. 2014:CD005055. doi: 10.1002/14651858.CD005055.pub3

8. Unegbu C, Noje C, Coulson JD, Segal JB, Romer L. Pulmonary hypertension therapy and a systematic review of efficacy and safety of PDE-5 inhibitors. Pediatrics. 2017;139:e20161450. doi: 10.1542/peds.2016-1450

9. Miller OI, Tang SF, Keech A, Pigott NB, Beller E, Celermajer DS. Inhaled nitric oxide and prevention of pulmonary hypertension after congenital heart surgery: a randomised double-blind study. Lancet. 2000;356:14641469. doi: 10.1016/S0140-6736(00)02869-5

10. Journois $D$, Baufreton $C$, Mauriat $P$, Pouard $P$, Vouhé $P$, Safran D. Effects of inhaled nitric oxide administration on early postoperative mortality in patients operated for correction of atrioventricular canal defects. Chest. 2005;128:3537-3544. doi: 10.1378/chest.128.5.3537

11. Abman SH, Hansmann G, Archer SL, Ivy DD, Adatia I, Chung WK, Hanna BD, Rosenzweig EB, Raj JU, Cornfield D, Stenmark KR, Steinhorn R, Thébaud B, Fineman JR, Kuehne T, Feinstein JA, Friedberg MK, Earing M, Barst RJ, Keller RL, Kinsella JP, Mullen M, Deterding R, Kulik T, Mallory G, Humpl T, Wessel DL; American Heart Association Council on Cardiopulmonary, Critical Care, Perioperative and Resuscitation; Council on Clinical 
Cardiology; Council on Cardiovascular Disease in the Young; Council on Cardiovascular Radiology and Intervention; Council on Cardiovascular Surgery and Anesthesia; and the American Thoracic Society. Pediatric Pulmonary Hypertension: Guidelines From the American Heart Association and American Thoracic Society. Circulation. 2015;132:2037-2099. doi: 10.1161/CIR.0000000000000329

12. Kelly LK, Porta NF, Goodman DM, Carroll CL, Steinhorn RH. Inhaled prostacyclin for term infants with persistent pulmonary hypertension refractory to inhaled nitric oxide. J Pediatr. 2002;141:830-832. doi: 10.1067/mpd.2002.129849

13. Morris K, Beghetti M, Petros A, Adatia I, Bohn D. Comparison of hyperventilation and inhaled nitric oxide for pulmonary hypertension after repair of congenital heart disease. Crit Care Med. 2000;28:2974-2978. doi: 10.1097/00003246-200008000-00048

14. Nair J, Lakshminrusimha S. Update on PPHN: mechanisms and treatment. Semin Perinatol. 2014;38:78-91. doi: 10.1053/j.semperi.2013.11.004

15. Moudgil R, Michelakis ED, Archer SL. Hypoxic pulmonary vasoconstriction. J Appl Physiol (1985). 2005;98:390-403. doi: 10.1152/ japplphysiol.00733.2004

16. Hopkins RA, Bull C, Haworth SG, de Leval MR, Stark J. Pulmonary hypertensive crises following surgery for congenital heart defects in young children. Eur J Cardiothorac Surg. 1991;5:628-634. doi: 10.1016/1010-7940(91)90118-4

17. Anand KJ, Hansen DD, Hickey PR. Hormonal-metabolic stress responses in neonates undergoing cardiac surgery. Anesthesiology. 1990;73:661-670. doi: 10.1097/00000542-199010000-00012

18. Kolovos NS, Bratton SL, Moler FW, Bove EL, Ohye RG, Bartlett RH, Kulik TJ. Outcome of pediatric patients treated with extracorporeal life support after cardiac surgery. Ann Thorac Surg. 2003;76:1435-41; discussion 1441. doi: 10.1016/s0003-4975(03)00898-1

19. Dhillon R, Pearson GA, Firmin RK, Chan KC, Leanage R. Extracorporeal membrane oxygenation and the treatment of critical pulmonary hypertension in congenital heart disease. Eur J Cardiothorac Surg. 1995;9:553556. doi: 10.1016/s1010-7940(05)80004-1

20. Puri V, Epstein D, Raithel SC, Gandhi SK, Sweet SC, Faro A, Huddleston CB. Extracorporeal membrane oxygenation in pediatric lung transplantation. J Thorac Cardiovasc Surg. 2010;140:427-432. doi: 10.1016/j. jtcvs.2010.04.012

21. Ricci M, Gaughan CB, Rossi M, Andreopoulos FM, Novello C, Salerno TA, Rosenkranz ER, Panos AL. Initial experience with the TandemHeart circulatory support system in children. ASAIO J. 2008;54:542-545. doi: 10.1097/ MAT.0b013e31818312f1

22. Morrell NW, Aldred MA, Chung WK, Elliott CG, Nichols WC, Soubrier F, Trembath RC, Loyd JE. Genetics and genomics of pulmonary arterial hypertension. Eur Respir J. 2019;53:Epub ahead of print. doi: 10.1183/13993003.01899-2018

23. Frank DB, Crystal MA, Morales DL, Gerald K, Hanna BD, Mallory GB Jr, Rossano JW. Trends in pediatric pulmonary hypertension-related hospitalizations in the United States from 2000-2009. Pulm Circ. 2015;5:339 348. doi: $10.1086 / 681226$

\section{MANAGEMENT OF TRAUMATIC CARDIAC ARREST}

Unintentional injuries are the most common cause of death among children and adolescents. ${ }^{1}$ Although many organizations have established trauma care guidelines, ${ }^{2-4}$ the management of traumatic cardiac arrest is often inconsistent. Cardiac arrest due to major blunt or penetrating injury in children has a very high mortality rate..$^{5-8}$ Thoracic injury should be suspected in all thoracoabdominal trauma because tension pneumothorax, hemothorax, pulmonary contusion, or pericardial tamponade may impair hemodynamics, oxygenation, and ventilation.

\begin{tabular}{|c|c|c|}
\hline \multicolumn{2}{|c|}{ Recommendations for the Management of Traumatic Cardiac Arrest } \\
\hline COR & LOE & Recommendations \\
\hline 2b & C-EO & $\begin{array}{r}\text { 1. In pediatric traumatic cardiac arrest, evaluate } \\
\text { for and treat potential reversible causes, such } \\
\text { as hemorrhage, tension pneumothorax, and } \\
\text { pericardial tamponade. }{ }^{9,10}\end{array}$ \\
\hline & C-LD & $\begin{array}{l}\text { 2. In pediatric cardiac arrest secondary to } \\
\text { penetrating injury with a short transport } \\
\text { time, it may be reasonable to perform } \\
\text { resuscitative thoracotomy. }{ }^{11-18}\end{array}$ \\
\hline
\end{tabular}

\section{Recommendation-Specific Supportive Text}

1. Early correction of reversible causes by reducing delays in the delivery of trauma-specific interventions may increase survival following penetrating traumatic cardiac arrest. ${ }^{9,10}$ Guidelines for cardiac arrest due to trauma recommend hemorrhage control, restoration of circulating blood volume, opening the airway, and relieving tension pneumothorax. These measures should be performed simultaneously with conventional resuscitation.

2. Recent systematic reviews, ${ }^{11-14}$ multicenter retrospective studies, ${ }^{15,16}$ and single-center retrospective studies $^{17}$ recommend emergent thoracotomy for pediatric patients who present pulseless after penetrating thoracic injury. There is no evidence to support emergent thoracotomy for infants and children with blunt injury who are without signs of life. ${ }^{12,18}$

\section{REFERENCES}

1. Heron M. Deaths: leading causes for 2010. Nat/ Vital Stat Rep. 2013;62:196

2. Western Trauma Association. Western Trauma Association algorithms. 2011. https://www.westerntrauma.org/algorithms/algorithms.html. Accessed March 6, 2020

3. Eastern Association for the Surgery of Trauma. EAST practice management guidelines. https://www.east.org/education/practice-managementguidelines. Accessed February 3, 2020.

4. Pediatric Trauma Society. Pediatric trauma society clinical practice guidelines. https://pediatrictraumasociety.org/resources/clinical-resources.cgi. Accessed February 3, 2020.

5. Calkins CM, Bensard DD, Partrick DA, Karrer FM. A critical analysis of outcome for children sustaining cardiac arrest after blunt trauma. J Pediatr Surg. 2002;37:180-184. doi: 10.1053/jpsu.2002.30251

6. Crewdson K, Lockey D, Davies G. Outcome from paediatric cardiac arrest associated with trauma. Resuscitation. 2007;75:29-34. doi: 10.1016/j.resuscitation.2007.02.018

7. Perron $A D$, Sing RF, Branas CC, Huynh T. Predicting survival in pediatric trauma patients receiving cardiopulmonary resuscitation in the prehospital setting. Prehosp Emerg Care. 2001;5:6-9. doi: 10.1080/10903120190940245

8. Lopez-Herce Cid J, Dominguez Sampedro P, Rodriguez Nunez A, Garcia Sanz C, Carrillo Alvarez A, Calvo Macias C, Bellon Cano JM. [Cardiorespiratory arrest in children with trauma]. An Pediatr (BarC). 2006;65:439447. doi: 10.1157/13094250

9. Shibahashi K, Sugiyama K, Hamabe Y. Pediatric Out-of-Hospital Traumatic Cardiopulmonary Arrest After Traffic Accidents and Termination of Resuscitation. Ann Emerg Med. 2020;75:57-65. doi: 10.1016/j.annemergmed.2019.05.036

10. Alqudah Z, Nehme Z, Williams B, Oteir A, Bernard S, Smith K. A descriptive analysis of the epidemiology and management of paediatric traumatic out-of-hospital cardiac arrest. Resuscitation. 2019;140:127-134. doi: 10.1016/j.resuscitation.2019.05.020 
11. Nevins EJ, Bird NTE, Malik HZ, Mercer SJ, Shahzad K, Lunevicius $R$, Taylor JV, Misra N. A systematic review of 3251 emergency department thoracotomies: is it time for a national database? Eur J Trauma Emerg Surg. 2019;45:231-243. doi: 10.1007/s00068-018-0982-z

12. Moskowitz EE, Burlew CC, Kulungowski AM, Bensard DD. Survival after emergency department thoracotomy in the pediatric trauma population: a review of published data. Pediatr Surg Int. 2018;34:857-860. doi: 10.1007/s00383-018-4290-9

13. Seamon MJ, HautER, VanArendonkK, BarbosaRR, ChiuWC, DenteCJ, FoxN, Jawa RS, Khwaja K, Lee JK, Magnotti LJ, Mayglothling JA, McDonald AA, Rowell S, To KB, Falck-Ytter Y, Rhee P. An evidence-based approach to patient selection for emergency department thoracotomy: A practice management guideline from the Eastern Association for the Surgery of Trauma. J Trauma Acute Care Surg. 2015;79:159-173. doi: 10.1097/TA 0000000000000648

14. Moore HB, Moore EE, Bensard DD. Pediatric emergency department thoracotomy: A 40-year review. J Pediatr Surg. 2016;51:315-318. doi: 10.1016/j. jpedsurg.2015.10.040

15. Flynn-O'Brien KT, Stewart BT, Fallat ME, Maier RV, Arbabi S, Rivara FP, McIntyre LK. Mortality after emergency department thoracotomy for pediatric blunt trauma: analysis of the National Trauma Data Bank 2007-2012. J Pediatr Surg. 2016;51:163-167. doi: 10.1016/j.jpedsurg.2015.10.034

16. Nicolson NG, Schwulst S, Esposito TA, Crandall ML. Resuscitative thoracotomy for pediatric trauma in Illinois, 1999 to 2009. Am J Surg. 2015;210:720-723. doi: 10.1016/j.amjsurg.2015.05.007

17. Easter JS, Vinton DT, Haukoos JS. Emergent pediatric thoracotomy following traumatic arrest. Resuscitation. 2012;83:1521-1524. doi: 10.1016/j. resuscitation.2012.05.024

18. Duron V, Burke RV, Bliss D, Ford HR, Upperman JS. Survival of pediatric blunt trauma patients presenting with no signs of life in the field. $J$ Trauma Acute Care Surg. 2014;77:422-426. doi: 10.1097/TA.0000000000000394

\section{CRITICAL KNOWLEDGE GAPS AND ONGOING RESEARCH}

During the literature review process, we identified several critical knowledge gaps related to pediatric basic and advanced life support. These topics are either current areas of ongoing research or lack significant pediatric evidence to support evidence-based recommendations. In addition, we identified topics for which systematic or scoping reviews are in process by the ILCOR Basic Life Support or Pediatric Life Support Task Forces and elected not to make premature recommendations until these reviews are available.

As is so often the case in pediatric medicine, many recommendations are extrapolated from adult data. This is particularly true for the BLS components of pediatric resuscitation. The causes of pediatric cardiac arrest are very different from cardiac arrest in adults, and pediatric studies are critically needed. Furthermore, infants, children, and adolescents are distinct patient populations. Dedicated pediatric resuscitation research is a priority given the more than 20000 infants, children, and adolescents who suffer cardiac arrest in the United States each year.

Critical knowledge gaps are summarized in Table 2.
Table 2. Critical Knowledge Gaps Due to Insufficient Pediatric Data

What is the optimal method of medication delivery during CPR: IO or IV?

What is the optimal method to determine body weight for medication administration?

In what time frame should the first dose of epinephrine be administered during pulseless cardiac arrest?

With what frequency should subsequent doses of epinephrine be administered?

With what frequency should epinephrine be administered in infants and children during CPR who are awaiting ECMO cannulation?

Are alternative compression techniques (cough CPR, fist pacing, interposed abdominal compression (PR) more effective alternatives to CPR?

With what frequency should the rhythm be checked during CPR?

What is the optimal method of airway management during OHCA-bagmask ventilation, supraglottic airway, or endotracheal tube?

What is the optimal $\mathrm{FiO}_{2}$ to administer during CPR?

What is the optimal ventilation rate during CPR in patients with or without an advanced airway? Is it age dependent?

What is the optimal chest compression rate during CPR? Is it age dependent?

What are the optimal blood pressure targets during CPR? Are they age dependent?

Can echocardiography improve CPR quality or outcomes from cardiac arrest?

Are there specific situations in which advanced airway placement is beneficial or harmful in OHCA?

What is the appropriate timing of advanced airway placement in IHCA?

What is the role of ECPR for patients with OHCA and IHCA due to noncardiac causes?

What is the optimal timing and dosing of defibrillation for VF/pVT?

What clinical tools can be used to help in the decision to terminate pediatric IHCA and OHCA resuscitation?

What is the optimal blood pressure target during the post-cardiac arrest period?

Should seizure prophylaxis be administered post cardiac arrest?

Does the treatment of postarrest convulsive and nonconvulsive seizure improve outcomes?

What are the reliable methods for postarrest prognostication?

What rehabilitation therapies and follow-up should be provided to improve outcomes post arrest?

What are the most effective and safe medications for adenosinerefractory SVT?

What is the appropriate age and setting to transition from (1) neonatal resuscitation protocols to pediatric resuscitation protocols and (2) from pediatric resuscitation protocols to adult resuscitation protocols?

CPR indicates cardiopulmonary resuscitation; ECMO, extracorporeal membrane oxygenation; ECPR, extracorporeal cardiopulmonary resuscitation; $\mathrm{FIO}_{2}$, fraction of inspired oxygen; IHCA, in-hospital cardiac arrest; IO, intraosseous; IV, intravenous; OHCA, out-of-hospital cardiac arrest; pVT, pulseless ventricular tachycardia; SVT, supraventricular tachycardia; and VF, ventricular fibrillation. 


\section{ARTICLE INFORMATION}

The American Heart Association requests that this document be cited as follows: Topjian AA, Raymond TT, Atkins D, Chan M, Duff JP, Joyner BL Jr, Lasa JJ, Lavonas EJ, Levy A, Mahgoub M, Meckler GD, Roberts KE, Sutton RM, Schexnayder SM; on behalf of the Pediatric Basic and Advanced Life Support Collaborators. Part 4: pediatric basic and advanced life support: 2020 American Heart Association Guidelines for Cardiopulmonary Resuscitation and Emergency Cardiovascular Care. Circulation. 2020;142(suppl 2):S469-S523. doi 10.1161/CIR.0000000000000901

\section{Acknowledgments}

The authors thank the following individuals (the Pediatric Basic and Advanced Life Support Collaborators) for their contributions: Ronald A. Bronicki, MD; Allan R. de Caen, MD; Anne Marie Guerguerian, MD, PhD; Kelly D. Kadlec, MD, MEd; Monica E. Kleinman, MD; Lynda J. Knight, MSN, RN; Taylor N. McCormick, MD, MSc; Ryan W. Morgan, MD, MTR; Joan S. Roberts, MD; Barnaby R. Scholefield, MBBS, PhD; Sarah Tabbutt, MD, PhD; Ravi Thiagarajan, MBBS, MPH; Janice Tijssen, MD, MSc; Brian Walsh, PhD, RRT, RRT-NPS; and Arno Zaritsky, MD.

\section{Disclosures}

Appendix 1. Writing Group Disclosures

\begin{tabular}{|c|c|c|c|c|c|c|c|c|}
\hline $\begin{array}{l}\text { Writing } \\
\text { Group } \\
\text { Member }\end{array}$ & Employment & Research Grant & $\begin{array}{l}\text { Other } \\
\text { Research } \\
\text { Support }\end{array}$ & $\begin{array}{l}\text { Speakers' } \\
\text { Bureau/ } \\
\text { Honoraria }\end{array}$ & $\begin{array}{l}\text { Expert } \\
\text { Witness }\end{array}$ & $\begin{array}{l}\text { Ownership } \\
\text { Interest }\end{array}$ & $\begin{array}{l}\text { Consultant/ } \\
\text { Advisory } \\
\text { Board }\end{array}$ & Other \\
\hline $\begin{array}{l}\text { Alexis A. } \\
\text { Topjian }\end{array}$ & $\begin{array}{c}\text { The Children's Hospital of } \\
\text { Philadelphia, University of } \\
\text { Pennsylvania School of Medicine } \\
\text { Anesthesia and Critical Care }\end{array}$ & $\mathrm{NIH} *$ & None & None & Plaintiff* & None & None & None \\
\hline $\begin{array}{l}\text { Dianne } \\
\text { Atkins }\end{array}$ & $\begin{array}{l}\text { University of lowa } \\
\text { Pediatrics }\end{array}$ & None & None & None & None & None & None & None \\
\hline Melissa Chan & $\begin{array}{l}\text { University of British Columbia } \\
\text { Pediatrics BC Children's Hospital }\end{array}$ & None & None & None & None & None & None & None \\
\hline $\begin{array}{l}\text { Jonathan P. } \\
\text { Duff }\end{array}$ & $\begin{array}{c}\text { University of Alberta and Stollery } \\
\text { Children's Hospital } \\
\text { Pediatrics }\end{array}$ & None & None & None & None & None & None & None \\
\hline $\begin{array}{l}\text { Benny L. } \\
\text { Joyner Jr }\end{array}$ & $\begin{array}{l}\text { University of North Carolina } \\
\text { Pediatrics }\end{array}$ & None & None & None & None & None & None & None \\
\hline Javier J. Lasa & $\begin{array}{l}\text { Texas Children's Hospital, Baylor } \\
\text { College of Medicine } \\
\text { Pediatrics/Critical Care Medicine } \\
\text { and Cardiology }\end{array}$ & None & None & None & None & None & None & None \\
\hline $\begin{array}{l}\text { Eric J. } \\
\text { Lavonas }\end{array}$ & $\begin{array}{l}\text { Denver Health } \\
\text { Emergency Medicine }\end{array}$ & $\begin{array}{c}\text { BTG Pharmaceuticals } \\
\text { (Denver Health (Dr Lavonas' } \\
\text { employer) has research, } \\
\text { call center, consulting, and } \\
\text { teaching agreements with } \\
\text { BTG Pharmaceuticals. BTG } \\
\text { manufactures the digoxin } \\
\text { antidote, DigiFab. Dr Lavonas } \\
\text { does not receive bonus or } \\
\text { incentive compensation, and } \\
\text { these agreements involve an } \\
\text { unrelated product. When these } \\
\text { guidelines were developed, } \\
\text { Dr Lavonas recused from } \\
\text { discussions related to digoxin } \\
\text { poisoning.) }+\end{array}$ & None & None & None & None & None & $\begin{array}{c}\text { American } \\
\text { Heart } \\
\text { Association } \\
\text { (Senior } \\
\text { Science } \\
\text { Editor)† }\end{array}$ \\
\hline Arielle Levy & $\begin{array}{l}\text { University of Montreal } \\
\text { Pediatric }\end{array}$ & None & None & None & None & None & None & None \\
\hline $\begin{array}{l}\text { Melissa } \\
\text { Mahgoub }\end{array}$ & American Heart Association & None & None & None & None & None & None & None \\
\hline $\begin{array}{l}\text { Garth D. } \\
\text { Meckler }\end{array}$ & $\begin{array}{l}\text { University of British Columbia } \\
\text { Pediatrics and Emergency } \\
\text { Medicine } \\
\text { Ambulatory Care Building, BC } \\
\text { Children's }\end{array}$ & None & None & None & None & None & None & None \\
\hline $\begin{array}{l}\text { Tia T. } \\
\text { Raymond }\end{array}$ & $\begin{array}{c}\text { Medical City Children's Hospital } \\
\text { Pediatric Cardiac Intensive Care } \\
\text { Unit }\end{array}$ & None & None & None & None & None & None & None \\
\hline $\begin{array}{l}\text { Kathryn E. } \\
\text { Roberts }\end{array}$ & $\begin{array}{c}\text { Joe DiMaggio Children's } \\
\text { Hospital }\end{array}$ & None & None & None & None & None & None & None \\
\hline
\end{tabular}


Appendix 1. Continued

\begin{tabular}{|c|c|c|c|c|c|c|c|c|}
\hline $\begin{array}{l}\text { Writing } \\
\text { Group } \\
\text { Member }\end{array}$ & Employment & Research Grant & $\begin{array}{c}\text { Other } \\
\text { Research } \\
\text { Support }\end{array}$ & $\begin{array}{l}\text { Speakers' } \\
\text { Bureau/ } \\
\text { Honoraria }\end{array}$ & $\begin{array}{c}\text { Expert } \\
\text { Witness }\end{array}$ & $\begin{array}{c}\text { Ownership } \\
\text { Interest }\end{array}$ & $\begin{array}{l}\text { Consultant/ } \\
\text { Advisory } \\
\text { Board }\end{array}$ & Other \\
\hline $\begin{array}{l}\text { Stephen M. } \\
\text { Schexnayder }\end{array}$ & $\begin{array}{l}\text { Univ. of Arkansas/ Arkansas } \\
\text { Children's Hospital } \\
\text { Pediatric Critical Care }\end{array}$ & None & None & None & None & None & None & None \\
\hline $\begin{array}{l}\text { Robert M. } \\
\text { Sutton }\end{array}$ & $\begin{array}{l}\text { The Children's Hospital of } \\
\text { Philadelphia, University of } \\
\text { Pennsylvania School of Medicine } \\
\text { Anesthesia and Critical Care } \\
\text { Medicine }\end{array}$ & $\mathrm{NIH} \dagger$ & None & None & $\begin{array}{l}\text { Roberts \& } \\
\text { Durkee, } \\
\text { Plantiff, } \\
\text { 2019† }\end{array}$ & None & None & None \\
\hline
\end{tabular}

This table represents the relationships of writing group members that may be perceived as actual or reasonably perceived conflicts of interest as reported on the Disclosure Questionnaire, which all members of the writing group are required to complete and submit. A relationship is considered to be "significant" if (a) the person receives $\$ 10000$ or more during any 12 -month period, or $5 \%$ or more of the person's gross income; or (b) the person owns $5 \%$ or more of the voting stock or share of the entity, or owns $\$ 10000$ or more of the fair market value of the entity. A relationship is considered to be "modest" if it is less than "significant" under the preceding definition.

*Modest.

†Significant.

Appendix 2. Reviewer Disclosures

\begin{tabular}{|c|c|c|c|c|c|c|c|c|}
\hline Reviewer & Employment & $\begin{array}{l}\text { Research } \\
\text { Grant }\end{array}$ & $\begin{array}{l}\text { Other } \\
\text { Research } \\
\text { Support }\end{array}$ & $\begin{array}{l}\text { Speakers' } \\
\text { Bureau/ } \\
\text { Honoraria }\end{array}$ & $\begin{array}{l}\text { Expert } \\
\text { Witness }\end{array}$ & $\begin{array}{l}\text { Ownership } \\
\text { Interest }\end{array}$ & $\begin{array}{l}\text { Consultant/ } \\
\text { Advisory } \\
\text { Board }\end{array}$ & Other \\
\hline $\begin{array}{l}\text { Nandini } \\
\text { Calamur }\end{array}$ & Saint Louis University & None & None & None & None & None & None & None \\
\hline $\begin{array}{l}\text { Leon } \\
\text { Chameides }\end{array}$ & $\begin{array}{c}\text { Connecticut Children's Medical } \\
\text { Center }\end{array}$ & None & None & None & None & None & None & None \\
\hline Todd P. Chang & $\begin{array}{l}\text { Children's Hospital Los Angeles } \\
\text { \& Keck School Of Medicine }\end{array}$ & None & None & None & None & None & None & $\begin{array}{l}\text { Oculus from } \\
\text { FaceBookt }\end{array}$ \\
\hline Ericka L. Fink & $\begin{array}{c}\text { Primary Work } \\
\text { Children's Hospital of } \\
\text { Pittsburgh }\end{array}$ & $\mathrm{NIH}+$ & None & None & None & None & None & None \\
\hline $\begin{array}{l}\text { Monica E. } \\
\text { Kleinman }\end{array}$ & Children's Hospital Boston & None & None & None & None & None & $\begin{array}{l}\text { International } \\
\text { Liaison } \\
\text { Committee on } \\
\text { Resuscitation* }\end{array}$ & None \\
\hline $\begin{array}{l}\text { Michael-Alice } \\
\text { Moga }\end{array}$ & $\begin{array}{l}\text { The Hospital for Sick Children, } \\
\text { Labatt Family Heart Center and } \\
\text { University of Toronto (Canada) }\end{array}$ & $\begin{array}{l}\text { CIHR*; CIHR/ } \\
\text { NSERC }+\end{array}$ & None & None & None & None & None & None \\
\hline Tara Neubrand & $\begin{array}{l}\text { Children's Hospital Colorado, } \\
\text { University of Colorado }\end{array}$ & None & None & None & None & None & None & None \\
\hline $\begin{array}{l}\text { Ola Didrik } \\
\text { Saugstad }\end{array}$ & University of Oslo (Norway) & None & None & None & None & None & None & None \\
\hline
\end{tabular}

This table represents the relationships of reviewers that may be perceived as actual or reasonably perceived conflicts of interest as reported on the Disclosure Questionnaire, which all reviewers are required to complete and submit. A relationship is considered to be "significant" if (a) the person receives $\$ 10000$ or more during any 12-month period, or $5 \%$ or more of the person's gross income; or (b) the person owns $5 \%$ or more of the voting stock or share of the entity, or owns $\$ 10000$ or more of the fair market value of the entity. A relationship is considered to be "modest" if it is less than "significant" under the preceding definition.

*Modest.

†Significant. 